\title{
Access to Higher Education: Which Financial Factors Are Most Closely Associated with Enrollment of Students Based on Their Race or Ethnicity?
}

Jeff Terpstra

Follow this and additional works at: https://researchrepository.wvu.edu/etd

\section{Recommended Citation}

Terpstra, Jeff, "Access to Higher Education: Which Financial Factors Are Most Closely Associated with Enrollment of Students Based on Their Race or Ethnicity?" (2013). Graduate Theses, Dissertations, and Problem Reports. 7352.

https://researchrepository.wvu.edu/etd/7352

This Dissertation is protected by copyright and/or related rights. It has been brought to you by the The Research Repository @ WVU with permission from the rights-holder(s). You are free to use this Dissertation in any way that is permitted by the copyright and related rights legislation that applies to your use. For other uses you must obtain permission from the rights-holder(s) directly, unless additional rights are indicated by a Creative Commons license in the record and/ or on the work itself. This Dissertation has been accepted for inclusion in WVU Graduate Theses, Dissertations, and Problem Reports collection by an authorized administrator of The Research Repository @ WVU.

For more information, please contact researchrepository@mail.wvu.edu. 


\title{
Jeff Terpstra
}
Dissertation submitted to the College of Education and Human Services at West Virginia University in partial fulfillment of the requirements for the degree of

\author{
Doctor of Education \\ in \\ Higher Education Administration \\ Sebastián Díaz, Ph.D., J.D., Chair \\ William Hisker, Ph.D., Member \\ Allison Swan-Dagen, Ph.D., Member \\ Adriane Williams, Ph.D., Member \\ Lauryl Lefebvre, Ph.D., Member \\ Morgantown, West Virginia
}

2013

Keywords: Financial Aid, Access, Diversity

Copyright 2013 Jeff Terpstra 
UMI Number: 3605882

All rights reserved

INFORMATION TO ALL USERS

The quality of this reproduction is dependent upon the quality of the copy submitted.

In the unlikely event that the author did not send a complete manuscript and there are missing pages, these will be noted. Also, if material had to be removed, a note will indicate the deletion.

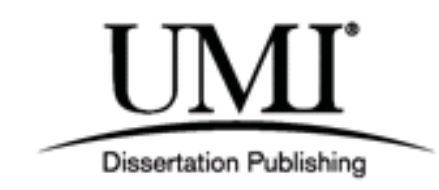

UMI 3605882

Published by ProQuest LLC (2013). Copyright in the Dissertation held by the Author.

Microform Edition (C) ProQuest LLC.

All rights reserved. This work is protected against unauthorized copying under Title 17, United States Code

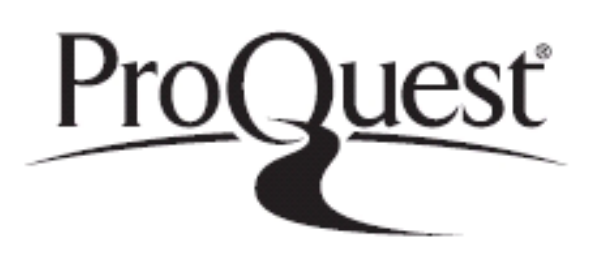

ProQuest LLC.

789 East Eisenhower Parkway

P.O. Box 1346

Ann Arbor, MI 48106 - 1346 


\section{Abstract \\ Access to Higher Education: Which Financial Factors Are Most Closely Associated with Enrollment of Students Based on Their Race or Ethnicity?}

\section{Jeff Terpstra}

Financial access and promoting diversity within the student population at colleges and universities are ongoing concerns in higher education. Rising costs and diminished financial support are raising the financial stakes associated with investing in a higher education. Research completed by authors like DesJardins and Bell (2006), Hossler and Vesper (1993), Kim (2004), McPherson and Schapiro (1991), and St. John, Paulsen, and Carter (2005), suggests there are differences in the way students from different race/ethnic backgrounds make their decision on whether or not to attend college as well as what type of college they attend. This quantitative study addresses the problem of how the costs associated with public higher education impact the enrollment of students from diverse racial and ethnic backgrounds. Since financial resources can come in many forms and students from different backgrounds approach personal finances differently, there is a need for additional research to inform colleges and higher education policies on the best approach to making higher education accessible to all students. This study sought to fill part of this research gap by identifying financial variables associated with the enrollment of students based on their race/ethnicity. Chi-square Automatic Interaction Detection (CHAID) found that Pell Grant awards was the independent variable (of the 10 independent variables examined) most closely associate with enrollment at public four-year colleges and universities. Two additional variables of Amount of Tuition and Fees Paid and whether or not a student Worked During the Summer of 2007, were also found to be closely associated with enrollment at public four-year colleges and universities. Additionally, the study found a difference in the association of the independent variables with the dependent variable of enrollment based on the race/ethnicity of the student. 


\section{Acknowledgments}

The journey of completing this degree has been an interesting and challenging one, and completing this dissertation study was no exception. Tackling both challenges would not have been possible without the ongoing support of family, friends, committee members, and colleagues. The following individuals provided the extra push I needed when times were tough, and without their support the completion of this journey would not have been possible.

To my wife and daughters: You are more precious to me than I could ever put down into words. Your sacrifices, support, and encouragement have made accomplishing this goal possible. Thank you for coming along with me on this journey and I hope that someday I am able to show you how truly grateful I am.

To the students in my program cohort: You know who you are!! I admit, there were times I wasn't sure if any of us would make it through. In many ways I saw this as a team effort, where points were scored with each semester under our belts and the game was won with the completion of our degrees. Thanks to each of you for helping me through the process.

To Dr. Sebastián Díaz: Throughout the completion of this program, every time I thought I was left to fend for myself, you were there to help see me through. Thank you for the words of encouragement and for taking the time to know me well enough to understand why completing this degree was so important. I hope to live up to the investment you've made in me as a student and researcher. I look forward to the time when our paths will cross again.

To Dr. Allison Swan-Dagen: Your willingness to jump on to my committee and provide the support and resources needed to complete this project were truly inspiring. There were times where I wasn't sure who was more discouraged by the setbacks and encouraged by the successes that came with this study. Thank you for providing me with an example of the type of educator I hope to be.

To Dr. William Hisker, Dr. Adriane Williams, and Dr. Lauryl Lefebvre: You stuck with me despite the changes that went on with my study and within the Higher Ed program. Thank you for not abandoning ship when the going got tough. I can't thank you enough for your kindness, patience, and input throughout this process.

To Dr. Tara Sullivan: There are few people who know how close I was to scrapping this

entire study. Without your help and encouragement this study would not have been possible!!

To Dr. Ernest Goeres: The man behind the scenes that makes things happen!! Without your help I'm sure I would have forgotten to register for a credit, neglected to file a paper, or been without a room to defend my dissertation. People talk about the glue that holds things together, you were the glue that held our cohort together through the end. 


\section{Dedication}

I dedicate this dissertation to my parents, James and Hope Terpstra. Your love and support throughout the different chapters of my life have been my rock and foundation. I aspire to model my life after the example you have given me on how to work hard, pray hard, love unconditionally, and stay focused on what really matters. I strive every day to make you proud. 


\section{Table Of Contents}

Chapter One: Introduction and Problem Statement .......................................................... 1

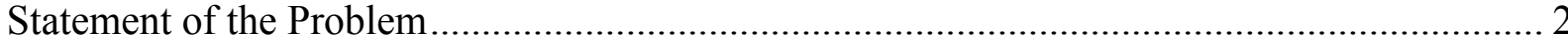

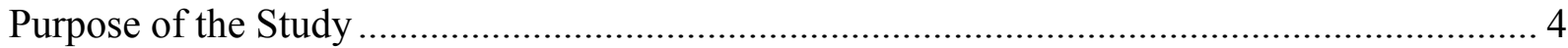

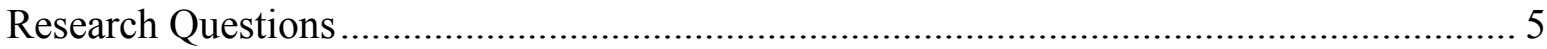

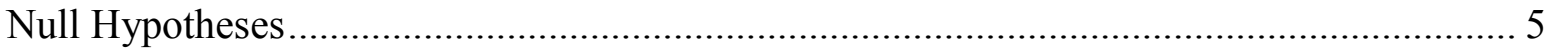

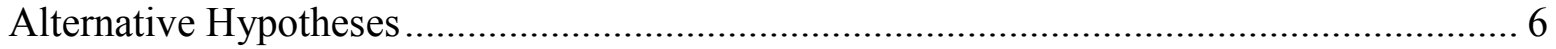

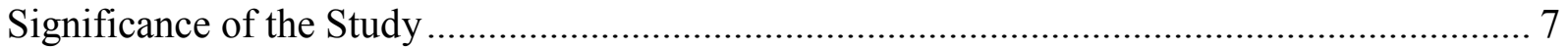

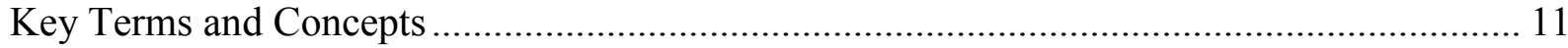

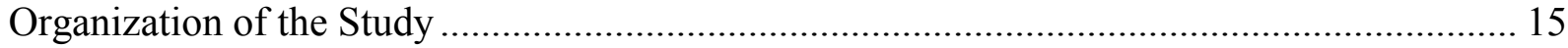

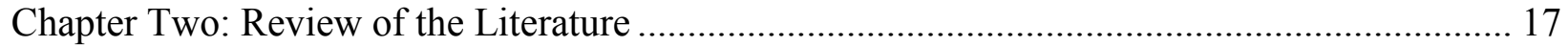

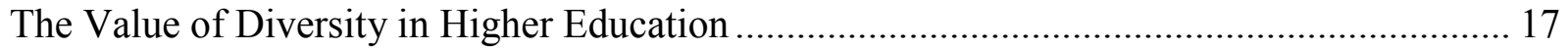

The Implied Social Contract as a Basis for a Public Higher Education System..................... 22

The Trends in Funding a Higher Education..................................................................... 27

Overview of Prior Studies and Research ......................................................................... 33

The National Postsecondary Student Aid Study and Sample Methods ................................. 37

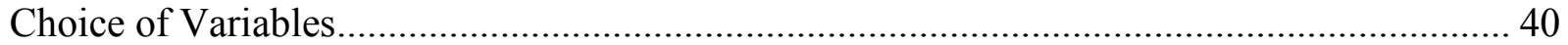

Chapter Three: Research Design and Methodology ......................................................... 42

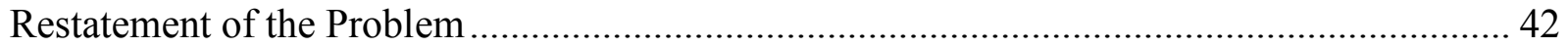

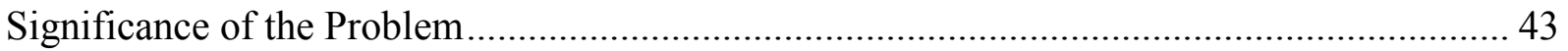

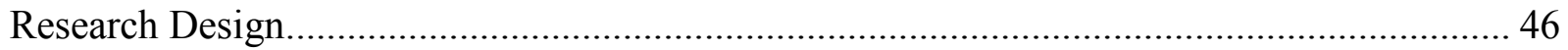

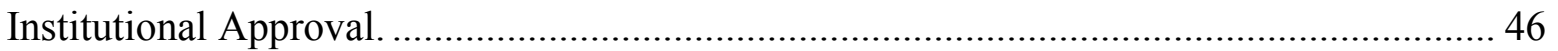

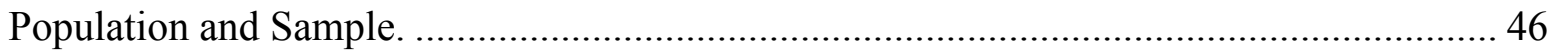

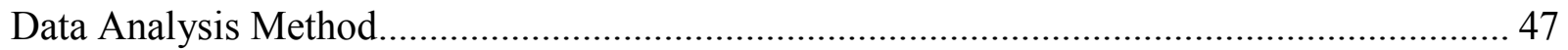

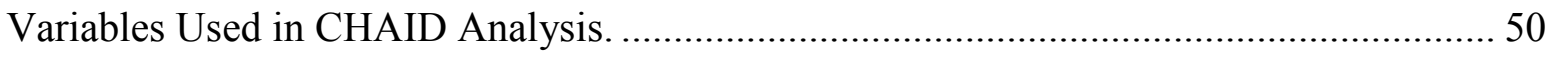

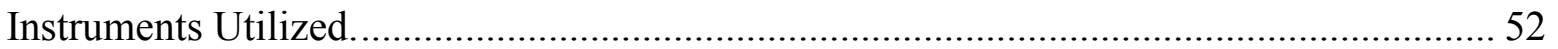

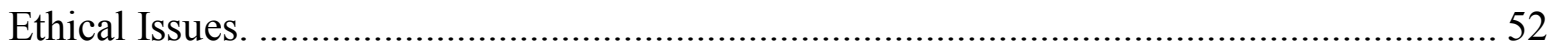

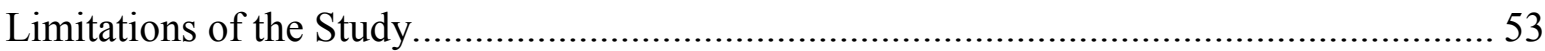

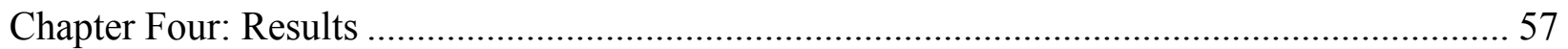

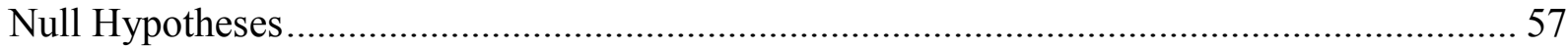

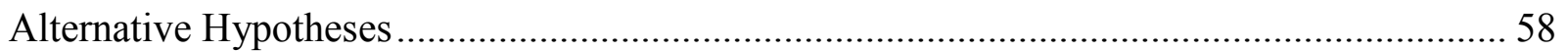

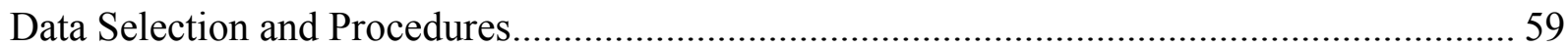

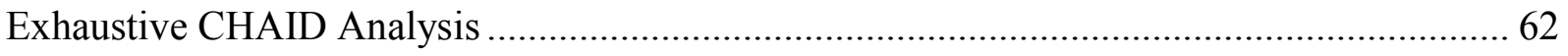

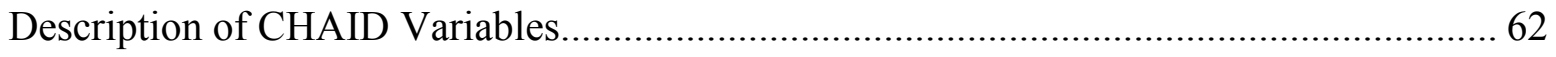




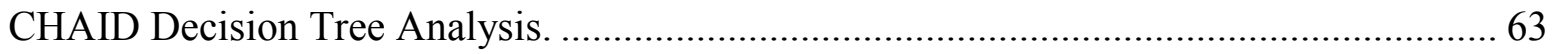

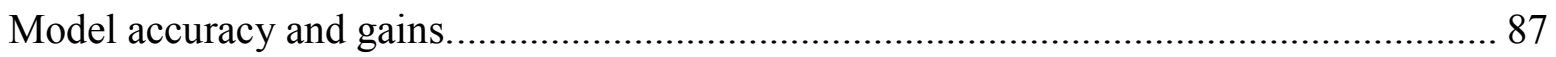

Chapter Five: Summary of the Findings, Recommendations for Policy, Practice, and Future

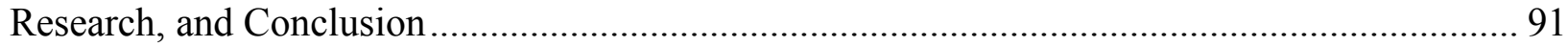

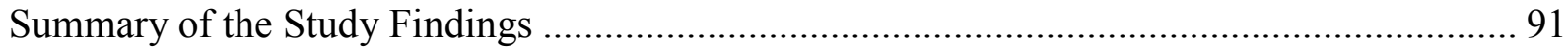

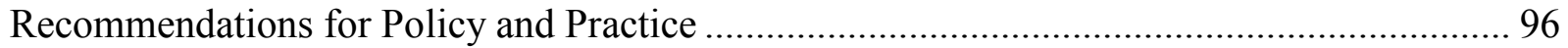

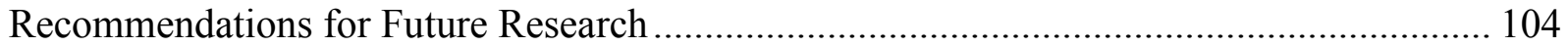

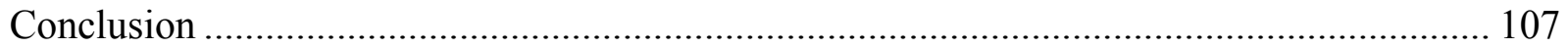

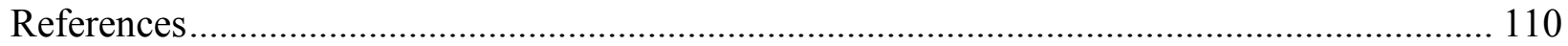

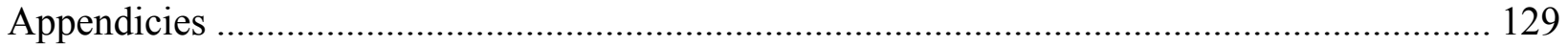




\section{List of Tables}

Table 1: Variables used in the CHAID Analysis ................................................................ 51

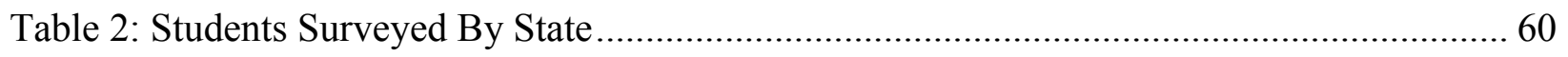

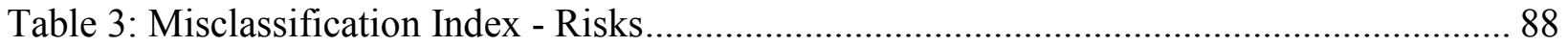




\section{List of Appendices}

Appendix A: Approval Acknowledgement from

WVU Institutional Review Board (IRB).

Appendix B: Letter of Approval to Conduct Research.................................. 130

Appendix C: Letter Approving License to Use Restricted Use Data....................... 131

Appendix D: Letter Approving Distribution of Dissertation

Based on Restricted Use Data.............................................. 132

Appendix E: Descriptive Statistics by Race/Ethnicity

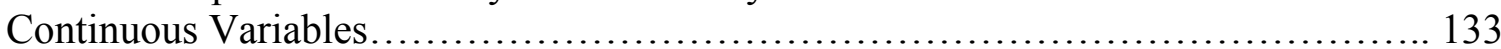

Appendix F: Descriptive Statistics by Race/Ethnicity

Categorical Variables.

Appendix G: Number of Students In Each Node by Race/Ethnicity

Categorical Variables

Appendix H: Summary of Output by CHAID Analysis. 


\section{List of Figures}

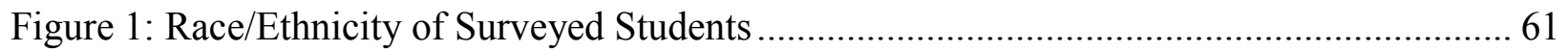

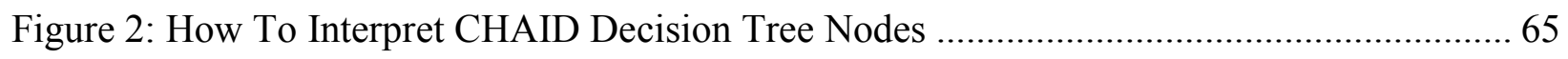

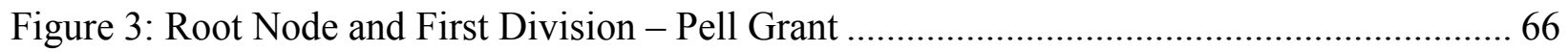

Figure 4: Second Division From Node 1 - Tuition and Fees Paid ........................................ 69

Figure 5: Third Division From Node 2 - Worked During The Summer of 2007..................... 73

Figure 6: Fourth Division From Node 3 - Tuition and Fees Paid .......................................... 76

Figure 7: Fifth Division From Node 4 - Tuition and Fees Paid ............................................ 80

Figure 8: Sixth Division From Node 5 - Tuition and Fees Paid ........................................... 85 


\section{Chapter One: Introduction and Problem Statement}

Diversity in higher education and access to higher education are ongoing concerns as society looks to higher education as a means of providing a skilled work force for the economy and an avenue for upward economic mobility for its citizens. Public institutions of higher education were established with the idea of making higher education more accessible to a broader range of the population. According to the Organisation for Economic Co-operation and Development (2010), public support of higher education is a smart investment with a financial return back to the public of approximately three times the initial investment. However, financial support from the state and federal governments for public universities continues to diminish. From the 1963-1964 academic year to the 1996-1997 academic year, aid provided by the federal and state governments to offset the cost of higher education increased by a factor of 100 from $\$ 557$ million to $\$ 55.7$ billion (St. John, Cabrera, Nora, \& Asker, 2000). Two sources of aid come from the Pell Grant program and federal subsidized student loan programs. While the Pell Grant program continues to subsidize the cost of higher education for many students, the cost of higher education has greatly outpaced the funding set aside for the program. Government subsidized student loan programs, which were also intended to make higher education more affordable and accessible, have also been outpaced by the cost of higher education and carry the additional burden of requiring students to pay back the loans upon graduation.

According to Leslie and Brinkman (1987), there are a group of studies they refer to as "Student Demand Studies" (p. 182). From 1967 to 1982 the authors list 25 separate student demand studies investigating how different student populations respond to various financial indicators including tuition, student aid, room and board costs, cost to income ratios, and the opportunity cost of postponing entry into the workforce and the resulting income in order to 
attend college. Since that time, additional studies have been conducted to shed light on how the cost of higher education and the shift in sources of financial aid continue to impact student access to higher education and students' ability to choose the type of institution that best suits their academic ability and career ambitions (Dongbin, 2004; Hossler \& Stage, 1992; Kim, DesJardins, \& McCall, 2009; Paulsen \& St. John, 1997; Paulsen \& St. John, 2002; Trent, Lee, \& Owens-Nicholson, 2006; Wojciechowska, 2010). The particular focus of much of the research is on how the changing financial landscape of higher education is impacting diversity within the student body and access to higher education (Carter, 2006; Dongbin, 2004; Kane \& Spizman, 1994; Kim, DesJardins, \& McCall, 2009).

While democratization of higher education is the ultimate long term goal of public higher education, current trends in the cost of providing a college education, compounded by diminishing sources of government aid, are shifting more of the cost of a higher education back on to the student (Graham, 1978; Trow, 1972). As more of the costs of a higher education are born by the student, access to higher education will become more restricted. This paper attempts to follow a recommendation by St. John, Paulsen, and Carter (2005) by examining the following independent variables: tuition charged, student loan indebtedness, Pell Grant award, Work Study award, housing costs, EFC, balance on credit cards, parent home ownership, whether or not a student worked during the summer of 2007, and receipt of parental financial assistance have impacted access to higher education based on students' race and ethnicity and therefore the diversity of the student body at public four-year colleges and universities.

\section{Statement of the Problem}

Incorporating and maintaining diverse perspectives in higher education is a benefit to students and faculty in the richness it brings to the education process (Turner \& Pusser, 2004). 
Countless resources in the way of targeted scholarships, targeted admissions recruiting, and the intentional hiring of faculty and staff who represent more racial and ethnic diversity are dedicated to recruiting and retaining racially diverse students, yet in many cases, those resources are insufficient to create a fully integrated educational experience in regard to diversity. According to a report by Deloitte LLP (2011), one of the top 10 problems facing higher education is, "Education for all: Tackling diversity, accessibility, and affordability" (p. 25). It is important to examine which financial factors in our current financial aid system have the greatest impact on enrollment and if those factors influence the racial and ethnic composition of the student body. The need for this type of research has also been demonstrated by previous studies which include an examination of how finances impact a student's decision to attend college (Cabrera \& La Nasa, 2000; Carter, 2006; DesJardins \& Bell, 2006; Dervarics, 2009; Dowd, 2008; Edward \& St. John, 1990; Haynes, 2009; Hwang, 2003; Kim D. , 2004; King, 1999; McPheson \& Schapiro, 1991). Using data collected by the National Center for Educational Statistics and contained in National Postsecondary Student Aid Study (NPSAS), this study examines which independent variables of tuition charged, student loan indebtedness, Pell Grant award, Work Study award, housing costs for the student, EFC, balance on credit cards, whether or not a student's parents own their home, whether or not a student worked during the summer of 2007, and whether or not students have reported receiving financial assistance from their parents are most significantly associated with attendance at state universities by students from the racial and ethnic categories of: White, Black or African American, Hispanic or Latino, Asian, American Indian or Alaska Native, Native Hawaiian/Other Pacific Islander, or Other. In addition to determining which independent variables are most significantly associated with the attendance of students at the public universities examined, this study sheds light on whether or 
not the independent variables play different roles in a student's decision to attend a public university based on the race and ethnicity of the student.

Although there is value in maintaining diversity and incorporating diverse perspectives in the higher education process, the diversity currently present within higher education does not currently reflect the diversity present in society as a whole. As a result, majority students are not gaining the experience they need to successfully navigate a society and workplace that is becoming increasingly more diverse. At the same time, minority students are not gaining access to public higher education institutions at the same rate as their representation in society and are therefore at a disadvantage when seeking out positions in the workforce that require a college degree. Therefore it is important to determine how to make higher education more accessible for students from diverse racial and ethnic backgrounds

This study attempted to uncover the impact the cost of a higher education is having on the racial diversity of the students attending state universities. Significant relationships between the independent financial variables and the dependent variable of enrollment were examined to determine which financial variables were most closely associated with attendance of students from the racial and ethnic populations examined. As a result, action could then be taken to make changes to the independent variables in a manner that will make higher education accessible to a more diverse population of students. The risk of not taking action on significant relationships could be the reduction or elimination of racial and ethnic diversity in the student population attending public institutions.

\section{Purpose of the Study}

The purpose of this study was to examine what effect the cost of higher education has on students' decision to attend public universities. The study determined which of the independent 
financial variables examined are most closely associated with the enrollment rates of students from different races and ethnicities at the public colleges and universities examined. The analysis also determined if the association of independent variables to the dependent variable differed based on the race and ethnicity of the student.

\section{Research Questions}

1. When examining historical enrollment demographics of $31,760(n=31,760)$ students from public universities which factors (tuition charged, student loan indebtedness, Pell Grant award, Work Study award, housing costs for the student, EFC, balance on credit cards, whether or not a student's parents own their home, whether or not a student worked during the summer of 2007, and whether or not students have reported receiving financial assistance from their parents) are most closely associated with the total enrollment of students?

2. Are the independent variables of tuition charged, student loan indebtedness, Pell Grant award, Work Study award, housing costs for the student, EFC, balance on credit cards, whether or not a student's parents own their home, whether or not a student worked during the summer of 2007, and whether or not students have reported receiving financial assistance from their parents associated with enrollment levels of students differently based on their race and ethnicity?

The following null and alternative hypotheses will be used to address this research question:

\section{Null Hypotheses}

$\mathrm{Ho}_{1}$ : There is no statistically significant degree of association, as evidenced by CHAID analysis, between total enrollment of particular races of students and a set of independent 
variables including: tuition charged, student loan indebtedness, Pell Grant award, Work Study award, housing costs for the student, EFC, balance on credit cards, whether or not a student's parents own their home, whether or not a student worked during the summer of 2007, and whether or not students have reported receiving financial assistance from their parents.

$\mathrm{Ho}_{2}$ : There is no difference in degree or order of association, as evidenced by CHAID analysis of total enrollment of students from different races and ethnicities and the independent variables of: tuition charged, student loan indebtedness, Pell Grant award, Work Study award, housing costs for the student, EFC, balance on credit cards, whether or not a student's parents own their home, whether or not a student worked during the summer of 2007, and whether or not students have reported receiving financial assistance from their parents.

\section{Alternative Hypotheses}

$H a_{1}$ : There is a statistically significant degree of association, as evidenced by CHAID analysis, between total enrollment of particular races of students and a set of independent variables including: tuition charged, student loan indebtedness, Pell Grant award, Work Study award, housing costs for the student, EFC, balance on credit cards, whether or not a student's parents own their home, whether or not a student worked during the summer of 2007, and whether or not students have reported receiving financial assistance from their parents.

$H a_{2}$ : There is a difference in degree or order of association, as evidenced by CHAID analysis of enrollment of students from different races and ethnicities and the independent variables of: tuition charged, student loan indebtedness, Pell Grant award, 
Work Study award, housing costs for the student, EFC, balance on credit cards, whether or not a student's parents own their home, whether or not a student worked during the summer of 2007, and whether or not students have reported receiving financial assistance from their parents.

\section{Significance of the Study}

The importance of access to higher education is demonstrated as early as the implementation of a public system of higher education supported by public funding. Along with the investment of public funds came the need to assess whether or not the goal of access was being achieved. While there are many studies examining the impact of the economics of higher education on the student population as a whole and on different sub-populations (College Access and Admission, 2007; Edward \& St. John, 1990; Hossler \& Vesper, 1993; Leslie \& Brinkman, 1987), this study is unique to other studies on the same phenomenon in a number of ways. First, many prior studies use longitudinal data available in the High School and Beyond study as well as prior National Postsecondary Student Aid Studies (NPSAS). This study used the most recent data available through the NPSAS 2007-2008 which is supported by St. John, Paulsen, and Starkey (1996) who used the NPSAS 1986-1987 study data for their Financial Nexus model. Paulsen and St. John (1997) in a subsequent study based on their prior research, further elaborate on their support of using a national survey and the NPSAS more specifically because of the “...range of financial variables and a corresponding set of college choice variables drawn from students' ratings of the importance of financial reasons for their college choice" (p. 69).

Second, this study is unique because the independent variables were examined using a Chi-square Automatic Interaction Detection (CHAID) approach to determine which independent variables are most significantly associated with the number of students attending the universities 
examined as measured by race and ethnicity. The final analysis placed value on each of the variables in a decision tree which best reflected the importance of each independent variable and its effect on the enrollment of students from each population (as measured by race and ethnicity) in attendance at public institutions.

Third, this study focuses on the independent variables of tuition charged, student loan indebtedness, Pell Grant award, Work Study award, housing costs for the student, expected family contribution (EFC), balance on credit cards, whether or not a student's parents own their home, whether or not a student worked during the summer of 2007, and whether or not students have reported receiving financial assistance from their parents. Several of these variables were chosen to focus on the net cost of a higher education based on the amount a student is expected to pay as indicated by their EFC and student loan indebtedness or perceived cost as indicated by the total amount of tuition charged. Other independent variables were chosen based on current research available and the variables examined in related studies. Additional variables were added to uncover any other associations that may exist in an effort to better understand the factors associated with the enrollment levels of students from different races and ethnicities.

Examining the direct cost to students also addressed a concern raised by Edward and St. John (1990) regarding the use of Student Price Response Coefficients (SPRCs) where they hypothesize that the assumptions used in the formulation of SPRCs would dictate a coefficient that approaches zero as the amount of aid available approaches the total amount of tuition. Furthermore, St. John, Cabrera, Nora, and Asker (2000) suggest there have been two types of, "Economic Models of Persistence" (p. 30). The two types of models mentioned by the authors are studies with a focus on economics and studies with a focus on the "student-institution fit" (p. 30). This study's focus was on the first approach. The choice of independent variables was 
supported by prior studies (see Choice of Variables section) and additional variables were chosen in an effort to exploit a strength of CHAID analysis in exploring and uncovering relationships between variables. The collection of variables and the statistical method of a CHAID analysis are not covered in current literature and supplemented prior research completed on the subject.

Furthermore, this study investigated the relationship between the independent and dependent variables at public rather than private institutions for three reasons. First, public higher education originated with and continues to have the goal of providing access to a diverse student population regardless of their personal demographics (see The Implied Social Contract as a Basis for a Public Higher Education System in the Literature Review). In addition, the designed purpose of public higher education is to provide access to higher education for a broad population of students as opposed to a selective process which takes place at most private institutions. Second, the economics, decision making process, and relative value placed on the education provided at public and private colleges can differ greatly. Focusing specifically on public colleges and universities limited the impact of any differences (perceived or real) on the study based on whether the institution is public or private. Third, the scope of the study was intentionally limited to public institutions based on the support they receive from the public for operating funds as well as funds received through federal and state financial aid programs.

Although several studies have been conducted on the relationship between the financing of higher education and students' choice and persistence in higher education (Carter, 2006; Dongbin, 2004; Hossler \& Stage, 1992; Kane \& Spizman, 1994; Kim, DesJardins, \& McCall, 2009; St. John, Paulsen, and Carter, 2005), Longanecker, Blanco, and Long (2004) highlight the need for more research on the relationship between federal and state aid programs, and colleges. The authors point out the difficulty in determining the impact changes in federal aid programs 
have on states and state funded universities since changes in federal aid programs have been minimal. This study attempted to fill part of the gap in this research by investigating if the independent variables examined are significantly related to enrollment at state funded universities, as well as if those programs have the ability to impact the racial composition of the student body.

While many independent variables may play a role in students' choice to attend a university and which university they decide to attend, prior studies focusing on tuition and financial aid most frequently utilize a linear or logistic regression approach (Dongbin, 2004; Edward \& St. John, 1990; Carter, 2006; Hossler \& Stage, 1992; Kane \& Spizman, 1994; Kim, DesJardins, \& McCall, 2009; Leslie and Brinkman, 1987; McPherson \& Schapiro, 1991; St. John, Paulsen, \& Carter, 2005). This study expands on current research by further investigating the role the independent variables play in enrollment levels at colleges and universities by utilizing a Chi-square Automatic Interaction Detection (CHAID) approach. Significant relationships found in the CHAID analysis were also used to predict how changes in the independent variables would impact the total enrollment at public universities as well as how those changes impact enrollment of students from different races and ethnicities.

This study is important because it examined the impact reduced state support, and consequently the additional financial responsibility taken on by students, has on the diversity of the student body at state funded universities. Furthermore, CHAID analysis identified the independent variables most significantly associated with the attendance at the public colleges and universities included in the study and whether or not the affiliation changed based on race and ethnicity of the student. Once the independent variables most significantly associated with the attendance rates of students were identified, the CHAID analysis was used to predict how 
changes in the independent variables would affect the attendance rates of students based on their race and ethnicity.

The information in this study is useful in informing state legislatures and public university administrators on how the enrollment of students at public universities is being impacted by the financial variables examined (tuition charged, student loan indebtedness, Pell Grant award, Work Study award, housing costs for the student, EFC, balance on credit cards, whether or not a student's parents own their home, whether or not a student worked during the summer of 2007, and whether or not students have reported receiving financial assistance from their parents), and how the impact on students differs based on their race and ethnicity. The results of this study can also be used to determine which financial variables examined could be modified to have the greatest impact on enrollment based on race and ethnicity with the goal of increasing access for a more diverse student population.

\section{Key Terms and Concepts}

The basis for the following list of terms comes from a similar study by Hwang (2003) and was modified and updated for the purpose of this study.

1. Age. The NPSAS calculates age as of $12 / 31 / 07$. Generally, a traditional undergraduate student is considered as less than or equal to 23 years of age.

2. Aid package. Defined as the type of aid package (combinations of grants, loans, work-study, institutional aid, other) received during 2007-2008 academic year.

3. Classroom diversity. Intentional interactions facilitated by the institution. These interactions can take place in the form of workshops, assignments, structured classes with intentionally an intentionally diverse student population (Terenzini, Cabrera, Colbeck, Bjorklund, \& Parente, 2001). 
4. Colleges. For the purposes of this study colleges and universities are used to refer to public 4 year degree granting institutions.

5. Controllable cost. Costs that can be controlled by students by choosing to adjust their budget by economizing. Living costs are included in this category.

6. Cost. Also referred to as net price. This is the price minus discounts.

7. Democratization. To make democratic. The idea expressed in this term when referring to access to higher education is providing the means where all eligible college age students have equal rights and the resources necessary to attend college.

8. Dependency. If a student is considered independent, then Adjusted Gross Income is based on the student's income alone. If a student is considered a dependent of their parent(s), then income is based on the Adjusted Gross Income of the parent(s).

9. Dependency Status. Students can be dependent or independent. NPSAS computes the dependency status of students as of December 31, 2007. All students are considered dependent unless they meet one of seven criteria. To be independent the student must be: 24 years old or older by December 31, 2007, enrolled in degree program beyond a bachelor's degree, married, orphaned or ward of the court, have legal dependents other than a spouse, a veteran of U.S. Armed Forces, on U.S. Armed Forces active duty.

10. Discounts. Any financial aid (excluding loans) that reduces the price of attending college.

11. Enrollment/Total Enrollment. A student enrolled at any time during the 2007-2008 academic year (National Center for Education Statistics, 2008). 
12. Expected Family Contribution (EFC). It is the amount a family is expected to pay out of pocket toward the cost of their education on an annual basis. Calculation of EFC is based on the financial resources of the student (and parents if still a dependent). EFC is deducted from the price (or net price, see below) to determine the financial need of the student (Kruse-Crocker, 2008).

13. Free Application for Federal Student Aid (FAFSA). The application made available by the U.S. Department of Education to apply for federal student aid programs. The information provided on the application is used to generate a Student Aid Report (SAR), which is used to determine the amount of aid needed to make the tuition at a particular institution accessible.

14. Federal Loans. NPSAS computes the cumulative student loan amount borrowed for their undergraduate education. This includes all student loans through federal programs including Direct Loans, Stafford Loans, and Perkins Loans. Parent Plus loans are made to parents and are not included in this number. Loans provide immediate funding for current tuition amounts owed and have specific terms under which the amount loaned to the student will be repaid.

15. Gains Analysis. A table or graph generated as a result of using the model generated from a CHAID analysis which indicates how changes in the inputs of the model will result in gains in the dependent variable.

16. Grants. NPSAS computes total amount of grants received by a student in 2007-2008. Grants are a type of student financial aid that does not require repayment or employment. Grants include merit-only scholarships, tuition waivers, and employer tuition reimbursements. 
17. Informal interaction diversity. The type of diversity encountered and measured by the number of times students interact with students of different gender, race, ethnicity, or other categorization being studied (Terenzini, Cabrera, Colbeck, Bjorklund, \& Parente, 2001).

18. Housing Costs. Includes the amount charged for room and board.

19. Net Price. See Cost.

20. Persistence. Persistence can refer to either within-year or between-year persistence. Within-year persistence is when a student continues on with their education from one semester to the next (fall semester to spring semester). Between-year persistence is when a student continues their education from one year to the next (fall semester to fall semester).

21. Price. A student's total cost of attendance. Price consists of tuition plus housing costs (St. John, Cabrera, Nora, \& Asker, 2000).

22. Quota System. An admission policy designed to target minority students with the goal of admitting a certain number or percentage of students from the desired target race/ethnic group.

23. Risks Analysis. A table or graph generated as a result of using the model generated from a CHAID analysis which compares actual dependent variable numbers to predicted dependent variable numbers.

24. Structural Diversity. The mix of students on campus as categorized by race, gender, or other categorical system (Terenzini, Cabrera, Colbeck, Bjorklund, \& Parente, 2001). 
25. Student Aid Report. The report generated by the information provided by students when they file a Free Application for Federal Student Aid. Used by institutions to determine the amount of aid needed to make attending a particular institution financially accessible to a student.

26. Title IV aid. Federal student aid provided through Title IV of the Higher Education Act of 1965. Title IV aid includes the Pell Grant, Supplemental Educational Opportunity Grant (SEOG), State Student Incentive Grant (SSIG), College Work Study, the Perkins Loan Program, Direct Loan and Stafford Loan programs.

27. Tuition. The amount charged for attending a college or university. This is the published or sticker price before any discounts or loan amount are deducted.

28. Universities. See Colleges.

29. Work-study. Total amount of all work study awards received during 2007-2008. Institutions were asked to report the amount actually earned rather than the award amount, which may be greater.

\section{Organization of the Study}

This dissertation is organized into five chapters. The first chapter provides an introduction to the topic, overview of the problem, purpose of the study, research questions, hypotheses, significance of the study to higher education, and definitions of key terms and concepts. Chapter two is a review of the associated literature on The Value of Diversity in Higher Education, The Implied Social Contract as a Basis for a Public Higher Education System, Trends in Funding a Higher Education, an Overview of Prior Studies and Research, The National Postsecondary Student Aid Study and Sample Methods, and Rational for the Choice of Variables. Chapter three includes information regarding the research design employed in the 
study which includes: the choice of variables and their role in the analysis, the analysis techniques and statistical assumptions, an overview of the design and purpose of the NPSAS survey, disclosure of any possible ethical issues, and limitations of the study. Chapter four presents the results of the study in the context of the research questions and null hypotheses. Chapter five discusses the findings of the study and highlights implications and recommendations for policy, practice, and future research. 


\section{Chapter Two: Review of the Literature}

\section{The Value of Diversity in Higher Education}

There is great potential for connecting learning outcomes to the diversity students encounter as a part of their higher education experience. Aside from broadening students' experiences and perspective, encountering racial and ethnic diversity in curricular and cocurricular experiences prepares students for their lives beyond their higher education experience. According to Kotkin (2010), the United Nations forecasts an estimated two million people will immigrate to the United States annually over the next four decades. Not only will this in surge of people contribute significantly to the economy, Kotkin states the white population will no longer be the majority race in the United States and how, "No other advanced, populous country will see such diversity" (p. 2). Given the changing racial landscape of society and the workforce in the United States, higher education will have no choice but to change as well. The shift will be necessary to make higher education accessible to a more diverse student population and to provide an education which prepares students to encounter a more diverse society. Several studies have shown how higher education has a positive effect on students' feelings regarding race and ethnicity (Astin, 1993; Milem, 1998; Pascarella, Edison, Hagedorn, Nora, and Terenzini, 1996; Pascarella and Terenzini, 2005).

According to Terenzini et al. (2001), research conducted on the benefits of diversity in higher education has resulted in a few consistent findings. First, a more diverse student body results in higher retention of students from diverse backgrounds and therefore positively perpetuates a diverse population. Second, students who are challenged by diverse perspectives show "greater cognitive development" (p. 511). Third, students who encounter diversity are more accepting of diversity. Fourth, students who interact with students who are different from 
themselves exhibit greater racial/cultural literacy and advocacy. Fifth, students who are exposed to diversity are more confident in their interactions with others inside and outside the classroom. Lastly, students who are exposed to diversity in their educational experience are more likely to be involved in volunteering or in civic duty.

Gurin, Dey, Hurtado, and Gurin (2002), wrote a paper based on information gathered from the University of Michigan and the Cooperative Institutional Research Program in an effort to find evidence of a tie between students' experiences with students from diverse racial backgrounds and learning outcomes. Gurin et al. point out structural diversity, informal interactional diversity, and classroom diversity as three different ways students encounter diversity. The authors explain how there are four lines of research used to point out the benefits of promoting diversity. The approaches outlined by the authors are:

1. Research on students' perceptions of the benefits they receive.

2. Research focused on evidence provided by faculty on how diversity impacts learning outcomes.

3. Research providing evidence of the benefits to the community in terms of economic gains, graduation rates, and students who are better equipped to take on leadership positions in their communities.

4. Research results providing evidence of diversity experiences contributing to learning outcomes.

Gurin et al. go on to explain how encountering students from diverse populations formally inside the classroom as well as informal interactions outside the classrooms "consistently and meaningfully affect important learning and democracy outcomes" (p. 358). 
In a follow up study, Gurin, Nagda, and Lopez (2004) investigate how democratic citizenship is positively impacted by diversity in education. The study compared two groups of students during their senior year. One group participated in a multicultural program during their freshman year and the control group did not. Although both groups had a similar mix of genders, races and grew up in similar geographic regions, the authors confirmed their hypothesis that students who participated in the multicultural program were able to better relate to students of other races, better able to appreciate the contributions of students who were from different races, and were more likely to be civically engaged.

The benefit of diversity on learning outcomes starts from the beginning of students' college experience. Pascarella, Edison, Nora, Hagedorn, and Terenzini (1996) wrote a paper exploring what experiences impacted students acceptance of diversity during their freshman year of college. The authors highlight the impact college has on helping students gain a greater appreciation for "openness and tolerance" (p. 175) in several areas including race and ethnicity. In their study, the authors find in six out of nine co-curricular experiences the students who participated in those activities were shown to be more open to diversity. These co-curricular experiences included living on campus, participating in a racial or cultural workshops, the number of hours the student worked per week, who the student associated with outside the classroom, the topics of conversation students engaged in, and the information exchanged when students had conversations with other students. The authors conclude there are many experiences that influence how accepting a student is of diversity and there is a cumulative and interrelated effect of how these experiences positively influence students' openness to diversity. The authors also make the logical conclusion of a positive relationship existing between student 
involvement and the impact the college experience has on students, which is supported by their findings.

Diversity is shown to be an important aspect of students' experiences in relationship to becoming more open and accepting of diverse viewpoints as well as being prepared to interact with a diverse society. Birnbaum (1983) points out the importance of providing choice in the types of colleges where students are able to pursue a higher education in order to appeal to a more diverse student population. The author examines diversity in higher education by analyzing differences and similarities in universities with a discussion of how institutions are becoming more similar over time. Birnbaum concludes that accessibility and diversity are more likely to be achieved if diversity in the types of institutions providing education continues to exist. Since institutions are able to serve differing needs of students differently, diversity in the types of institutions available assures the specific needs of different populations can be met somewhere within the higher education system.

Turner and Pusser (2004) examine the student population at the University of Virginia to determine if a highly selective public university is able to maintain a student population reflective of the broader state demographics in regard to personal demographics (including race), as well as the geographical region represented by each student. Turner and Pusser's study addresses one of the limitations highlighted by Pascarella and Terenzini (2005), of the need to determine how well the benefits outlined by their research can be applied to individual institutions. Turner and Pusser also point out how despite the benefits of having a diverse student body, the student body has become less diverse even during a time of increased college enrollment. The trend of having a less diverse student body during a time of increased enrollment is even more pronounced at highly selective colleges and universities as students 
from diverse racial backgrounds are less prepared to meet stringent admission requirements. As a result, students from more diverse backgrounds are more likely to attend universities that are less selective, but also tend to have lower graduation rates. Both the selectivity of the admission process at elite universities, as well as the reduced likelihood that students who attend less selective institutions will graduate from those institutions, has a compounding effect on access to higher education for students from diverse backgrounds. Several studies have demonstrated the educational and developmental benefits of diversity in the student body and recommendations on how to reverse the trend of declining enrollment of students representing diverse racial and ethnic backgrounds (Advisory Committee on Student Financial Assistance, 2001; Bowen \& Bok, 1998; Chang, Witt, Jones, \& Hakuta, 2003; Hurtado, Milem, Clayton-Pedersen, \& Allen, 1999). Turner and Pusser's work has been supported by a number of other studies which demonstrate how access for Economically and Educationally Challenged (EEC) students is affected based on their economic situation and their educational background (College Access and Admission, 2007; Astin \& Oseguera, 2004; Hearn J. C., 1984; Hearn J. C., 1991; Karabel \& Astin, 1975; McDonough, 1994; Tinto, 2006). Additional studies have shown how economically and educationally advantaged students are more likely to enroll in college and have a disproportionately high acceptance rate to highly selective and elite colleges and universities (Astin, 1993; Astin, 1999; Terenzini, Cabrera, \& Bernal, 2001). Some studies have suggested that aside from the economic challenges students face in funding a higher education, EEC students also have a higher comfort level with starting work over going to college (College Access and Admission, 2007; Freeman, 1999; Willis, 1977).

While the benefits of diversity on educational outcomes seem to be clearly outlined in the research, discussion and concern still exist as to whether or not democratization of higher 
education is indeed occurring. A two pronged concern over diversity within the college student body persists. First, do students regardless of race and ethnicity have equal access to higher education? Second, and equally important, is: Is the race/ethnic diversity currently present in higher education sufficient to equip students with the learning outcomes and skills needed to interact effectively with an increasingly diverse society? The following section of the literature review outlines the desire to make higher education more accessible to all students for these reasons and others as well.

\section{The Implied Social Contract as a Basis for a Public Higher Education System}

Increasingly society is relying on human capital through the knowledge and skills a particular person can bring to the table in order to increase the productivity and value of students to their future employers. In a competitive environment, companies are relying on people who bring with them specific knowledge and skills. As a result, the stakeholders in higher education (companies, students, parents, and accrediting agencies) are looking to higher education to provide the training and preparation necessary to enter the information society.

The idea of the information society is discussed by Drucker (1994). In a paper titled The Age of Social Transformation, Drucker makes the argument that before the turn of the $20^{\text {th }}$ century, economies of most if not all of the world were agriculturally based. Subsequently, there was the rise and fall of the Industrial Society along with the blue collar worker, which was then replaced by knowledge workers who possess information coupled with skills to perform specialized tasks. In addition, the knowledge worker is equipped with the skills necessary to continue to learn and apply new knowledge. Instead of being content in one job, the knowledge worker is always looking to acquire new skills and knowledge. St. John et al. (1996) discuss higher education in the context of "human capital theory" and "preference utility theory" (p. 
179). The two theories point out the opportunity costs associated with making a decision to invest in higher education. Human capital theory and preference utility theory compare the cost of an education to the potential of additional income by mastering additional skills and knowledge through the higher education experience. The assumption is if the potential additional income exceeds the cost of the education, potential students will make the monetary investment for additional education. While society and students continue to see the value in investing in higher education based on the potential returns, as the cost of higher education continues to increase, eventually the cost of higher education will exceed the potential benefits.

However, higher education has the potential of creating more equality between people of different races and ethnicities in regard to future earnings. Carter (2006) explores this idea in a paper covering the challenges of retaining minority students in higher education. Carter highlights how African Americans on average make approximately 2/3 the income of their white counterparts. However if the same analysis is done where both races have obtained their 4 year undergraduate degree that margin narrows from a $34 \%$ difference to a $5 \%$ difference.

The effort to make higher education equally accessible to students from all races and ethnicities will need to include a close examination of how students react differently to different types of financial aid. Carter explains that although there is a great potential for higher education to create equity between races, the problem is white students' graduation rates are approximately twice as high as those of African American students and more than three times higher than those of Hispanic students. Part of the challenge of retaining minority students is the difference in how they react to different types of financial aid. In terms of financing college, African Americans are mentioned as having a large population of economically challenged students and how persistence is linked to students' "ability to pay" (p. 42). Carter's study finds no significant 
difference in how Hispanic and White students respond to different types of financial aid, but African American students' retention rates were positively impacted by both grant and loan aid. Carter's findings are consistent with the findings of Thomas Green (2005). Green wrote a paper on how financial aid impacts student access to a higher education within the context of the implied social contract between society and college age citizens. Green uses the Brown et al. v. Board of education decision of separate but equal as a backdrop for examining the progress made since that time of providing equal access to higher education to all students without regard to their race. Green summarizes the history of legislation in the United States regarding racial equity in having access to higher education. Green's examination dates back to the presidency of Harry S. Truman and later the establishment of federal student loan programs, federal grant programs, and graduate fellowships. After the establishment of these programs, Green reports there were initially higher attendance rates of black and Hispanic students. However as the cost of higher education continued to rise, more financial aid was allocated to middle income families and grants were replaced with loans. Consistent with Carter's findings, Green's statement of more financial aid being allocated to middle income families and Carter's point of a higher percentage of African American students coming from economically challenged families makes a powerful argument as to why encouraging diversity may necessitate implementing policies allocating financial aid differently based on a student's race. Without additional consideration given to students based on their economic situation as well as their race, Green's finding of how in recent years the population of minority students attending college has been declining is likely to continue into the future.

Although it would seem affirmative action policies would be an effective way of addressing the concern raised by Green and Carter, affirmative action policies come with their 
own challenges and may not actually increase access for minority students. Gupta (2006) wrote a paper comparing access to higher education in India and the United States of America by examining access and affirmative action measures in place in both countries. The history and culture of the two countries which led up to the disparity in access to higher education is also discussed. The author points out the difference between diversity and affirmative action and how successful past attempts of achieving diversity by employing affirmative action measures have been. Gupta closes the paper by stating affirmative action measures designed to achieve diversity are a "zero sum game" (p. 16) meaning where one group gains another group must lose.

The idea of the zero sum game is also supported by Spaulding and Kargodorian (1982). In their paper, the authors investigate the societal pressures involved in limiting economic mobility. The authors examine access to higher education within the context for four criteria: “...equality of access to higher education, equality of participation within the higher education institutions, quality of education results, and equality of education effects in life changes in the future" (p. 1). A comparison is made between different countries and the methods used to make higher education more accessible. The authors examine the idea of access and point out how there are many different ideas of what accessibility means and the methods employed to encourage diversity are numerous as well. Spaulding and Kargodorian come to the conclusion that socio-economic and political structures encourage a continued disparity in access to higher education. This disparity is perpetuated by the needs of society and the expectation that certain classes of people are in the best position to fulfill that societal need.

The role of quota systems in Higher Education is an ongoing debate. Recently, students have challenged public universities admission policies based on Affirmative Action or quota systems. The basis of students' arguments has been that students were unfairly penalized and 
denied admission to a public university based purely on their race. Student challenges to university quota systems have called these policies into question. Current admissions practices in this area are dictated by the Supreme Court's decision in Gutter v. Bollinger (2003), where the court determined race could be considered as a part of college's admissions process if there was a compelling reason to increase diversity in the student body and the policy was narrowly tailored to address that need. In 2013, the Supreme Court ruled on Fisher v. University of Texas where the court overturned the lower court rulings supporting the university's affirmative action policy. The Supreme Court determined the University of Texas's policy was not reviewed with the level of scrutiny required by Gutter $v$. Bollinger. The case was remanded to the lower courts and is currently pending (Fisher v. University of Texas at Austin et al., 2013). By enacting quota systems and Affirmative Action policies, colleges are acknowledging the need to increase diversity in the student body. The Supreme Court has upheld the practice, but only when the policy is narrowly defined to address a specific and compelling reason to increase diversity in the student body. However, the future of policies using race/ethnicity as a consideration for admission is uncertain with a decision on Fisher v. University of Texas at Austin et al. pending. Adelman (2010) goes into great detail about accountability in Higher Education. In Adelman's short paper, he discusses accountability in Higher Education by examining the following areas: the relationships present in the business of education, implicit contracts, warranty relationships, regulatory relationships, markets, and the educational environment. While Adelman does not explicitly address diversity and access to Higher Education in this paper, Adelman's main points can be applied to both topics. If an implicit contract exists between an institution of higher education and the student to adequately prepare them for a career, is that implicit contract being broken if the educational environment does not reflect the 
work environment the student will enter once they graduate? If an implicit contract does exist and is being broken, what kind of warranty or responsibility does the college or university bare as a result? Are the regulations that exist to promote access to a higher education for students from racially diverse backgrounds sufficient to ensure an education to every student who desires one, regardless of race? And finally: What role does the market play in determining how diversity should be represented as a part of the student body attending public institutions of higher education? All of these questions are important to examine, especially if financial indicators can predict whether or not students from racially diverse backgrounds are less likely to attend a public institution. If a significant relationship does exist, what then is our responsibility to make changes to those financial systems in order to meet the obligations raised by Adelman's questions? This study attempted to answer these questions by taking the first step in providing evidence as to whether or not there is a significant association between the independent financial variables examined and attendance rates of students based on their race and ethnicity.

\section{The Trends in Funding a Higher Education}

In the previous section of this literature review, an examination was performed on society's responsibility to provide equal access to higher education regardless of a student's race or ethnicity. Part of the examination included studies which provided evidence of different types of aid impacting students from different races differently. This section of the literature review investigates this phenomenon further by taking a closer look at the current trends in how students fund their higher education.

The rising cost of higher education has impacted all students in one way or another. An article posted to Inside Higher Ed by Wojciechowska (2010) highlights how access to higher education has been impacted by rising tuition and cuts in state funding for public universities. 
Wojciechowska also quotes Patrick Callan the president of the National Center for Public Policy and Higher Education at the time of the article. One of the areas Wojciechowska highlights from Callan is the idea of students "trading down" (p. 3) the quality of their educational experience based on what they can afford instead of selecting an institution which most closely matches their academic achievements. While Wojciechowska suggests the rising cost of higher education impacts all students, other studies suggest a difference in how access is impacted based on different student demographics including their race and ethnicity.

Peter and Horn (2005) utilize data gathered from the Integrated Postsecondary Education Data System (IPEDS) and the Current Population Survey (CPS) to examine differences in attendance rates at colleges and universities of men and women. Part of their study includes an examination of participation rates of males and females broken down by racial classifications of Black, Hispanic, American Indian, Asian/Pacific Islander, Non-resident alien, and White. While representation of women as a part of the student population at colleges and universities has gone up, participation rates of women from minority groups remained constant. This study concludes that the college student population has become more diverse in regard to gender, but diversity in regard to race remained constant.

Steelman and Powell (1993) investigate the difference in financial support provided by parents of students from white families and students from minority families. The authors find from their study of data from High School and Beyond and the Nation Educational Longitudinal Study of 1988 that parents of minority students are more accepting of government aid to help finance higher education for their children. Steelman and Powell also found minority parents are more likely to set aside savings to help finance their children's college education. In regard to increasing diversity, the authors note how federally funded programs are predominately racially 
neutral. As a result, the federally funded programs have a disproportionate advantage to white students since the majority of students attending college are white.

Since Steelman and Powell's study, additional studies have provided evidence refuting their finding of federally funded programs being racially natural. Lack of diversity in higher education in regard to race is explored by Cabrera and La Nasa (2000). In their study, the authors investigate the phenomenon of changes in aid programs having a disproportionate effect on different populations of students. Cabrera and La Nasa provide support for the finding that students from low income families are highly sensitive to changes in grant aid, but largely unaffected by changes in aid provided by loan programs. Swail, Redd, and Perna (2003) create a tie between Cabrera and La Nasa's work and how changes in grant aid have a greater impact on access for minority students than white students. Swail et al. present evidence of a relationship between socioeconomic status and race, with minority families earning less than their white counterparts. The result is on average, a student from a racially diverse background is not only more likely to have less financial resources, but is also less likely to attend college if student loan aid is substituted for grant aid (Hu \& St. John, 2001; Perna, 2007; Swail et al., 2003). King (1999) wrote an article which also points out an inequity in the amount of income earned by the households of students from different races and ethnicities. King opens her article by stating how most studies regarding how students pay for college focus on income or institution type and she attempts to fill a gap in the research by examining how differences in race and gender impact how students finance their college education. King goes on to summarize there is a notable difference in the average household income for students from white families in comparison to other racial/ethnic groups. The author also points out that the data suggests students will make 
choices of what type of college/university to attend and whether to attend full-time or part-time based on the "immediate cost of attending college" (p. 20).

Financial support for potential college students goes beyond merely providing financial resources to cover tuition costs. Liu (2011) investigates the impact of for-profit businesses on college access who engage in some or all of four activities: standardized test prep, private college counseling, providing mass media resources, and management and marketing of enrollment. Liu supports the findings of several other studies which point out how students from different races, ethnicities and income groups perform differently on standardized tests (Atkinson, 2001; Carnevale \& Rose, 2003; National Association for College Admission Counseling, 2008; Sackett, Hardison, \& Cullen, 2004; Walpole, et al., 2005; Zwick, 2007). Since most colleges and universities rely on standardized test scores as part of the admissions requirements, students who can afford to pay for test preparation courses have a significant advantage over students who do not have the same opportunity. Similar to the use of standardized test preparation services, private college counseling services, mass media, and marketing efforts are biased toward students who come from a privileged background. In Liu's conclusion she makes the following statements, “...the admission industrial complex appears to be most effective in protecting privilege" and "...it would appear that the playing field for college access will remain precipitous for students from underprivileged socioeconomic backgrounds" (p. 17).

In a paper examining the supply and demand in higher education, Ehrenberg (2001) discusses how higher education has expanded both in the types of institutions providing a higher education, but also in the total number of institutions. Ehrenberg echoes Liu's conclusions and highlights the disparity between public funding for public and private colleges and universities. Ehrenberg points out how more research is needed on what the impact of this difference in 
financial support has on students from different, "socioeconomic, ethnic, and racial groups" (p. 20).

Penske, Porter and DuBrock (1999) examine how the substitution of loan aid for grant aid impacts the retention of minority and majority students. The authors note a trend for colleges to slowly replace grants and scholarships with loan aid as students progress into their sophomore, junior, and senior years. As grant and scholarship money are replaced with loan money, students are more likely to withdraw from an institution. The authors also point out a trend in more financial aid being awarded to minority students, but despite the additional aid, students with the most financial need and students from underrepresented minority groups experience the highest withdraw rates. This finding confirms Swail et al.'s and Cabrera and La Nasa's conclusions about minority students and more specifically African American students withdrawing or choosing not to attend college when financial aid packages are more heavily weighted with student loans.

African American students avoiding loans as a source of subsidizing the rising cost of higher education is also supported by Kim (2004), St. John (1999), and St. John and Noell (1989) who provide evidence to support the idea of minority students avoiding loans as a source of funding for their education. Swail et al. (2003) are in agreement and state, “...the research also suggests that the shifts in aid from grants to loans and from need-based to merit-based programs adversely affects both enrollment and persistence for minority students" (p. ix).

Depending on the income level and race of the student, the findings of Cabrera and La Nasa in combination with Penske, Porter, and DuBrock's study as well as Kim, St. John, and St. John and Noell's studies suggest low income students from racially diverse backgrounds with limited options for financing their education will be the most likely students to withdraw from 
college or will decide not to enroll in college at all. Swail et al. (2003) point out how low income and minority students who are Native American, Hispanic, or African American have lower access and retention rates than white students.

Despite the evidence of increased cost and the shifting of financial aid from grants to loans directly affecting the participation of minority students in higher education, the trend of rising costs being supported by loan aid is not changing. A recent article by Greene (2012), lends support to the notion this trend is continuing and will be a burden on students as well as their parents. The article points out how the number of students who are unable to meet their financial obligations after they graduate is continuing to grow, and even if graduates are able to keep up with their financial obligations, many of them will still be paying off their student loans when their children enter college.

Other studies have been done to examine specific populations of students and how access to higher education is impacted by financial aid. One study done by Santiago and Cunningham (2005) investigated how Latino students fund their college education. One of their findings was Latino students are more likely, by four percentage points, to receive federal financial aid than other racial/ethnic groups. While Latino students are more likely to receive federal financial aid, Latinos on average receive at least $\$ 500.00$ less federal financial aid than any other racial/ethnic group. The authors also point out the type of federal aid received is weighted more heavily in loan money than in grant money. One of the recommendations the authors have for encouraging greater participation in higher education by Latino students is to increase the Pell grant program. This finding is consistent with Kim's (2004) and Swail et al.'s (2003) study. Each study supports the notion that students who represent racial or ethnic diversity are more likely to attend college if financial aid is more heavily weighted with grants than with loans. 
Dervarics (2009) discusses short term regulations implemented in 2007 to increase funding for higher education. The author discusses the importance of the funding for higher education institutions which have traditionally served minority populations. The proposed legislation was the Student Aid and Fiscal Responsibility Act which passed in 2009. The legislation included increasing in funding for colleges who have traditionally served Native American students by $\$ 36$ million and funding to historically black colleges and universities received $\$ 13.7$ million dollars. While reducing the cost of higher education is important in providing access to students from all racial and cultural backgrounds, this legislation highlights the importance in providing extra funding to students from racially and culturally diverse backgrounds if college and universities continue to pursue a more diverse student population.

\section{Overview of Prior Studies and Research}

As indicated earlier in this project, the interest and investigation into the rising cost of higher education and how that cost is being funded by students is not new. Edward and St. John (1990) highlight prior studies conducted to determine Student Price Response Coefficients (SPRCs) which sought to find the relationship between tuition increases and the resulting impact on students' decision to enroll at a college or university. The authors highlight how earlier studies of the same phenomenon were conducted prior to the implementation of the Pell Grant program and most studies neglect the effect of financial aid on enrollment decisions. Edward and St. John reference the work of Dresch (1975) and state how enrollment decision making models that do not include the effects of tuition charges and discounts in the form of financial aid are not accurate tools for universities to use in enrollment forecasting. In addition, the authors point out how SPRCs should approach zero as the amount of aid available approaches the price of tuition. As the amount and availability of financial aid changes over time, SPRCs become less 
reliable because a student's decision making process is affected by the changes occurring in how higher education is financed. Edward and St. John determine family income, tuition charges, and "all aid variables" (p. 168) are significant in the decision a student makes to enroll at a college or university. In addition, the authors note a difference the impact of tuition and financial aid on students from different income groups.

St. John et al. (2000) highlight two approaches used in most studies to examine student persistence in higher education. The Economic Approach is described as those studies who investigate the cost of higher education and the resulting changes in enrollment when changes are made to the cost of a higher education. Cost is usually associated with net price which is made up of two factors: price (most frequently tuition and housing costs), and discounts in the form of grants, scholarships and other types of financial aid. College Choice in America by Manski and Wise (1983) utilize the Economic Approach to determine how students choose to go to college or go to work and how students determine which college they will attend. St. John (1990) examines students' decisions to attend college based on the amount of financial aid students received and the amount of tuition charged. The Student-Institution Fit approach is described as an approach used in studies that associate a student's decision to continue or persist at a university with the best fit between the student and the student's environment, social or academic. Braxton, Sullivan and Johnson (1997) attempt to find support for Tinto's (1987) college persistence theory and both studies utilize the Student-Institution Fit approach. St. John et al. (2000) state a shortcoming of this approach is the assumption that students are able to meet their financial needs once they have initially decided to attend a particular college.

St. John, Paulsen, and Starkey (1996) formulated the Financial Nexus Model in response to their findings of how finances effect students' decision to enroll in college. Prior research 
focused on either how students initially choose a college or on the decision making process when they continue to attend a particular college (Jackson, 1978; Jackson, 1982; Paulsen, 1990; Pascarella \& Terenzini, 2005; Tinto, 1987; Tinto, 2006). The focus of St. John, Paulsen, and Starkey's model is finding the connection between the two models or the nexus between college choice and finances. Hwang (2003) completed a study applying the Financial Nexus Model. The author's study focused on "full-time, first-time, first-year freshman population" at, "baccalaureate/comprehensive and doctoral research institutions in both public and private sectors separately" (unnamed section, para. 3). Results of the study suggest there are differences in the way students react to changes in grants based on the type of institution a student attends. Hwang's findings point to a direct relationship between tuition rates and students' sensitivity to changes in grant awards, as tuition rates get higher, so do students' sensitivity to changes in grant awards.

Several studies have explored the difference in how access to higher education is achieved through quota systems versus a system based on ranking students on objective criteria. The authors conclude that students who are admitted to college based purely on fulfilling a quota system do not have as high of a degree of success in college as those admitted based on objective criteria (Hashway, Brentley \& Carter, 2001; Barinaga, 1998; Bowen, Bok, \& Burkhart, 1999). Hashway, Brentley, and Carter highlight how students who are admitted based on objective criteria and had to strive to meet the minimum standards for acceptance are more prone to succeed and have similar graduation rates as students who were accepted with high achievement scores. The authors attribute this success to the students' realization of the their need to work hard to succeed, a lesson rarely learned and appreciated by students who are accepted based on fulfilling a quota system. 
McPherson and Schapiro (1991) summarize prior work completed on how finances impact enrollment. The authors state how most studies focus on tuition or tuition less discounts through financial aid. Although methods and approaches of the studies differ, McPherson and Schapiro point out two consistent themes. Most of the prior studies examined by the authors conclude that enrollment decisions are directly related to aid increases and inversely related to tuition increases. A study by Manski and Wise (1983), cited earlier in this section of the literature review, is mentioned specifically for its finding of how increases in Pell grant aid had a disproportionately positive effect on enrollment based on income, with enrollment level increases from lower income families increasing by a factor of 20 over the corresponding increase in enrollment from students from upper income families (59\% and 3\% respectively). However another study done by Hansen in 1983 examined enrollment levels at two different time periods and measured the ratio of enrollment levels from students of students based on gender, race, and income. Hansen's study found that aid targeted at lower income families had little corresponding effect on enrollment levels in that income category.

These conflicting studies warrant further research to determine the differing affect changes in aid programs as well as changes in tuition have on students from different income levels and racial categories. Fortunately additional studies have been completed since 1983. Many of these studies were mentioned earlier in this review of the literature (College Access and Admission, 2011; Edward and St. John, 1990; Ehrenberg, 2001; King, 1999; Liu, 2011; Santiago and Cunningham, 2005; Peter and Horn, 2005; Penske, Porter and DuBrock, 1999; St. John, Paulsen and Starkey, 1996; Steelman and Powell, 1993). Kim (2004) conducted a study with a specific focus on how different types of financial aid influence the attendance of minority students at the institutions examined. Kim found that while student loans on their own had no 
statistically significant impact on enrollment of minority students to their first choice institution, however grants or a combination of grants and loans were shown to increase the likelihood minority students would attend their first choice of colleges. This study attempted to further the investigation and body of literature on the subject by lending support to which financial variables examined are most closely associated with enrollment and whether or not the association differs based on the race and ethnicity of the student.

\section{The National Postsecondary Student Aid Study and Sample Methods}

Data from the NPSAS 2008 survey was selected for this study for several reasons. First, the NPSAS is a national survey designed to gather data on a wide variety of variables relating to how students pay for college. The number of colleges and consequently the number of students the data represents would be difficult to duplicate with a survey developed specifically for this study. The NPSAS has also been implemented several times with the most recent 6 survey years being 1990, 1993, 1996, 2000, 2004, and 2008. Data contained in the study is collected from several sources adding to the depth of the data available both at the student level as well as the institutional level. Tools utilized to collect the data are the following:

- Student records - data from financial aid and the registrar's office at selected institutions were able to enter data into an online form or were able to upload the data to the same system.

- Student interviews - data was collected from online or telephone interview questions.

- Central Processing System - data was collected from the U.S. Department of Education's database of information collected from the FAFSA. 
- National Student Loan Data System - Title IV federal loans, Pell Grants, and SMART grant data was collected from this data pool.

- National Student Clearinghouse - Participating school data was used from this commercial database.

- ACT file - data regarding ACT scores for students accepted to college were collected from this database.

- SAT file - similar to the ACT, data regarding SAT scores for students accepted to college were collected from this database.

- IPEDS - the National Center for Educational Statistics maintains this database containing institutional level data on post-secondary educational institutions (U.S. Department of Education: National Center for Education Statistics, RTI International, 2010).

The survey tool has been tested and continues to be used to collect longitudinal data. The reliability of the data from a tested tool would also be difficult to duplicate with a self-designed survey. Additionally, the ease in which this study can be replicated is greatly increased by using a pool of data accessible by any researcher who might want to verify the findings of this study, or to perform the same analysis on a different set of data.

The use of the NPSAS in this type of study is not new and is supported in the work done by other researchers. Paulsen and St. John (2002) used NPSAS data in their Financial Nexus Model to identify how financial factors play an important role in the geographical location of the institution a student attends as well as the type of institution a student attends. Hwang (2003) utilized NPSAS data and the Financial Nexus Model to determine if students' decisions to persist from freshman to sophomore year differ based on the type of institution they attend. Horn 
(1998) used NPSAS data to develop a profile of students who work while in school and differentiates students who work to pay for school and students who attend school while maintaining employment. Dowd and Coury (2006) investigated the relationship between Federal Student Loan aid and student persistence and associate degree attainment utilizing NPSAS data. While the work of Paulsen and St. John (2002) and Hwang (2003) most closely match the type of research conducted in this project, the breadth of data available in the NPSAS survey allows investigation in many different areas including the relationships regarding the financing of higher education and its impact on enrollment and diversity, which is the topic of this study.

The population the NPSAS attempts to represent by the sample the study examines is all students who attend higher education institutions eligible for federal financial aid programs. The sampling method used for the NPSAS 2008 survey was performed in two stages. First, a sample of colleges and universities was chosen for the study, and second a sample of students from those schools was chosen. A sample size of 127,700 students enrolled at any time between July 1 , 2007 and June 30, 2008 was included in the 2008 study. In addition, the sample included state representative samples for California, Georgia, Illinois, Minnesota, New York, and Texas.

31,760 students in the 2008 NPSAS sample were from public four-year undergraduate universities and 11,210 of those students are from the state representative samples gathered from California, Georgia, Illinois, Minnesota, New York, and Texas. All 31,760 students from public four-year undergraduate institutions were included in this study $(\mathrm{n}=31,760)$. Including all 31,760 students from four-year undergraduate institutions in the study allowed a larger and therefore a more robust sample for the CHAID analysis. At the same time, the effect of oversampling in the six state representative samples increased the chance of overstating an effect present only in those six states. A suggestion for further research is to determine if the findings 
of this study are representative of just these six states, or if the findings are representative of the entire population of students attending all public four-year undergraduate institutions in the United States. All institutions included in the study met the guidelines to be eligible for federal financial aid programs. (U.S. Department of Education, 2011; U.S. Department of Education: National Center for Education Statistics, RTI International, 2010).

\section{Choice of Variables}

The dependent variable of enrollment based on race and ethnicity was chosen because of the value of having diverse populations represented in the student body as outlined in the section above (see Value of Diversity in Higher Education). In addition, previous studies suggest students from different races and ethnicities are retained at different rates (please refer to The Trends in Funding a Higher Education and Overview of Prior Studies and Research sections above). This study sought to determine which of the independent financial variables examined are most closely associated with the attendance of students from different racial and ethnic groups.

Paulsen and St. John (2002) describe the changing landscape of financing a higher education as a "...period of high tuition, high aid, but with an emphasis on loans rather than grants" (p. 189). This statement is made at the beginning of a paper where the Financial Nexus Model by St. John, Paulsen, and Starkey (1996) is used to examine how persistence of students from one year to the next is affected by social class and college costs. In addition, St. John, Paulsen, and Starkey include housing costs and work study awards as financial variables in their Financial Nexus model. For this reason, tuition, loans, grants, work study awards, and housing costs are included in the analysis as five independent variables. 
In a paper by McPherson and Schapiro (1991), the authors point out and provide support for a relationship between enrollment levels and the net cost of higher education. The authors present evidence to suggest that both tuition changes as well as changes in the net cost by making changes in financial aid resulted in a corresponding change in enrollment. Paradoxically, McPherson and Schapiro also highlight other studies which indicate how enrollment rates of students from below median income households do not change with increases or decreases in tuition or financial aid. Based on this finding, household income will also be considered in this study in the form of the EFC as calculated from information submitted about students' financial situation on the Free Application for Federal Student Aid (FAFSA) and reported back to students on their Student Aid Report (SAR).

Additional independent financial variables were included in this study in an effort to explore other factors associated with student enrollment at the institutions in this study's sample. These additional variables include: the balance carried on credit cards, whether or not a student's parents own their home, whether or not a student worked during the summer of 2007, and whether or not a student is receiving financial assistance from their parents. Exploratory variables were included in an effort to uncover additional factors which are associated with the enrollment of students from different races and ethnicities, to expand on the existing research on this topic, and to exploit the value of using CHAID analysis as an exploratory method to uncover associations that might otherwise be overlooked. 


\section{Chapter Three: Research Design and Methodology}

The purpose of this study was to determine how higher education could be made more accessible to a more diverse student population. Since prior research has determined students from different races and ethnicities are impacted differently by a number of financial factors in making their decision to attend college, politicians and administrators should be equipped with more research providing direction on how to best use our financial resources to make higher education equally accessible for all students regardless of their race (Heller, 1997; Hu \& St. John, 2001; Perna, 2000; Perna, 2007). The research design used in this study is described in this chapter and includes details about the instrument used to collect the data, the sample used in the study, how the data was analyzed, and the limitations of the study.

\section{Restatement of the Problem}

An implied social contract exists between society and public higher education. The use of public funding to support a system of public higher education was implemented with public interests in mind. The idea of serving the public by providing skilled workers for the workforce and as a means of achieving social and economic mobility is a reoccurring rationale for the

founding and continued financial support of public higher education. Research suggests earning potential is significantly increased by earning a college degree, but it also serves as an equalizer to the racial inequity that exists in income earned by individuals of different races (Carter, 2006). While many studies have been done on how finances impact access to higher education, there is a gap in the current research which this study attempted to fill. This study utilized a unique approach (CHAID analysis), to determine which financial variables are most closely associated with attendance rates at public four-year undergraduate universities. Furthermore, this study 
examined whether or not the degree or order of association between attendance rates and the financial variables differed based on the race and ethnicity of the student.

\section{Significance of the Problem}

According to Leslie and Brinkman (1987) and cited by Heller (1997) research done on higher education accessibility is an ongoing concern in the environment where students' ability to pay for college has been greatly diminished by the rapid increase in the cost. Heller quotes Leslie and Brinkman stating, “...expanding and equalizing student access long has been a major public policy goal, and manipulation of price has been seen as the major policy instrument for achieving this goal” (p. 624).

As outlined earlier in this study, there are numerous studies examining the impact of the rising cost of higher education. Studies on the phenomenon take different approaches. Edward and St. John (1990) and Leslie and Brinkman (1987) highlight a number of studies employing a Student Price Response Co-Efficient which looks at the incremental changes in attendance rates for every $\$ 100$ increase in tuition. Another prevalent method stems from the Financial Nexus model developed by St. John, Paulsen and Starkey (1996) which seeks out the connection between financial variables and college choice variables. Still other methods seek out direct relationships between different financial variables and enrollment rates (Curs \& Singell, 2010; DesJardins, Ahlburg, \& McCall, 2002; Feeney \& Heroff, 2010; McPheson \& Schapiro, 1991; Monks, 2009). Additional studies have started to unravel the effect of using different types of financial aid to subsidize the cost of higher education based on different demographic characteristics (Carter, 2006; Green, 2005; Spaulding \& Kargodorian, 1982). This study sought to employ a combination of the last two approaches, and attepted to find a direct relationship 
between financial variables and enrollment rates based on the demographic characteristic of race and ethnicity.

Research Questions

1. When examining historical enrollment demographics of 31,760 students $(n=$ 31,760) from public four-year undergraduate universities which factors (tuition charged, student loan indebtedness, Pell Grant award, Work Study award, housing costs for the student, EFC, balance on credit cards, whether or not a student's parents own their home, whether or not a student worked during the summer of 2007, and whether or not students have reported receiving financial assistance from their parents) are most closely associated with the total enrollment of students?

2. Are the independent variables of tuition charged, student loan indebtedness, Pell Grant award, Work Study award, housing costs for the student, EFC, balance on credit cards, whether or not a student's parents own their home, whether or not a student worked during the summer of 2007, and whether or not students have reported receiving financial assistance from their parents associated with enrollment levels of students differently based on their race and ethnicity?

The following null and alternative hypotheses were used to address this research question:

\section{Null Hypotheses}

$\mathrm{Ho}_{1}$ : There is no statistically significant degree of association, as evidenced by CHAID analysis, between the enrollment of particular races of students and a set of independent variables including: tuition charged, student loan indebtedness, Pell Grant award, Work Study award, housing costs for the student, EFC, balance on 
credit cards, whether or not a student's parents own their home, whether or not a student worked during the summer of 2007, and whether or not students have reported receiving financial assistance from their parents.

$\mathrm{Ho}_{2}$ : There is no difference in degree or order of association, as evidenced by CHAID analysis of the enrollment of students from different races and ethnicities and the independent variables of: tuition charged, student loan indebtedness, Pell Grant award, Work Study award, housing costs for the student, EFC, balance on credit cards, whether or not a student's parents own their home, whether or not a student worked during the summer of 2007, and whether or not students have reported receiving financial assistance from their parents.

\section{Alternative Hypotheses}

$H a_{1}$ : There is a statistically significant degree of association, as evidenced by CHAID analysis, between total enrollment of students and a set of independent variables including: tuition charged, student loan indebtedness, Pell Grant award, Work Study award, housing costs for the student, EFC, balance on credit cards, whether or not a student's parents own their home, whether or not a student worked during the summer of 2007, and whether or not students have reported receiving financial assistance from their parents.

$H a_{2}$ : There is a difference in degree or order of association, as evidenced by CHAID analysis of the enrollment of students from different races and ethnicities and the independent variables of: tuition charged, student loan indebtedness, Pell Grant award, Work Study award, housing costs for the student, EFC, balance on credit cards, whether or not a student's parents own their home, whether or not a student 
worked during the summer of 2007, and whether or not students have reported receiving financial assistance from their parents.

\section{Research Design}

A quantitative research design was used in this study to determine the level of association between the dependent variable and the independent variables. The study examined the factors that most significantly influence the enrollment of students as evidenced by the financial variables examined in this study. Additionally, the degree of association between the dependent variable and independent variables was analyzed to determine if the independent variables have differing effects on student enrollment based on the race and ethnicity of the student.

Institutional Approval. The researcher applied for and was approved to conduct the research outlined in this study by the West Virginia University Institutional Review Board (IRB) as Not Human Subject Research (Appendix A) and was subsequently granted permission to perform the research at Loyola University of Chicago (Appendix B).

In addition, the research as outlined required access to restricted use data from the National Center for Educational Statistics. A restricted use license was granted to conduct the research conducted in this study (Appendix C) and approval was granted to distribute the contents of this dissertation based on Restricted Use Data (Appendix D).

Population and Sample. The population for this study was all public four-year undergraduate institutions in the United States of America. The sample for the study mirrored the sample of publically funded four-year undergraduate institutions in the NPSAS 2008 study. The NPSAS also includes state representative samples from California, Georgia, Illinois, Minnesota, New York, and Texas which account for 11,210 of the 31,760 students sampled from public four-year undergraduate institutions (see National Postsecondary Student Aid Study 
Sample and Methods section of the literature review). All 31,760 students from public four-year undergraduate colleges and universities were included in this study $(n=31,760)$. The inclusion of all 31,760 students allowed for a more robust CHAID analysis to identify the dependent variables most closely associated with the attendance of students based on their race and ethnicity. A suggestion for further research is to determine if the findings of this study over represent the effect of the 6 states with state representative samples or if the findings are true regardless of the location.

\section{Data Analysis Method}

CHAID analysis was the statistical method used in this study to determine which variables were most significantly associated with attendance rates of students at public four-year universities and furthermore how closely those variables were associated with the attendance of students based on their race and ethnicity. The associations found between the independent variables and dependent variable were also used to predict the attendance of students based on their race and ethnicity with a given set of values for the independent variables. CHAID analysis and neural network models are often used in marketing to determine how to best segment and target different populations (McCarty \& Hastak, 2007). In the case of this study, results could be used to target specific populations of students.

Okell (1999) states three strengths of CHAID analysis are explicability, ease of implementation, and ease of construction. The author explains how a CHAID analysis is clear, easy to explain, and easy to understand. As a result, errors in inputs are easily identified and the tree and its branches can be informed by the user's past experience. The results of a CHAID analysis can also be easily incorporated into business models to inform decision making, or, in the case of this study, the results can be used to inform the way colleges recruit students. Okell 
also explains how CHAID analysis is flexible in that it can handle variables with interactions and is suited for both categorical and continuous variables within the same study.

Levin and Zahavi (2001) describe CHAID analysis as a tree classifier. The analogy to a tree is a good one because CHAID analysis results in an initial node or trunk of the tree which is the whole population or sample. From the point of the trunk or Root Node, CHAID analysis uses a "systematic approach to grow a tree into 'branches' and 'leaves"' (p. 5). At each subsequent node after the trunk, the algorithm determines if there is statistical significance to break down the node into further branches or if the node terminates and the branch cannot be broken down any further. Additionally nodes are set to terminate if the number of students in the node drops below 50 or $\mathrm{n}<50$.

The process of segmenting and targeting specific populations is also referred to as data mining. Okell (1999) identifies CHAID analysis as a data mining method and statistical model where the decision tree analysis can be used for "classification and prediction purposes" (p. 4). Okell goes on to describe how CHAID analysis is particularly suited for situations where there are interactions between different variables and seeks out the "combinations of independent variables that affect the outcome" (p. 4). For this reason, CHAID analysis was also well suited for this study since financial variables describing a student's financial situation rarely act in a vacuum. Instead, it is more likely a combination of variables will paint the best picture of how the independent variables can be used to predict enrollment as a whole and to predict enrollment of sub-populations based on race and ethnicity.

In addition to business and marketing applications, CHAID analysis has been used to examine different phenomenon in the education setting. Green (2012) describes CHAID analysis as, "a modern visually appealing variant of log-linear analysis, in which multiple 
variables are explored using Chi-Square analysis" (p. 59). Green chooses CHAID analysis for a study to determine which factors in a set of independent variables "are most closely associated with math-related college readiness" (p. 10). Borden (1995) uses CHAID analysis to analyze the demographics of individual students at a large public university with the goal of segmenting the population to develop targeted programs and assessment based on the characteristics and needs of each segment. Borden's study identified academic unit as the independent variable most closely associated with differences in student satisfaction. The study went on to identify nodes or branches based on the class level, sex, and age of the student.

Thomas and Galambos (2004) used CHAID analysis to determine which "characteristics and experiences affect satisfaction" (p. 251). The authors aimed to provide stakeholders with the factors most closely associated with student satisfaction as evidence to support whether or not students are learning new skills, if students graduate, if students are successful in their careers, if students had a rewarding experience in college, if students believe they have grown through the college experience, and if students feel they are satisfied. Thomas and Galambos found that students' perception of intellectual growth was the independent variable most closely associated with students' satisfaction with their higher education experience. From the "trunk" of the tree the other nodes or branches identified as being associated with student satisfaction were: intellectual growth, satisfaction with their academic experience, size of class, whether the student attended college full-time or part-time, having a sense of belonging, and quality of instruction.

The examples mentioned above highlight the use of CHAID analysis for a number of different studies demonstrating the flexibility of the analysis to find meaningful relationships in a variety of applications with different types of data sets. In addition, these studies set a precedent 
and demonstrate the value of using CHAID analysis in a higher education setting, making it an ideal tool for analyzing the data in this study.

The probability $(p)$ value used for interpreting the results of the test statistic in the CHAID analysis was any value less than 0.05 . A value of 0.05 means there is a $95 \%$ confidence level that a statistically significant relationship exists and a less than $5 \%$ chance of a false rejection of the null hypothesis. Therefore a $p$ value of 0.05 or less was assumed to be statistically significant resulting in the null hypothesis being rejected and the experimental or alternative hypothesis being accepted. The CHAID analysis continued to branch into different nodes until there was no longer any significant degree of association between the different variables, or the node terminated when the number of students in the node dropped below 50 (n $<$ 50). Additionally, the scope of this study limited the CHAID analysis to two levels due to the exponential growth in the number of nodes for each level of the tree.

Variables Used in CHAID Analysis. The rationale and value of inclusion of the variables used in this study are outlined in the "Choice of Variables" section of the literature review. Below, Table 1 outlines each of the variables included in the study, their role as either the dependent variable or one of the independent variables, the scale of measurement used for the variable, and how the variable was measured. 
Table 1

Variables used in the CHAID Analysis

\begin{tabular}{|c|c|c|c|}
\hline Variable & $\begin{array}{l}\text { Role of } \\
\text { Variable in } \\
\text { CHAID } \\
\text { Analysis }\end{array}$ & $\begin{array}{l}\text { Scale of } \\
\text { Measurement }\end{array}$ & How Variable is Measured \\
\hline $\begin{array}{l}\text { Enrollment by } \\
\text { Race/Ethnicity } \\
\text { (RACE) }\end{array}$ & $\begin{array}{l}\text { Dependent } \\
\text { Variable }\end{array}$ & Categorical & $\begin{array}{l}\text { Student Reported (unit of measure is at } \\
\text { the student level) } \\
\text { 1) White, } \\
\text { 2) Black or African American, } \\
\text { 3) Hispanic or Latino, } \\
\text { 4) Asian, } \\
\text { 5) American Indian or Alaska Native, } \\
\text { 6) Native Hawaiian/Other Pacific } \\
\text { Islander, } \\
\text { 7) Other }\end{array}$ \\
\hline $\begin{array}{l}\text { Tuition Charged } \\
\text { (TUITION2) }\end{array}$ & $\begin{array}{l}\text { Independent } \\
\text { Variable }\end{array}$ & Continuous & $\begin{array}{l}\text { Dollar amount charged by term reported } \\
\text { by the institution }\end{array}$ \\
\hline $\begin{array}{l}\text { Student Loan } \\
\text { Indebtedness } \\
\text { (N8UGLN) }\end{array}$ & $\begin{array}{l}\text { Independent } \\
\text { Variable }\end{array}$ & Continuous & $\begin{array}{l}\text { Amount of student loan indebtedness as } \\
\text { reported by the student via interview }\end{array}$ \\
\hline $\begin{array}{l}\text { Pell Grant Award } \\
\text { (CFADPELL) }\end{array}$ & $\begin{array}{l}\text { Independent } \\
\text { Variable }\end{array}$ & Continuous & $\begin{array}{l}\text { Amount of Pell Grant aid received by } \\
\text { the student as reported by the institution }\end{array}$ \\
\hline $\begin{array}{l}\text { Work Study Award } \\
\text { (CFATDFWS) }\end{array}$ & $\begin{array}{l}\text { Independent } \\
\text { Variable }\end{array}$ & Continuous & $\begin{array}{l}\text { Amount of Work Study aid received by } \\
\text { the student as reported by the institution }\end{array}$ \\
\hline $\begin{array}{l}\text { Worked to Pay for } \\
\text { Living Expenses } \\
\text { (N8WKRNA) }\end{array}$ & $\begin{array}{l}\text { Independent } \\
\text { Variable }\end{array}$ & $\begin{array}{l}\text { Categorical } \\
\text { (Yes or No) }\end{array}$ & $\begin{array}{l}\text { Did the student work to pay for living } \\
\text { expenses as reported by the student as } \\
\text { reported by the student }\end{array}$ \\
\hline $\begin{array}{l}\text { Expected Family } \\
\text { Contribution } \\
\text { (CCADEEFC) }\end{array}$ & $\begin{array}{l}\text { Independent } \\
\text { Variable }\end{array}$ & Continuous & $\begin{array}{l}\text { Amount of a student's Expected Family } \\
\text { Contribution as reported by the } \\
\text { institution }\end{array}$ \\
\hline $\begin{array}{l}\text { Balance on Credit Cards } \\
\text { (N8CRDBAL) }\end{array}$ & $\begin{array}{l}\text { Independent } \\
\text { Variable }\end{array}$ & Continuous & $\begin{array}{l}\text { Balance amounts on all credit cards as } \\
\text { reported by the student }\end{array}$ \\
\hline $\begin{array}{l}\text { Does the student's } \\
\text { parent(s) own their } \\
\text { home? } \\
\text { (N8PARHOM) }\end{array}$ & $\begin{array}{l}\text { Independent } \\
\text { Variable }\end{array}$ & $\begin{array}{l}\text { Categorical } \\
\text { (Yes or No) }\end{array}$ & $\begin{array}{l}\text { Does the student's parents own their } \\
\text { own home as reported by the student }\end{array}$ \\
\hline $\begin{array}{l}\text { Did the student work } \\
\text { during the summer of } \\
2007 ? \\
\text { (N8SUMMR) }\end{array}$ & $\begin{array}{l}\text { Independent } \\
\text { Variable }\end{array}$ & $\begin{array}{l}\text { Categorical } \\
\text { (Yes or No) }\end{array}$ & $\begin{array}{l}\text { Did the student work during the summer } \\
\text { of } 2007 \text { as reported by the student }\end{array}$ \\
\hline $\begin{array}{l}\text { Did the student report } \\
\text { receiving financial } \\
\text { assistance from their } \\
\text { parents for tuition and } \\
\text { fees? } \\
\text { (N8PARPA) }\end{array}$ & $\begin{array}{l}\text { Independent } \\
\text { Variable }\end{array}$ & $\begin{array}{l}\text { Categorical } \\
\text { (Yes or No) }\end{array}$ & $\begin{array}{l}\text { Whether or not the student received } \\
\text { financial assistance from their parents as } \\
\text { reported by the student }\end{array}$ \\
\hline
\end{tabular}


Instruments Utilized. Data was gathered from the National Center for Education Statistics, more specifically the National Postsecondary Student Aid Study of 2008 (NPSAS:08). A Restricted Use License was granted for access to the data used in the analysis. Statistical analysis was conducted using PASW Modeler (Version 14).

Ethical Issues. The data used for the study is confidential and was treated with extreme care to assure the security of the data and the anonymity of the students represented by the data. Appropriate measures were taken in accordance with the terms of the Restricted Use License issued from the National Center for Education Statistics to secure the data while the study was conducted. Some of these measures included: a stand-alone, password protected, desktop computer (no network or internet access) in secured office, read-only access to the data, auto shut-down of the computer after 5 minutes of inactivity, and a posted warning informing potential users of the computer that unauthorized access is a violation of federal law and will result in prosecution.

An additional concern stems from the use of the information resulting from this study. The intention was to determine whether or not there is a statistically significant relationship between the financial indicators examined and the sub-populations of students examined. The goal was to raise awareness of how different financial barriers to a post-secondary education might be affecting students from different racial and ethnic backgrounds. Armed with this information, institutions can determine how finances affect the mix of students attending a particular institution. Additionally, Federal and State governments can use this information to determine the best way to intervene with programs designed to encourage attendance of students from underrepresented populations. However there is a chance the outcome of this analysis 
could be used to target and intentionally exclude particular populations of students as opposed to using the results to increase access to higher education for those populations.

Limitations of the Study. Limitations of the study include the use of a fixed instrument with historical data being analyzed. A specifically designed survey looking for additional detail about the financial reasons that have the greatest impact on a student's decision to attend a state funded institution could provide additional detail about the decisions made by those student populations which would not be revealed by this study. Regarding the NPSAS, Paulsen and St. John (2002) point out how the study's design includes a sample of students who are surveyed in the fall semester and then again in the spring. The authors highlight how excluding students who were initially surveyed in the fall, but do not persist until the spring means conclusions drawn from the initial sample may or may not apply to the latter group. Another limitation listed by Paulsen and St. John is since the fall survey is typically administered several weeks into the semester, a sample at the time of the survey does not account for students who initially attended, but dropped out before the survey is administered. In the case of this study, the sample examined came from the 2008 NPSAS which (at the time of the study) was already four years old. The age of the data means many of the students in the study sample would have already graduated when the study was conducted. If more recent data was available, study results would be a better representation of students currently attending college.

Another limitation is related to the use of CHAID analysis as the statistical method chosen for the study. While CHAID analysis was an appropriate method of analysis for this type of study and the strengths of CHAID analysis far outweigh the drawbacks, a weakness of CHAID analysis in PASW Modeler 14 is the inability to generate descriptive statistics for each node in the tree. The descriptive statistics cited in chapter 4 were taken from Node 0 which 
includes all students included in the study. However, generating two separate models one with the dependent variable being race and the other being state (in order to determine how many students in the study were from each state) resulted in a margin of error of .04\%.

An additional limitation stems from the requirements set by the Department of Education regarding the use of Restricted Use Data Sets. The Department of Education requires that all unweighted sample sizes be rounded to the nearest 10. Therefore an additional amount of error is introduced as a result of meeting this requirement.

As stated earlier, all public four-year undergraduate institutions surveyed in the 2008 NPSAS were included in the study. Of the 31,760 students included in the study, 11,210 students were from the states of California, Georgia, Illinois, Minnesota, New York, and Texas because the 2008 NPSAS also gathered state representative samples from those states. A suggestion for further research is to conduct additional studies on different samples using the same independent variables and statistical analysis to determine if the findings in this study overstate the effects of those six states, or if the results are indeed representative of the population the sample in this study is intended to represent.

Two thirds of the NPSAS 2008 study sample were found to be from the White race/ethnic category. Since CHAID analysis identifies the associations between the dependent and independent variables and ranks them with the strongest association located closer to the base of the tree (Node 0), a limitation of the analysis was the possibility of over-stating the effects of White students in the model. Over-stating the effects of White students in the model ran the risk of more subtle associations with students from other race/ethnic categories to be excluded from the model. A suggestion for further study is to determine if the model changes when the effects of White students are removed. 
The NPSAS compiles data from several sources which increases the depth of variables available for analysis. However, gathering data from several sources and matching the data from different sources to a specific variable introduces a margin of error due to the matching process. Records from colleges that could not be matched to the Central Processing System (CPS) at the Department of Education were not included in the study. While eliminating those records from the study reduced this error, the possibility exists for those eliminated records to have an influence on the outcome of the study which should not be overlooked. CPS data is gathered from the Free Application for Federal Student Aid (FAFSA), as such, students who did not fill out the application were eliminated from the study since their records would not be able to be matched.

Federal regulations dictate certain requirements when using Restricted Use Data which was included in this study. Requirements outlined in the procedures manual present two challenges in replicating or basing subsequent studies from the results contained in this study. The first challenge is obtaining the license required to examine and analyze the data. The resources necessary to obtain a license make it difficult to fulfill the requirements unless the sponsoring institution is willing and able to provide those resources. The second challenge results from a small amount of error introduced when fulfilling the requirement that all unweighted sample sizes be rounded to the nearest 10 (National Center for Education Statistics, 2011).

A limitation in the scope of the study was the decision to end the CHAID analysis at two levels. Since CHAID analysis grows exponentially with each additional level of the tree, it was necessary to limit the growth of the tree to two levels. Additional levels of the tree may reveal other areas where segments of the population differ in the order in which the independent 
variables are associated with dependent variable (similar to division 3 of the tree based on Worked during the summer of 2007 versus divisions 2, $4-6$ based on Tuition and Fees Paid; see Figures $4-8)$.

One additional limitation is an acknowledgment that many factors contribute to a student's decision to attend a particular college or university. While other factors might have also played a role in a student's decision to attend a public four-year undergraduate institution, the scope of this study was limited to the financial indicators of tuition charged, student loan indebtedness, Pell Grant award, Work Study award, housing costs for the student, EFC, balance on credit cards, whether or not a student's parents own their home, whether or not a student worked during the summer of 2007, and whether or not students have reported receiving financial assistance from their parents. Likewise the student population can also be broken down into other racial and ethnic categories. Lastly, the scope of this study was limited to the categories designated by the National Center for Educational Statistics. 


\section{Chapter Four: Results}

This chapter presents the results of the statistical analysis performed on the data collected by the United States Department of Education and contained in the National Postsecondary Student Aid Study of 2008. The study used CHAID quantitative analysis to address the following research questions:

1. When examining historical enrollment demographics of $31,760(n=31,760)$ students from public universities which factors (tuition charged, student loan indebtedness, Pell Grant award, Work Study award, housing costs for the student, EFC, balance on credit cards, whether or not a student's parents own their home, whether or not a student worked during the summer of 2007, and whether or not students have reported receiving financial assistance from their parents) are most closely associated with the total enrollment of particular races of students?

2. Are the independent variables of tuition charged, student loan indebtedness, Pell Grant award, Work Study award, housing costs for the student, EFC, balance on credit cards, whether or not a student's parents own their home, whether or not a student worked during the summer of 2007, and whether or not students have reported receiving financial assistance from their parents associated with enrollment levels of students differently based on their race and ethnicity?

The following null and alternative hypotheses were used to address these research questions:

\section{Null Hypotheses}

$\mathrm{Ho}_{1}$ : There is no statistically significant degree of association, as evidenced by CHAID analysis, between total enrollment of particular races of students and a set of independent 
variables including: tuition charged, student loan indebtedness, Pell Grant award, Work Study award, housing costs for the student, EFC, balance on credit cards, whether or not a student's parents own their home, whether or not a student worked during the summer of 2007, and whether or not students have reported receiving financial assistance from their parents.

$\mathrm{Ho}_{2}$ : There is no difference in degree or order of association, as evidenced by CHAID analysis of total enrollment of students from different races and ethnicities and the independent variables of: tuition charged, student loan indebtedness, Pell Grant award, Work Study award, housing costs for the student, EFC, balance on credit cards, whether or not a student's parents own their home, whether or not a student worked during the summer of 2007, and whether or not students have reported receiving financial assistance from their parents.

\section{Alternative Hypotheses}

$H a_{1}$ : There is a statistically significant degree of association, as evidenced by CHAID analysis, between total enrollment of students and a set of independent variables including: tuition charged, student loan indebtedness, Pell Grant award, Work Study award, housing costs for the student, EFC, balance on credit cards, whether or not a student's parents own their home, whether or not a student worked during the summer of 2007, and whether or not students have reported receiving financial assistance from their parents.

$H a_{2}$ : There is a difference in degree or order of association, as evidenced by CHAID analysis of enrollment of students from different races and ethnicities and the independent variables of: tuition charged, student loan indebtedness, Pell Grant award, 
Work Study award, housing costs for the student, EFC, balance on credit cards, whether or not a student's parents own their home, whether or not a student worked during the summer of 2007, and whether or not students have reported receiving financial assistance from their parents.

\section{Data Selection and Procedures}

This study attempted to answer the research questions by examining 31,760 students who were enrolled at four-year public colleges at any time during the 2007-2008 academic year and were surveyed by the National Postsecondary Student Aid Study of 2008. The population for this study was all students who attended public four-year undergraduate institutions in the United States of America. The sample for the study mirrored the sample of publically funded four-year undergraduate institutions included in the NPSAS 2008 study which included a sample size of 31,760 students enrolled at any time between July 1, 2007 and June 30, 2008. Permission was given to examine the records of those 31,760 students by the Institute of Educational Sciences and included information on the following variables: tuition charged, student loan indebtedness, Pell Grant award, Work Study award, housing costs for the student, EFC, balance on credit cards, whether or not a student's parents own their home, whether or not a student worked during the summer of 2007, and whether or not students have reported receiving financial assistance from their parents. Table 2 and Figure 1 present a breakdown of the survey participants included in this study by state and by race/ethnicity. 
Table 2

Students Surveyed By State

\begin{tabular}{|c|c|c|}
\hline & Frequency & Percent \\
\hline$\{$ Missing $\}$ & 0 & $0.00 \%$ \\
\hline Alabama & 820 & $2.59 \%$ \\
\hline Alaska & 120 & $0.38 \%$ \\
\hline Arizona & 440 & $1.39 \%$ \\
\hline Arkansas & 280 & $0.88 \%$ \\
\hline California & 2590 & $8.18 \%$ \\
\hline Colorado & 550 & $1.74 \%$ \\
\hline Connecticut & 180 & $0.57 \%$ \\
\hline Delaware & 110 & $0.35 \%$ \\
\hline District of Columbia & 0 & $0.00 \%$ \\
\hline Florida & 1410 & $4.45 \%$ \\
\hline Georgia & 1560 & $4.93 \%$ \\
\hline Hawaii & 70 & $0.22 \%$ \\
\hline Idaho & 180 & $0.57 \%$ \\
\hline Illinois & 1220 & $3.85 \%$ \\
\hline Indiana & 900 & $2.84 \%$ \\
\hline Iowa & 250 & $0.79 \%$ \\
\hline Kansas & 330 & $1.04 \%$ \\
\hline Kentucky & 490 & $1.55 \%$ \\
\hline Louisiana & 690 & $2.18 \%$ \\
\hline Maine & 70 & $0.22 \%$ \\
\hline Maryland & 600 & $1.90 \%$ \\
\hline Massachusetts & 570 & $1.80 \%$ \\
\hline Michigan & 500 & $1.58 \%$ \\
\hline Minnesota & 1550 & $4.90 \%$ \\
\hline Mississippi & 270 & $0.85 \%$ \\
\hline Missouri & 740 & $2.34 \%$ \\
\hline Montana & 230 & $0.73 \%$ \\
\hline Nebraska & 250 & $0.79 \%$ \\
\hline Nevada & 290 & $0.92 \%$ \\
\hline New Hampshire & 120 & $0.38 \%$ \\
\hline New Jersey & 770 & $2.43 \%$ \\
\hline New Mexico & 160 & $0.51 \%$ \\
\hline New York & 2230 & $7.04 \%$ \\
\hline North Carolina & 770 & $2.43 \%$ \\
\hline North Dakota & 80 & $0.25 \%$ \\
\hline Ohio & 980 & $3.10 \%$ \\
\hline Oklahoma & 580 & $1.83 \%$ \\
\hline Oregon & 570 & $1.80 \%$ \\
\hline Pennsylvania & 1390 & $4.39 \%$ \\
\hline Rhode Island & 90 & $0.28 \%$ \\
\hline South Carolina & 460 & $1.45 \%$ \\
\hline South Dakota & 170 & $0.54 \%$ \\
\hline Tennessee & 660 & $2.08 \%$ \\
\hline Texas & 2060 & $6.51 \%$ \\
\hline Utah & 610 & $1.93 \%$ \\
\hline Vermont & 20 & $0.06 \%$ \\
\hline Virginia & 800 & $2.53 \%$ \\
\hline Washington & 590 & $1.86 \%$ \\
\hline West Virginia & 290 & $0.92 \%$ \\
\hline Wisconsin & 620 & $1.96 \%$ \\
\hline Wyoming & 60 & $0.19 \%$ \\
\hline Puerto Rico & 290 & $0.92 \%$ \\
\hline American Samoa & 0 & $0.00 \%$ \\
\hline Foreign country & 30 & $0.09 \%$ \\
\hline Total & 31660 & $100.00 \%$ \\
\hline
\end{tabular}


Figure 1

Surveyed Students By Race/Ethnicity

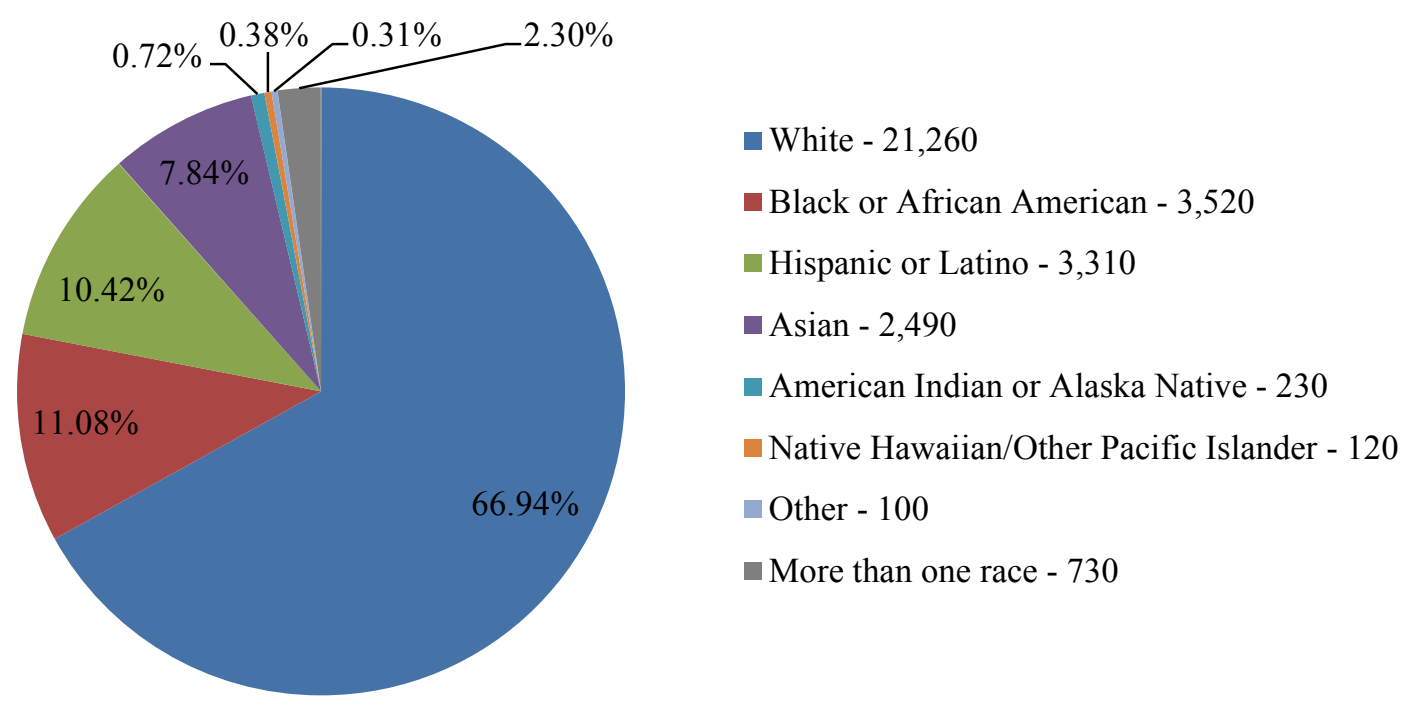

A close look at the table and the figure reveals a difference in study size of 100 students (i.e. 31,660 versus 31,760 ). The difference occurred as a result of generating two different CHAID analyses in order to obtain descriptive statistics of the students included in the study and a Department of Education requirement that all sample numbers based on Restricted Use Data be rounded to the nearest 10. The inability of PASW Modeler 14 to generate descriptive statistics for each node as well as the Department of Education requirement of rounding sample numbers are acknowledged in the limitations of the study. For the purpose of this study, the study sample size is 31,760 which is the sample size when segmented by race and segments are rounded to the nearest 10. Additional descriptive statistics on the continuous and categorical variables are included in Appendices E and F. 


\section{Exhaustive CHAID Analysis}

PASW Modeler (Version 14) was used to perform an Exhaustive CHAID (Chi-squared Automatic Interaction Detection) analysis on the data included in this study. CHAID was chosen as the method of analysis for this study for its ability to uncover relationships between variables and present the results in an easy to interpret and visually appealing classification tree. CHAID analysis is often used to segment populations based on a set of criteria and the results can be used as an alternative to linear and logistic regression to make predictions. CHAID analysis uses the Chi-square test to determine the optimum position to split the variables on each level of the classification tree and which variables are most closely affiliated with the dependent variable at each subsequent level of the classification tree. Exhaustive CHAID was chosen over the original CHAID algorithm because it continually tests all possible relationships between the variables and combines related pairs until a statistically significant difference is found between the pairs.

Description of CHAID Variables. This study examined which of the independent variables examined were most closely associated with attendance at public four-year universities and whether or not the association differed based on the race and ethnicity of the student. CHAID analysis was identified as being particularly suited for this type of study because of its ability to identify significant relationships between and combinations of the variables examined. CHAID analysis can also be used to make predictions and determine how a change in the independent variables affects the dependent variable or in the case of this study how a change in the independent variables affects college enrollment based on the race and ethnicity of the student.

The independent variables examined in the CHAID analysis to determine which variables are most closely associated with the dependent variable are: tuition charged, student loan 
indebtedness, Pell Grant award, Work Study award, housing costs for the student, EFC, balance on credit cards, whether or not a student's parents own their home, whether or not a student worked during the summer of 2007, and whether or not students have reported receiving financial assistance from their parents.

CHAID Decision Tree Analysis. This study demonstrates why CHAID analysis has also been referred to as tree analysis. CHAID analysis established Node 0 which includes all participants in the study $(\mathrm{n}=31,760)$. CHAID analysis then examined each of the independent variables to determine which independent variable was most closely associated with the dependent variable and if segmenting the population of the node based on the independent variable resulted in a statistically significant division of the dependent variable. Whether or not students received a Pell Grant was found to be the independent variable most closely associated to the attendance of students based on their race/ethnicity and resulted in the first branch of the tree.

Each node of the tree was examined to determine which independent variable was most closely associated with the dependent variable and then CHAID analysis determined if splitting the node into additional branches of the tree based on the independent variable resulted in a statistically significant effect (based on the lowest $p$ value) on the dependent variable. This process continued until splitting a node based on one of the independent variables no longer resulted in a statistically significant effect on the dependent variable. For the purpose of this study, divisions were considered statistically significant with a $p$ value less than or equal to .05 , and nodes terminated with a $p$ value greater than .05 or if division of the node resulted in branches with less than 50 students. Due to the size of the study sample and the exponential growth in the number of nodes at each level of the decision tree, the maximum depth of the tree 
for this study was set at two levels to focus in on the independent variables most closely associated with the dependent variable and to keep the information contained in the analysis down to a manageable size. A close examination of the different branches of the tree revealed how the different independent variables had differing effects on the dependent variable. An examination of the branches of the tree also revealed how each of the independent financial variables had a differing effect on the attendance of students based on the student's race/ethnicity.

At each node, CHAID analysis re-examined the association between the dependent variable and each of the independent variables to determine if a node should be split into further branches or if the node terminated because no further statistically significant associations remained. If CHAID analysis revealed a statistically significant relationship between the dependent and one of the independent variables, the independent variable was then examined to determine significant cutoff points within the independent variable. Cutoff points were determined by merging categories (of a categorical variable) or groups of a continuous variable if no statistically significant difference between categories was found with respect to the dependent variable. Once a statistically significant difference was found, the category or range of a continuous variable was split into a separate node where the process continued until all values of the independent variable were merged. Figure 2 provides as an explanation of how to interpret the information contained in each of the branches and nodes. 
Figure 2

How To Interpret CHAID Decision Tree Nodes

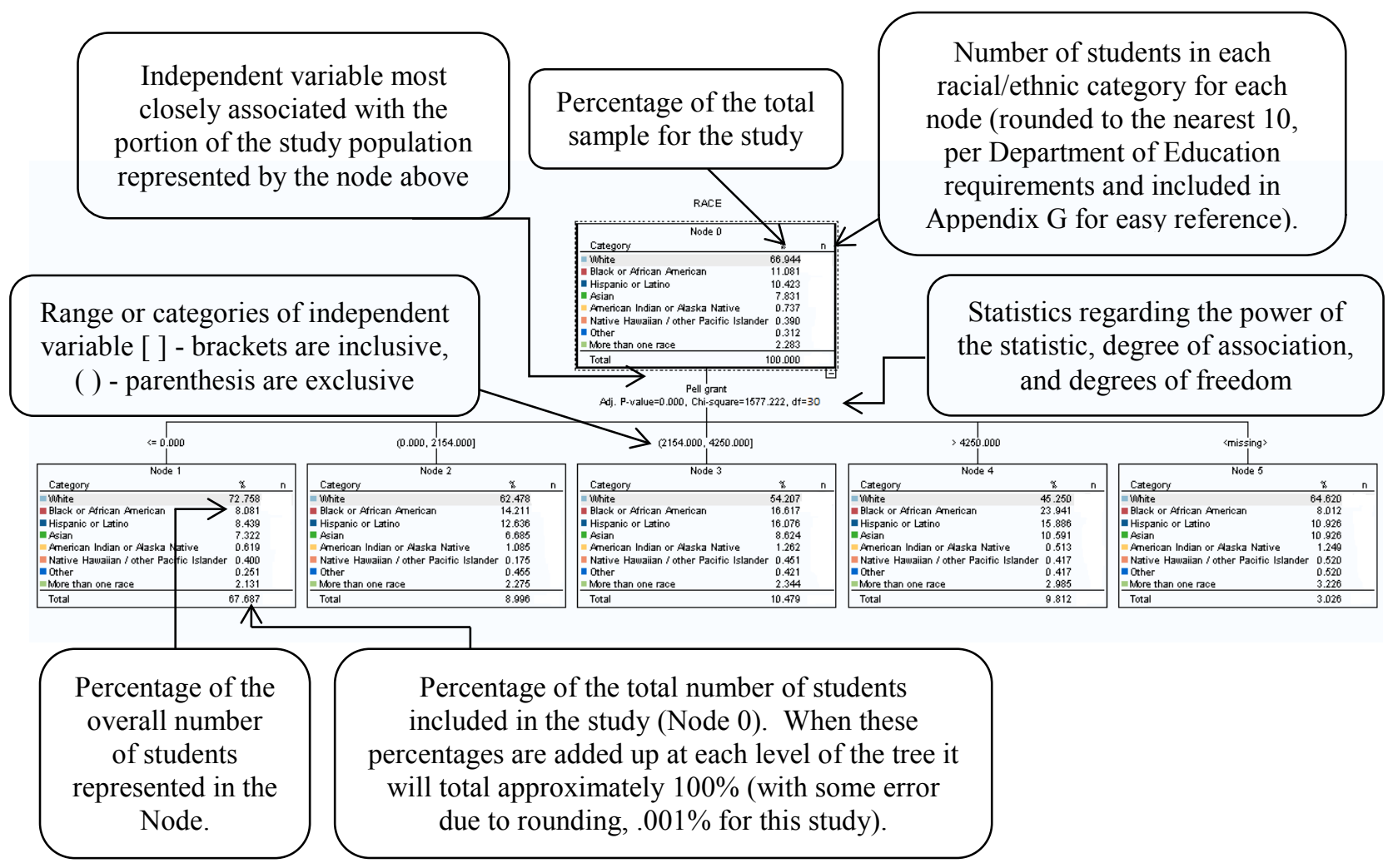

The CHAID analysis identified three independent variables as being most closely associated with the dependent variable. Additionally, the association of the independent variables with the dependent variable changes based on the race/ethnicity of the student. In light of these findings, we reject the null hypotheses lending support to the alternative hypotheses. The details below provide an explanation of the output by the CHAID analysis and the discussion following each node highlights how the significant findings are manifested at each node level. In addition, a summary of the CHAID analysis output, in table form, is included in Appendices $\mathrm{G}$ and $\mathrm{H}$ for easy reference.

Identification of the Root Node and first division. For the purpose of this study, CHAID analysis was limited to two levels which resulted in six divisions where 33 nodes or subgroups of 
the study's sample were identified. Figure 3 shows the Root Node (Node 0) representing the study's sample size of 31,760 students along with the first division resulting in 5 branches (Nodes $1-5$, Level 1) based on the independent variable most closely associated with the entire sample for the study. CHAID analysis identified Pell Grant awards as being the independent variable most closely associated with Node $0\left(X^{2}=1577.222 ; \mathrm{df}=30 ; p<0.001\right)$ with cutoff points being $\$ 0.00, \$ 2,154.00, \$ 4,250.00$, and missing values.

Figure 3

Root Node and First Division - Pell Grant (degrees of freedom rounded to the nearest 10)

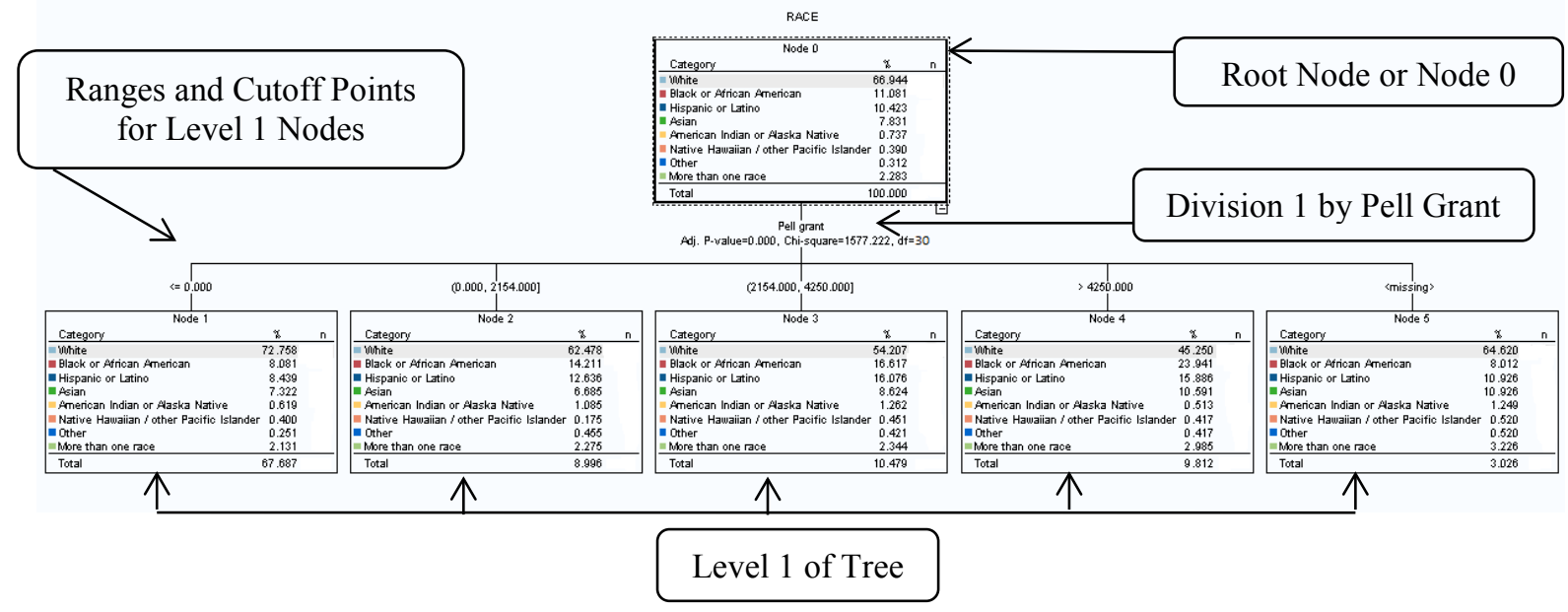

First Division Node 1. Close examination of nodes $1-5$ revealed that the majority of the students included in the study did not receive Pell Grants (67.687\% of Node 0 or Node 1$)$. Additionally, a greater portion of White students and Native Hawaiian or other Pacific Islander students did not receive Pell Grants than their representation in the overall sample size $(72.758 \%$ versus $66.944 \%$ for White students and $.400 \%$ versus $.390 \%$ for Native Hawaiian or other Pacific Islander students).

First Division Nodes 2 - 5. Likewise the differences in Nodes $2-5$ when compared to the breakdown of the study's entire sample represented in Node 0 were noted. White, Asian, 
Native Hawaiian, and More Than One Race categories were less likely (62.478\% versus $66.944 \%, 6.685 \%$ versus $7.831 \%$, and $2.275 \%$ versus $2.283 \%$ respectively) to receive Pell Grants in the amount of $\$ 0.01-\$ 2,154.00$ (Node 2) whereas White students were the only population who were less likely $(54.207 \%$ versus $66.944 \%)$ to fall into the $\$ 2,154.01-\$ 4,250.00$ range (Node 3). Node 4 indicates that White and American Indian or Alaska Native students were less likely (45.250\% versus $66.944 \%$ and $.513 \%$ versus $.737 \%$ ) to receive more than $\$ 4,250$ in Pell Grants. In Node 5, it is important to note White and Black students were less likely (64.620\% versus $66.944 \%$ and $8.012 \%$ versus $11.081 \%)$ to have a missing value which may indicate those populations are better informed about the process to receive Pell Grants.

Second level of the decision tree. Before analyzing the nodes that resulted from divisions $2-6$ of the decision tree, a broader view of the second level of the decision tree revealed a few notable differences that were not clear when looking at each division and node separately. The first item noted was the change in the order of the independent variables being associated with the dependent variable in the division from Node 2 which is based on Worked during the summer of 2007 in contrast to the divisions from Nodes 1, 3, 4, and 5 which is based on Tuition and Fees Paid. The change in order is discussed further in the section that examines the third division of the tree.

The second item noted was the cutoff points for the divisions from Nodes 1, 3, 4, and 5 . While a couple of the cutoff points are shared in divisions 2, 4, 5, and 6 (skipped values and $\$ 1,481.00$ ), the remainder of the cutoff points are either unique to that particular division or are not shared by all 5 divisions (those values include $\$ 2,671.00, \$ 4,381.00, \$ 5,287.00, \$ 6,189.00$, $\$ 7,355.00$, and $\$ 9,912.00$ ). The divisions where one of those values did not appear meant that for that particular division of the tree, there was no statistically significant difference at that 
particular point and so the point was merged into another branch of the tree. Likewise if one of the divisions of the tree possesses a unique value not shared by other divisions of the tree, then the CHAID analysis identified a statistically significant difference at that point of the continuous variable as the algorithm merged values of the continuous variable together into one category. An example of a value not shared by all divisions is $\$ 6,189.00$ which is unique to the fourth division of the tree.

Second division from Node 1. The second division of the tree stems from Node 1 where the independent variable most closely associated with the students identified in Node 1 is the amount of Tuition and Fees Paid (Figure 4). The second division of the tree resulted in Nodes 6 - 12 and suggests that if students did not receive any Pell Grant award, the dependent variable most closely associated with attendance at a public four-year college is the amount of Tuition and Fees Paid $\left(X^{2}=870.734 ; \mathrm{df}=40 ; p<0.001\right)$. The CHAID analysis identified skipped values (-3), $\$ 1,481.00, \$ 4,381.00, \$ 5,287.00, \$ 7,355.00$, and $\$ 9912.00$ as significant cutoff points for the branches. The second division of the tree is the largest division from the first level of the tree containing $67.687 \%$ of the study sample. 
Figure 4

Second Division From Node 1 - Tuition and Fees Paid

(degrees of freedom rounded to the nearest 10)

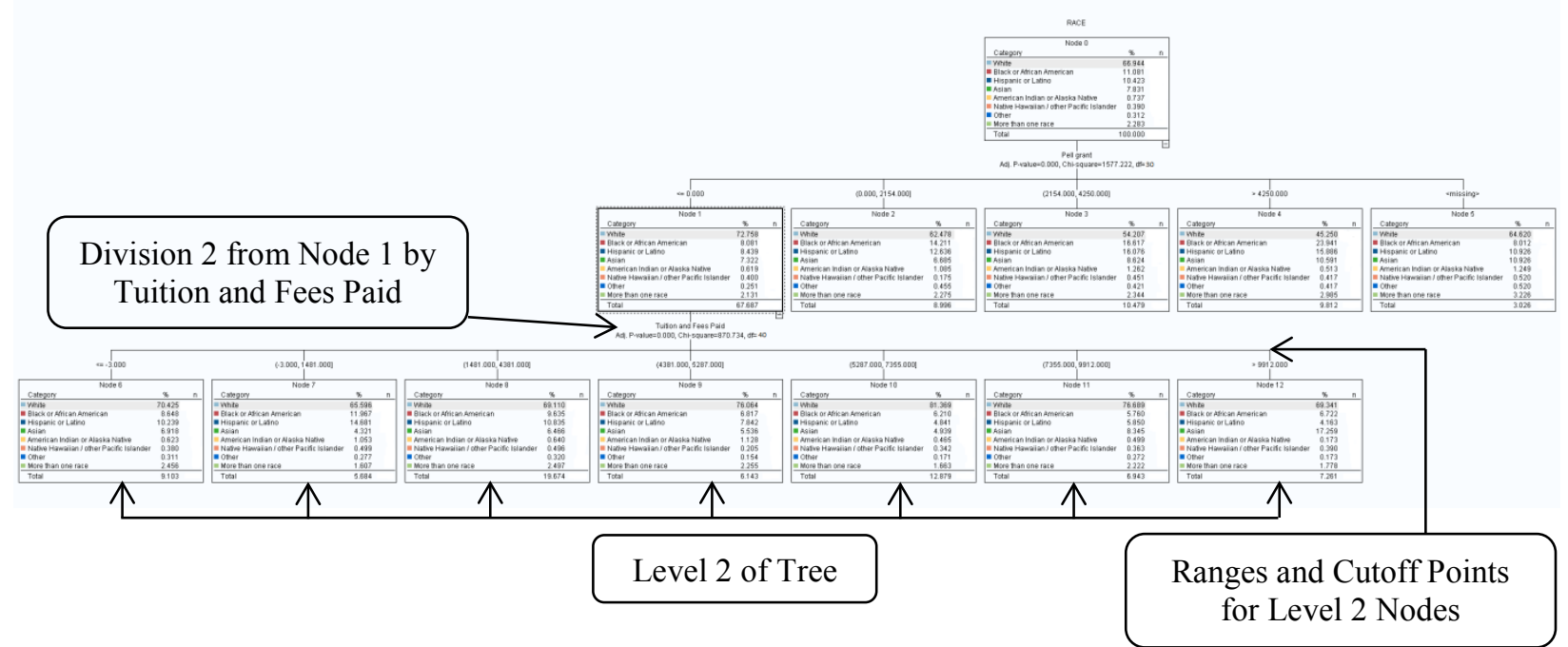

Similar to the earlier comparison made between the sub-populations represented in Nodes $1-5$ to the Root Node, percentages from each category of the dependent variable of nodes $6-$ 12 were compared to those in Node 1. The comparison was made to determine if the students in that race/ethnic category were over-represented or under-represented in the sub-population of the node (in comparison to Node 1 ).

Second Division Node 6. Node 6 represents students who received $\$ 0.00$ in Pell Grants and the amount of Tuition and Fees Paid was skipped. $9.103 \%$ of the students included in the study are represented in Node 6. Black or African American (8.648\% versus 8.081\%), Hispanic or Latino (10.239\% versus 8.439\%), American Indian or Alaska Native (0.623\% versus $0.619 \%)$, Other $(0.311 \%$ versus $0.251 \%)$, and More than one race $(2.456 \%$ versus $2.131 \%)$ categories were over-represented in comparison to Node 1 , the start of the this branch of the tree. Since the amount of Tuition and Fees paid was reported by the institution, it was difficult to draw a 
conclusion as to why students who did not receive Pell Grants were also more likely to not have Tuition and Fees reported.

In addition, Black, Hispanic, American Indian or Alaska Native, and Other students continue to be over-represented in Nodes 7 and 8 representing lower amounts of Tuition and Fees Paid in comparison to Nodes $9-12$. Each one of these groups is over-represented in Nodes $6-8$ which means they were more likely to either have skipped the question, or paid between $\$ 0.00-\$ 4,381.00$ in Tuition and Fees. In contrast, the Race/Ethnic categories consistently overrepresented at the upper end of the scale of Tuition and Fees Paid are White and Asian students who were over-represented in Nodes $9-11$, and Nodes $11-12$ respectively.

Second Division Node 7. 5.684\% of the study sample was grouped into Node 7. Students who received $\$ 0.00$ in Pell Grants and paid tuition and fees in the range of $\$ 0.01-$ $\$ 1481.00$ are represented in Node 7. Black or African American (11.967\% versus 8.081\%), Hispanic or Latino (14.681\% versus $8.439 \%$ ), American Indian or Alaska Native (1.053\% versus 0.619\%), Native Hawaiian or Other Pacific Islander (0.499\% versus $0.400 \%$, and Other $(0.277 \%$ versus $0.251 \%)$ categories are over-represented in Node 7 when compared to Node 1 . Another finding that stood out in this node was Asian students are under-represented in the node by just over $3.5 \%$ (4.321\% versus $7.831 \%$ ). In other words Asian students who receive $\$ 0$ in Pell Grant awards were likely to pay more than $\$ 1,481.00$ in tuition. A look ahead revealed Nodes 8-10 continue to under-represent the Asian student population in Node 1, which means not only were Asian students more likely to pay more than $\$ 1,481.00$, but they were more likely to pay more than $\$ 7,355$ (see Node 11 where the Asian student percentage of $8.345 \%$ tops the Node 1 percentage of $7.322 \%$ ), with a large portion of Asian students who paid more than $\$ 9,912.00$ in Tuition and Fees (Node $12,17.259 \%$ versus Node $1,7.322 \%$ ). 
Second Division Node 8. Students who did not receive a Pell Grant and paid tuition and fees in the range of $\$ 1,481.01-\$ 4,381.00$ are represented in Node 8 . Node 8 also represents $19.674 \%$ of the study's sample. In Node 8 , Black (9.635\% versus $8.081 \%)$, Hispanic $(10.835 \%$ versus $8.439 \%)$, American Indian or Alaska Native (0.640\% versus $0.619 \%)$, Native Hawaiian/Other Pacific Islander (.496\% versus .400\%), Other (0.320\% versus $0.251 \%)$ and More than one race $(2.497 \%$ versus $2.131 \%)$ categories are over-represented when compared to Node 1.

Second Division Node 9. Node 9 represents students who did not receive Pell Grant money and paid between $\$ 4,381.01-\$ 5,287.00$ in Tuition and Fees Paid. Node 9 contains $6.143 \%$ of the students included in the study. Race and Ethnic Categories over-represented in Node 9 include: White (76.064\% versus 72.758\%), American Indian or Alaskan Native (1.128\% versus $0.619 \%$ ), and More than One Race (2.255\% versus $2.131 \%$ ). In Node 9, not only were American Indian or Alaskan Native students twice as likely to fall into this range when compared to Node 1, but Native Hawaiian / Other Pacific Islander students were half as likely to fall into this range of Tuition and Fees Paid.

Second Division Node 10. White students were found to be the only race/ethnic category over-represented in Node 10 which covers Tuition and Fees Paid in the range of \$5,287.01 $\$ 7,355.00$ of students who received no Pell Grant Aid. All other race/ethnic categories were under-represented in this node with Hispanic or Latino students being almost half as likely (4.841\% versus $8.439 \%)$ to fall in this range of Tuition and Fees Paid than their representation in this branch of the tree (in Node 1). Although all but one race/ethnic category is underrepresented in Node 10 , because White students represent $66.944 \%$ of the study sample, Node 10 still contains $12.879 \%$ of the study sample. 
Second Division Node 11 . Node 11 represents $6.943 \%$ of the students included in the study who did not receive any Pell Grant aid, and paid between $\$ 7,355.01-\$ 9,912.00$ in tuition and fees. In Node 11, White (76.689\% versus $72.758 \%)$, Asian (8.345\% versus $7.322 \%)$, Other (.272\% versus $.251 \%)$, and More than one race $(2.222 \%$ versus $2.131 \%)$ categories were overrepresented in comparison to Node 1. Both Black or African American (2.321\%) and Hispanic or Latino $(2.589 \%)$ students were almost $2.5 \%$ less likely to pay fees and tuition in the amount of $\$ 7,355.01-\$ 9,912.00$ when compared to Node 1 .

Second Division Node 12. The Asian category was the only race/ethnic category found to be over-represented in Node 12 which includes students who did not receive any Pell Grant Aid and paid over $\$ 9,912.00$ in tuition and fees. Node 12 also contains $7.261 \%$ of the students included in the study. Asian students were approximately 2.5 times more likely to pay over $\$ 9,912.00$ than their respective representation in Node $1(17.259 \%$ versus $7.322 \%)$. All other race/ethnic categories were under-represented in Node 12. The largest under-represented group in Node 12 is American Indian or Alaska Native students who were a little over 3.5 times less likely to pay over $\$ 9,912.00$ than their representation in Node $1(0.173 \%$ versus $0.619 \%)$.

Third division from Node 2. The third division of the tree stems from Node 2 where the independent variable most closely associated with the students who received Pell Grants in the amount of $\$ 0.01-\$ 2154.00$ is whether or not they worked during the summer of $2007\left(X^{2}=\right.$ 153.961; $\mathrm{df}=20 ; p<0.001)$. Worked during the summer of 2007 is a categorical variable which CHAID identified as being most closely associated with students in Node 2 and resulted in four branches of the tree based on if students worked or did not work during the summer of 2007, skipped the question, or the answer was missing (Figure 5). The CHAID analysis identified each answer as a statistically significant division of the tree and did not need to merge 
any of the categories together to achieve a $p$ value of $<0.000$. Node 15 is the largest node resulting from the third division of the tree with $47.217 \%$ of the students from Node 2 who received between $\$ 0.01-\$ 2,154.00$ in Pell Grants and worked during the summer of 2007 . The third division contains $8.996 \%$ of the study sample or the portion of the study sample identified in Node 2.

The third division from Node 2 was also noted because it represents a change in the order of association between the dependent variable and independent variables. All other divisions from Nodes 1, 3, 4, and 5 resulted from Tuition and Fees Paid being most closely associated with the dependent variable. As previously stated, the third division from Node 2 resulted from whether or not the student worked during the summer of 2007 which was the independent variable most closely associated with students who received Pell Grants in the amount of $\$ 0.01-$ $\$ 2,154.00$.

Figure 5

Third Division From Node 2 - Worked During The Summer of 2007 (degrees of freedom rounded to the nearest 10)

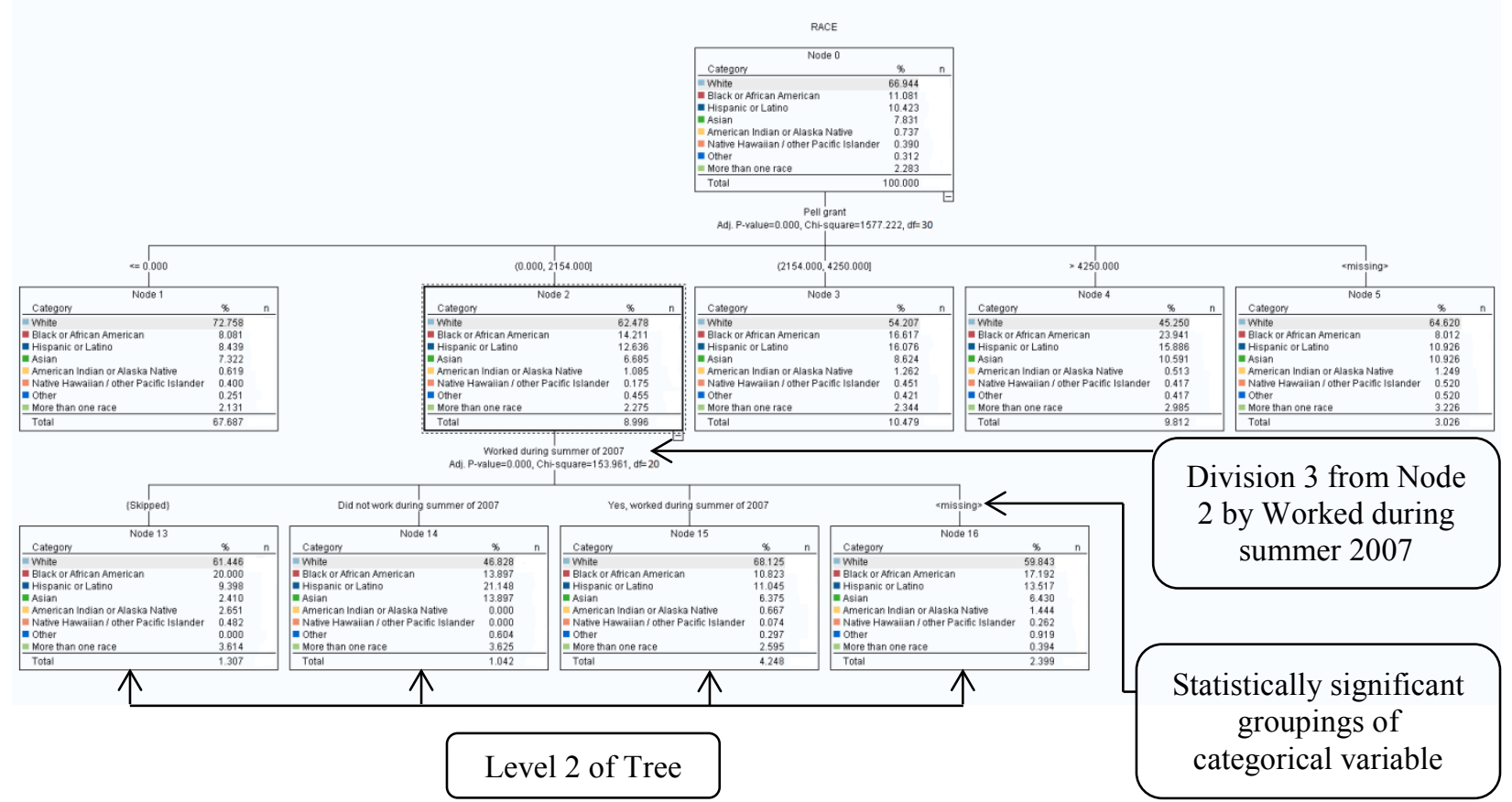


Third division Node 13. Node 13 signifies students who received between $\$ 0.01-$ $\$ 2,154.00$ in Pell Grant aid and skipped answering the question of whether or not they worked during the summer of 2007 . Node 13 also contains $1.307 \%$ of the students included in the study. In Node 13, the race/ethnic groups over-represented in relationship to Node 2 are Black or African American (20.000\% versus 14.211\%), American Indian or Alaskan Native (2.651\% versus 1.085$)$, Native Hawaiian/Other Pacific Islander ( $0.482 \%$ versus $0.175 \%)$, and More than one race (3.614\% versus 2.275\%). While the difference for Black or African American students was found to be almost $6 \%$, Native Hawaiian or Other Pacific Islander students were approximately 2.75 times more likely to have skipped the answer when compared to Node 2 . Another finding in Node 13 was that Hispanic or Latino students were under-represented by $3.238 \%$ when compared to Node 2.

Third division Node 14. Node 14 represents students who received Pell grant aid in the amount of $\$ 0.01-\$ 2,154.00$ and did not work during the summer of $2007.1 .042 \%$ of the students included in the study were grouped into Node 14 . Hispanic or Latino $(21.148 \%$ versus $12.636 \%)$, Asian (13.897\% versus $6.685 \%$, Other (0.604\% versus $0.455 \%)$, and More than one race $(3.625 \%$ versus $2.275 \%$ ) categories were found to be over-represented in Node 14 when compared to Node 2. A possible reason these racial ethnic groups are over-represented in this node may be related to the difficulty students have in fulfilling the necessary requirements to be able to legally work in the United States. This reasoning could also be related to the results of Nodes 13 and 16 where the values were missing or skipped.

Another finding in Node 14 was there are no students from the race/ethnic categories of American Indian or Alaskan Native and Native Hawaiian or Other Pacific Islander, however, in this branch of the tree the number of students in those racial/ethnic categories is small $(1.085 \%$ 
and $0.001 \%$ of Node 2 respectively) so it was not surprising to find some branches from Node 2 with few or no students in those categories.

Third division Node 15. Students who received between $\$ 0.01-\$ 2,154.00$ in Pell Grant aid and worked during the summer of 2007 are represented in Node 15. 47.2\% of the students from Node 2 were placed in Node 15 which also represents $4.248 \%$ of the total number of students included in the study. Racial/Ethnic categories that were found to be over-represented in Node 15 are White $(68.125 \%$ versus $62.478 \%)$, and More than one race $(2.595 \%$ versus $2.275 \%$ ). This finding is consistent with the idea that students from races/ethnicities other than White face significant barriers (or White students face less barriers) when trying to meet the requirements necessary to find employment in the United States.

Third division Node 16. Node 16 represents $2.399 \%$ of the students included in the study who received between $\$ 0.01-\$ 2,154.00$ in Pell Grant aid and the value for whether or not they worked during the summer of 2007 was missing. According to the NCES, valid choices for this variable were Yes, No, and Skipped (2008). Missing values therefore should be considered Skipped and the values of these two nodes can be considered collectively for analysis purposes. When Nodes 13 and 16 were considered collectively, percentages of the race/ethnic categories are: White $60.408 \%$, Black or African American 18.181\%, Hispanic or Latino $12.064 \%$, Asian 5.012\%, American Indian or Alaskan Native 1.869\%, Native Hawaiian/Other Pacific Islander $0.339 \%$, Other $0.594 \%$, and More than one race $1.529 \%$. When considered collectively, Black or African American, American Indian or Alaskan Native, Native Hawaiian/Other Pacific Islander, and Other race/ethnic categories are over-represented which was the same result as when Node 13 was considered separately. While considering the two groups collectively 
changed the percentages slightly, the same racial/ethnic groups continued to be over-represented when compared to Node 2.

Fourth division from Node 3. The fourth division of tree results from the amount of tuition and fees paid being most closely associated with the students who received Pell Grants in the amount of $\$ 2,154.01-\$ 4,250.00\left(X^{2}=315.691 ; \mathrm{df}=40 ; p<0.001\right)$. As noted above in regard to the third division being the only change in order of affiliation of the independent variables for the third level of the tree, for the fourth division of the tree from Node 3 , Tuition and Fees Paid is again the most closely associated independent variable with the students identified in Node 3 (Figure 6) representing $10.479 \%$ of the study sample. CHAID analysis identified Skipped, $\$ 1,481.00, \$ 2,671.00, \$ 4,381.00$, and $\$ 6,189.00$ as significant cutoff points in Tuition and Fees Paid for students who received between $\$ 2,154.01$ - \$4,250.00 in Pell Grants.

Figure 6

Fourth Division From Node 3 - Tuition and Fees Paid (degrees of freedom rounded to the nearest 10)

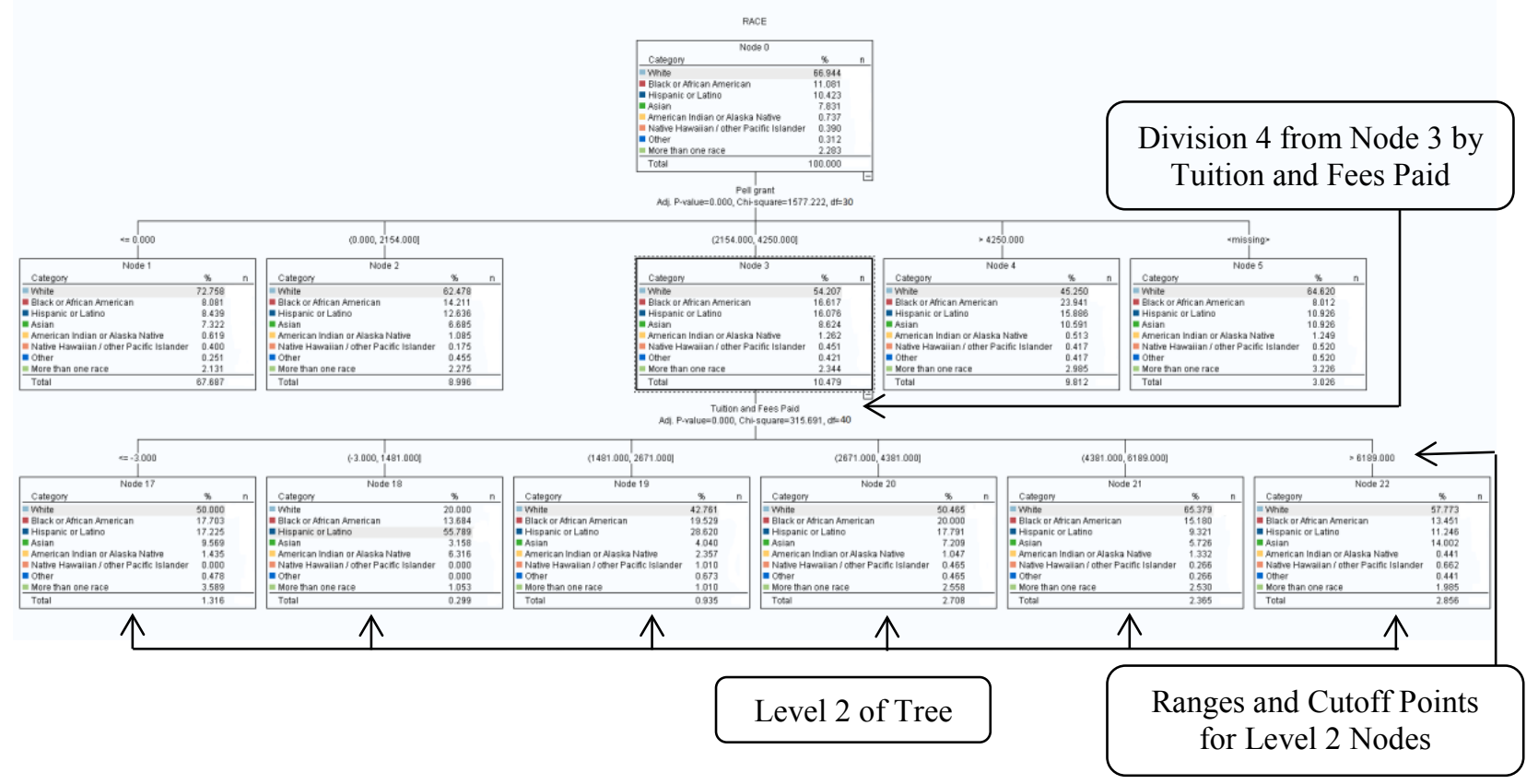


Fourth division Node 17. Node 17 represents students $1.316 \%$ of the students included in the study who received Pell Grants in the amount of $\$ 2,154.01-\$ 4,250.00$ and the question of how much they paid in tuition and fees was skipped. Black or African American (17.703\% versus $16.617 \%$ ), Hispanic or Latino (17.225\% versus $16.076 \%$ ), Asian $(9.569 \%$ versus $8.624 \%)$, American Indian or Alaskan Native (1.435\% versus $1.262 \%)$, Other $(0.478 \%$ versus $0.421 \%)$, and More than one race (3.589\% versus $2.344 \%$ ) categories are all over-represented in Node 17 when compared to Node 3 where the fourth division originates. It was difficult to speculate as to the reason for the over-represented race and ethnic categories in Node 17 , or why White and Native Hawaiian/other Pacific Islander categories are under-represented. However, the White race/ethnic category continues to be under-represented in Nodes $18-20$ and then is over-represented in Node 21 by over 10\% (65.379\% versus $54.207 \%)$ and more than 3\% in Node 22 (57.773\% vs. 54.207\%). The analysis indicates White students who received between $\$ 2,154.01-\$ 4,250.00$ in Pell Grants are most closely associated with paying more than $\$ 4,381.00$ in tuition and fees.

Fourth Division Node 18. Node 18 represents students who received between $\$ 2,154.01$ - \$4,250.00 in Pell Grants and paid between $\$ 0.00-\$ 1,481.00$ in tuition and fees. Node 18 includes $0.299 \%$ of the students included in the study. All racial/ethnic categories for this node were found to be under-represented with the exception Hispanic or Latino students who are overrepresented by $39.713 \%$ when compared to Node 3 . Hispanic or Latino students are overrepresented in Nodes 18 - 20 which indicates that Hispanic or Latino students who received between $\$ 2,154.00$ - $\$ 4,250.00$ in Pell Grants are also most closely associated with paying between $\$ 0.00-\$ 4,381.00$ in Tuition and Fees which is almost the exact opposite of their White student counterparts. 
Fourth Division Node 19. Node 19 represents $0.935 \%$ of the students in the study who received Pell Grants in the amount of $\$ 2,154.01-\$ 4,250.00$ and paid between $\$ 1,481.01-$ $\$ 2,671.00$ in tuition and fees. Black or African American (19.529\% versus $16.617 \%)$, Hispanic or Latino (28.620\% versus $16.076 \%)$, American Indian or Alaska Native $(2.357 \%$ versus $1.262 \%)$, Native Hawaiian/Other Pacific Islander (1.010\% versus $0.451 \%)$, and Other $(0.673 \%$ versus $0.421 \%$ ) categories were found to be over-represented in Node 19 when compared to Node 3. As indicated earlier, White and Asian students who received between $\$ 2,154.01-$ $\$ 4,250.00$ in Pell Grants are also closely associated with paying higher amounts in tuition and fees, so their under-representation in Node 19 was somewhat expected.

Fourth Division Node 20. Node 20 represents students who received \$2,154.01 $\$ 4,250.00$ in Pell Grants and paid between $\$ 2,671.01-\$ 4,381.00$ in tuition and fees. Node 20 represents $2.708 \%$ of the students included in the study. Race/ethnic categories found to be over-represented in Node 20 included: Black or African American (20.000\% versus 16.617\%), Hispanic or Latino (17.791\% versus $16.076 \%)$, Native Hawaiian/Other Pacific Islander (0.465\% versus $0.451 \%)$, Other $(0.465 \%$ versus $0.421 \%)$, and More than one race $(2.558 \%$ versus 2.344\%). While slight differences were found when comparing Node 20 to Node 3 , the differences were minor when compared to the differences found in other nodes, in other words with slight variances, Node 20 mirrors Node 3.

Fourth Division Node 21. CHAID analysis identified students who received between $\$ 2,154.01-\$ 4,250.00$ in Pell Grants and paid between $\$ 4,381.01-\$ 6,189.00$ in Tuition and Fees in Node 21 . Node 21 includes $2.365 \%$ of the students included in the study. White (65.379\% versus 54.207\%), American Indian or Alaskan Native (1.332\% versus $1.262 \%)$, and More than on race $(2.530 \%$ versus $2.344 \%)$ are over-represented in Node 21 . An examination of 
Node 21 revealed notable differences in the percentages for the race/ethnic categories underrepresented in Node 21. More specifically an examination of Node 21 revealed that Hispanic or Latino students are under-represented by $6.755 \%$, Asian students by $2.898 \%$, and Native Hawaiian/other Pacific Islander by .185\%. While the numbers may seem small, especially in the Native Hawaiian/other Pacific Islander category, the small difference was notable since the Native Hawaiian/other Pacific Islanders category was .390\% for the entire study sample.

Fourth Division Node 22. Node 22 represents students who received between $\$ 2,154.01$ $-\$ 4,250.00$ in Pell Grants and paid more than $\$ 6,189.01$ in tuition and fees. Node 22 contains $2.856 \%$ of the students included in the study. Categories over-represented in Node 22 include: White (57.773\% versus 54.207\%), Asian (14.002\% versus 8.624\%), Native Hawaiian/Other Pacific Islander $(0.662 \%$ versus $0.451 \%)$, and Other $(0.441 \%$ versus $0.421 \%)$. In Node 22 , there continues to be a notable difference in categories that are under-represented including: Black or African American by 3.166\%, Hispanic or Latino by $4.83 \%$, American Indian or Alaskan Native by $0.821 \%$, More than one race $0.359 \%$.

Fifth division from Node 4. The fifth division of tree resulted from the amount of Tuition and Fees Paid being most closely associated with the students who received Pell Grants of greater than $\$ 4,250.00\left(X^{2}=551.709, \mathrm{df}=40, p<0.001\right)$. CHAID analysis identified Skipped, $\$ 1,481.00, \$ 2,671.00, \$ 4,381.00, \$ 5,287.00$ and $\$ 9,912.00$ as significant cutoff points in Tuition and Fees Paid for students who received more than $\$ 4,250.00$ in Pell Grants (Figure 7). CHAID analysis identified cutoff points in the fifth division that were shared with at least one of the other divisions. The fifth division contains $9.812 \%$ of the study sample and shares the title, with the second division, of being the largest division of the tree in regard to the number of resulting nodes (Nodes $23-29)$. 
Figure 7

Fifth Division From Node 4 - Tuition and Fees Paid (degrees of freedom rounded to the nearest 10)

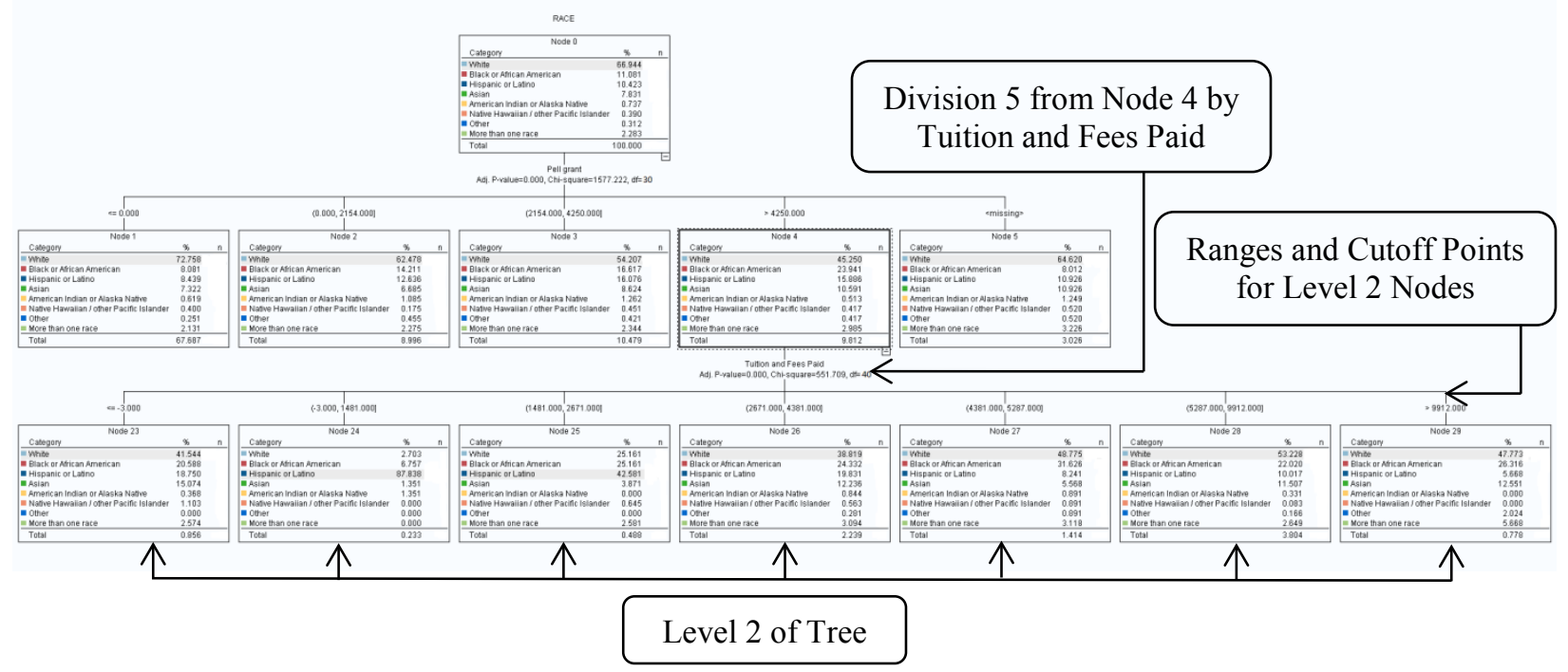

Fifth division Node 23. Node 23 represents students who received more than $\$ 4,250.00$ in Pell grants and the amount of Tuition and Fees Paid was skipped and contains $.0856 \%$ of the students included in the study. Hispanic or Latino (18.750\% versus $15.886 \%)$, Asian (15.074\% versus $10.591 \%$, and Native Hawaiian/Other Pacific Islander (1.103\% versus $0.417 \%$, categories were found to be over-represented in Node 23 when compared to Node 4 . It was noted earlier in this study how Tuition and Fees paid is reported by the institution. It is difficult to speculate why answers would be skipped for Tuition and Fees paid, furthermore an examination of divisions $2,4,5$, and 6 did not reveal any consistent findings of any race or ethnic categories being over-represented or under-represented in the Skipped Node of each division (Nodes 6, 17, 23, 30).

Fifth division Node 24. Students who received more than $\$ 4,250.00$ in Pell Grants and paid between $\$ 0.00-\$ 1,481.00$ in tuition and fees were identified by CHAID analysis in Node 24. An examination of Node 24 revealed some of the largest differences in the entire study in the number of students represented in the node (percentage wise) when compared to the node 
where the branch originated (Node 4 ). Although Nodes 4 and 24 only contain $9.812 \%$ and $0.233 \%$ of the students included in the study, both nodes met the minimum requirements for being included in the study ( $\mathrm{p}$ value for the division $<.05$, and $\mathrm{n}>=50$ in the node) and therefore the differences, although the numbers are small, are worth noting. Hispanic and Latino $(87.838 \%$ versus $15.886 \%)$ and American Indian or Alaskan Native (1.351\% versus $0.513 \%)$ are both over-represented in Node 24 and Hispanic and Latino students are over-represented by almost six times when compared to Node 4. Further investigation into the difference found in the Hispanic student population identified in Node 24 revealed an over-representation of the Hispanic population in the nodes where Pell Grants approximate the amount of Tuition and Fees Paid (Node 7, Nodes 19 and 20, and Node 24).

White, Black, Asian, Native Hawaiian/other Pacific Islander, Other, and More than one race are all under-represented with some race/ethnic categories having no students (Native Hawaiian/other Pacific Islander, Other, and More than one race). Other categories were found to be reduced by a factor of almost 4 or more when compared to Node 4 (White $2.703 \%$ versus 45.250\%, Black or African American 6.757\% versus 23.941\%).

A limitation on how financial aid is awarded also impacts how many students fall into Nodes 24 and 25. Financial Aid is awarded based on the cost of attendance established by the institution. Need based financial aid is limited to the total amount of the cost of attendance. Nodes 24 and 25 represent students who received more than $\$ 4,250.00$ in Pell Grants (which is need based financial aid), and have paid between $\$ 0.00-\$ 2,671.00$ in tuition and fees. While cost of attendance includes other items (books, housing, etc.), Nodes 24 and 25 represent students who would have most if not all of their tuition and fees covered by Pell grant aid. With 
the percentage of the total sample of the study represented by Node 24 being $0.233 \%$, it is clear this situation does not happen for many students.

Fifth division Node 25. CHAID analysis identified students who received more than $\$ 4,250.00$ in Pell Grants and paid between $\$ 1,481.00$ in tuition and fees in Node 25. Black or African American (25.161\% versus 23.941\%), Hispanic or Latino (42.581\% versus 15.886\%), and Native Hawaiian/other Pacific Islander (0.645\% versus $0.417 \%)$ racial/ethnic categories are over-represented when compared to Node 4. The limitation on how financial aid is awarded discussed in reference to Node 24 also applies to Node 25, which may explain part of the reason Node 25 represents only $0.488 \%$ of the students included in the study. White students are underrepresented in Node 25 by just over 20\% (25.161\% versus $45.250 \%$ ) and Asian students are under-represented by $6.720 \%$. The under-representation of White and Asian students in Node 25 supports the earlier finding that Asian and White students were more likely to pay more in tuition and fees than most of the other racial/ethnic categories.

Fifth division Node 26. Node 26 contains $2.239 \%$ of the study sample where CHAID analysis identified students who received Pell Grants of greater than $\$ 4,250.00$ and paid tuition and fees in the amount of $\$ 2,671.00-\$ 4,381.00$ as being most closely associated with students who attended public four-year colleges and universities based on their race/ethnicity. Race/ethnic categories over-represented in Node 26 include Black/African American (24.332\% versus $23.941 \%$ ), Hispanic or Latino (19.831\% versus $15.886 \%)$, Asian (12.236\% versus 10.591\%), American Indian or Alaskan Native (0.844\% versus 0.513\%), Native Hawaiian/other Pacific Islander $(0.536 \%$ versus $0.417 \%)$, and More than one race $(3.094 \%$ versus $2.985 \%)$. The top end of the range of tuition and fees paid in Node 26 closely mirrors the amount of Pell grants received, additional expenses above this threshold would need to be covered by another source 
of funding. The impact of this break-even point seems to affect students in the Hispanic or Latino race/ethnic category more consistently and pronounced than other race/ethnic categories. Accordingly, Nodes 27 - 29 under-represent Hispanic or Latino students by $7.645 \%, 5.869 \%$, and $10.218 \%$ respectively.

Fifth division Node 27. CHAID analysis identified students who received more than $\$ 4,250.00$ in Pell Grant aid and paid between $\$ 4,381.00-\$ 5,287.00$ in tuition and fees in Node 27. Race/ethnic categories over-represented in Node 27 are: White (48.775\% versus 45.250\%), Black or African American (31.626\% versus 23.941\%), American Indian or Alaska Native (0.891\% versus $0.513 \%)$, Native Hawaiian/other Pacific Islander (0.891\% versus $0.417 \%)$, Other $(0.891 \%$ versus $0.417 \%)$, and More than one race (3.118\% versus $2.985 \%)$. Node 27 also contains $1.414 \%$ of the study sample.

Trends in the data applicable to this node have already been identified in the discussion of previous nodes. One trend is the tendency for White students to be over-represented in the nodes associated with higher tuition and fees. The other trend is the over-representation of minority race/ethnic categories in nodes where Pell grant aid is sufficient to cover tuition and fees. However, the trend of minorities being over-represented in nodes with lower tuition and fees paid where Pell grant aid covers the cost, did not equate to a consistent under-representation of minorities at the upper end of the scale of Tuition and Fees paid, rather CHAID analysis revealed volatility in the representation of minority students in those corresponding nodes. This finding is consistent with Carter (2006) and Green's (2005) findings where Black or African American students' attendance was linked to their ability to pay and Hispanic or Latino and White students reacted differently to different types of aid. 
Fifth division Node 28. Node 28 represents students who received more than $\$ 4,250.00$ in Pell grants and paid between $\$ 5,287.00-\$ 9,912.00$ in tuition and fees. Node 28 contains $3.804 \%$ of the study sample with White (53.228\% versus $45.250 \%)$ and Asian $(11.507 \%$ versus $10.591 \%$ ) race/ethnic categories being the only categories over-represented in Node 28 . The volatility described in Node 27 continues in Node 28 where Asian students have been underrepresented in Node 25, over-represented in Node 26, under-represented in Node 27, and again over-represented in Node 28. Other race/ethnic categories representing minority students had pronounced swings as well, although they are not as consistent as the swings identified with students in the Asian race/ethnic category.

Fifth division Node 29. CHAID analysis identified students who received Pell Grants in excess of $\$ 4,250.00$ and paid more than $\$ 9,912.00$ in tuition and fees in Node 29. White (47.773\% versus 45.250\%), Black or African American (26.316\% versus 23.941\%), Asian (12.551\% versus $10.591 \%)$, Other $(2.024 \%$ versus $0.417 \%)$, and More than one race $(5.668 \%$ versus $2.985 \%$ ) are over-represented when compared to Node 4. Although the node represents a small portion of the total sample $(0.778 \%)$, the trends noted in Nodes 27 and 28 continue in Node 29.

Sixth division from Node 5. CHAID analysis identified Tuition and Fees Paid as the independent variable most closely associated with students who had a missing answer in the amount of Pell Grants received $\left(X^{2}=110.811 ; \mathrm{df}=20 ; p<0.001\right)$. The sixth division of the tree contains $3.026 \%$ of the study sample. Statistically significant cutoff points identified by CHAID analysis of Tuition and Fees Paid for students who had a missing answer for the amount of Pell Grants received are $\$ 0.00, \$ 1,481.00, \$ 7,355.00$, and missing answers (Figure 8). A review of the cutoff points for all four divisions based on Tuition and Feed Paid (2, 4, 5, and 6) revealed 
two consistent statistically significant cutoff points of skipped answers and \$1,481.00. A review of the literature did not produce any sources suggesting a reason why skipped answers and $\$ 1,481.00$ would be consistent cutoff points for the divisions of the tree based on amount of Tuition and Fees Paid. However, the consistency of these cutoff points warrants further investigation and is included as one of the suggestions for further research.

Figure 8

Sixth Division From Node 5 - Tuition and Fees Paid (degrees of freedom rounded to the nearest 10)

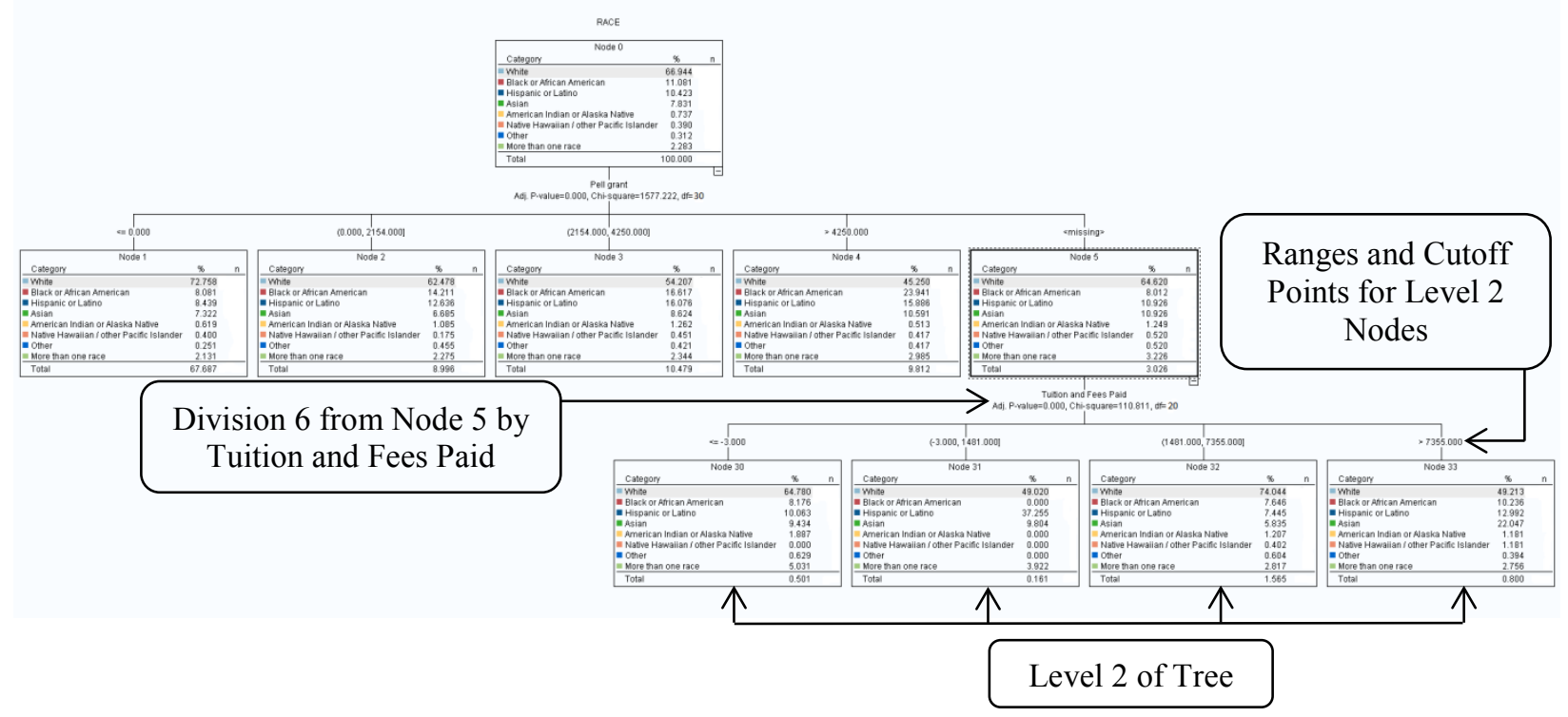

Sixth division Node 30. CHAID analysis identified students who had a missing answer for the amount of Pell grants received and also were missing an answer for the amount of Tuititon and Fees Paid in Node 30, representing $0.501 \%$ of the study sample. Race/ethinic categories over-represented in Node 30 when compared to Node 5 include White $(64.780 \%$ versus 64.620\%), Black or African American (8.176\% versus 8.012\%), American Indian or Alaskan Native (1.887\% versus $1.249 \%)$, Other (0.629\% versus $0.520 \%)$, and More than one race $(5.031 \%$ versus $3.226 \%)$. Investigation of the other nodes representing students who had missing answers for the amount of Tuition and Fees paid (Nodes 6, 17, 23, 30) did not reveal 
any consistent findings on which race/ethnic categories are most likely to have missing answers for the amount of Tuition and Fees Paid.

Sixth division Node 31. CHAID analysis identified students who had missing values for the amount of Pell Grants received and paid between $\$ 0.00-\$ 1,481.00$ in tuition and fees in Node 31 . Node 31 contains only $0.161 \%$ of the study sample and Black or African American, American Indian or Alaskan Native, Native Hawaiian/other Pacific Islander, and Other race/ethnic categories are not represented (have 0 students) in Node 31 . Hispanic or Latino (37.255\% versus $10.926 \%)$, and Other $(3.922 \%$ versus $3.226 \%)$ race/ethnic categories were overrepresented in Node 31 when compared to Node 5. \$1,481 was mentioned earlier as being one of the two consistent cutoff points for Tuition and Fees paid. The other consistent cutoff point of skipped values did not reveal any consistent findings regarding the students contained in those respective nodes. A similar comparison was made of the nodes containing the cutoff point of $\$ 1,481.00$ (Nodes 7, 18, 24, and 31) where Hispanic or Latino students were found to be overrepresented in each of those Nodes. Hispanic or Latino students consistency in association with the cutoff point of Tution and Fees Paid in the amount of $\$ 1,481.00$ is included as a suggestion for further study.

Sixth division Node 32 . Node 32 contains $1.565 \%$ of the study sample where CHAID analysis identified students who had missing answers for the amount of Pell grants received and paid between $\$ 1,481.01$ - $\$ 7355.00$ in tution and fees. Race/ethnic categories over-represented in Node 32 include White (74.044\% versus $64.620 \%)$ and Other (0.604\% versus $0.520 \%)$. Asian students were almost half as likely to pay between $\$ 1,481.01-\$ 7,355.00$ in tuition and fees than their representation in Node 5 (5.835\% versus $10.926 \%)$. 
Sixth division Node 33. Students who had a missing value for the amount of Pell grants received and paid more than $\$ 7,355.00$ in tuition and fees were identified in Node 33 . Node 33 contains $0.800 \%$ of the study sample where Black (10.236\% versus $8.012 \%)$, Hispanic or Latino (12.992\% versus $10.926 \%)$, Asian (22.047\% versus $10.926 \%)$, and Native Hawaiian/other Pacific Islander (1.181\% versus $0.520 \%)$ race/ethnic categories are over-represented when compared to Node 5.

Model accuracy and gains. CHAID analysis is used to segment existing populations based on a set of criteria (independent variables). The goal is to gain more information about that population and the ability to target specific segments of the population. In the case of this study, the dependent variable of enrollment at public four-year colleges based on the race/ethnicity of the student was segmented using the independent financial variables of Pell Grants received, Tuition and Fees Paid, and whether or not a student Worked during the summer of 2007. Once a CHAID analysis is performed, the resulting model can be used to make predictions on how the changes in the independent variable will affect the dependent variable. The dependability of those predictions is not based on the model's ability to represent what is, but rather to using the model to determine how changes in the independent variables will impact the dependent variable. PASW Modeler 14 used the model generated from the data included in this study to determine if the model could accurately predict the race/ethnicity of the student based on the inputs from the independent variables. Table 3 shows how the model generated from the data would predict the race of the students included in the study based on the independent variables. 
Table 3

Misclassification Index - Risks

(Rounded to the nearest 10)

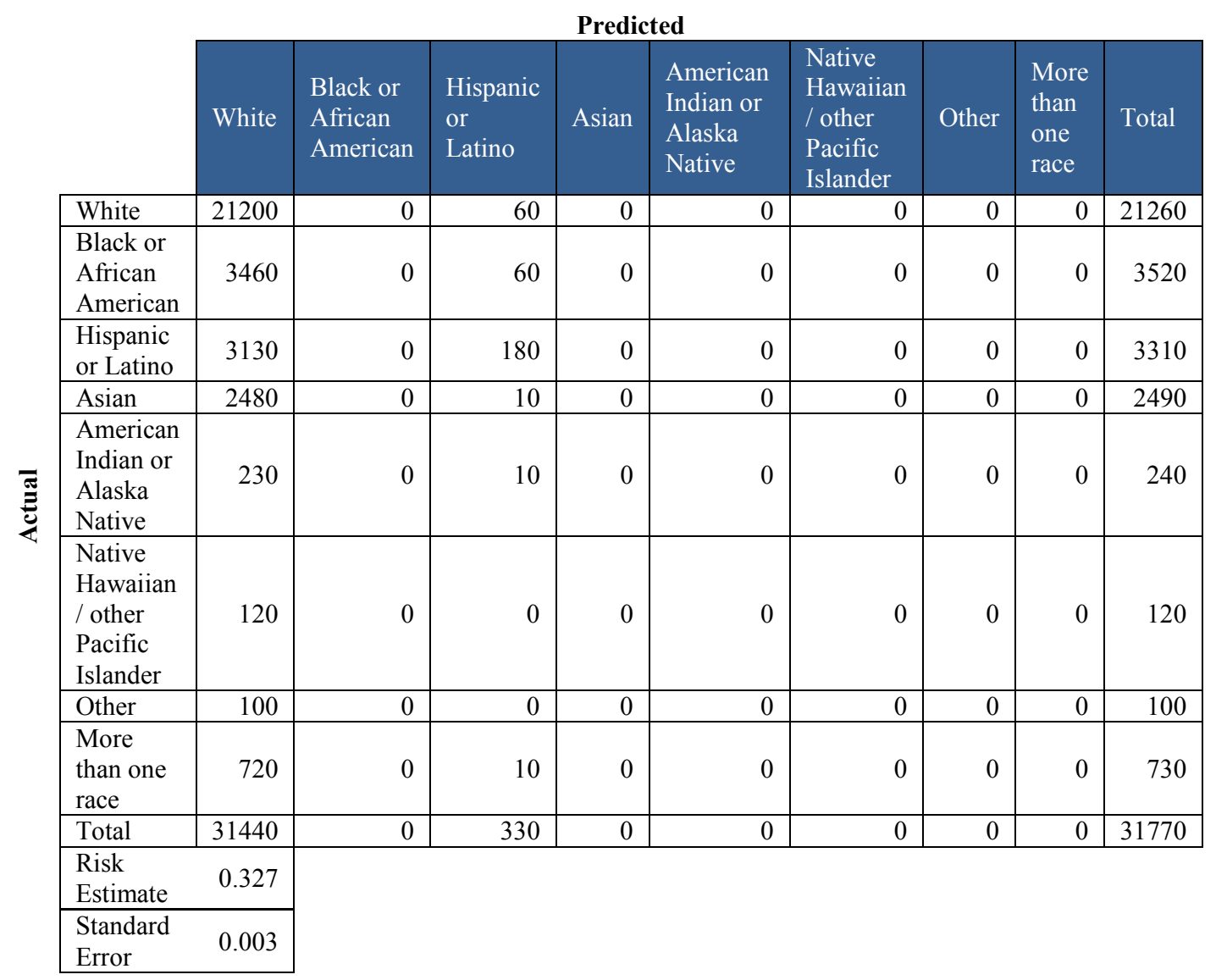

The Risk Estimate is the risk of mis-classifying a student, so the model predicted the race/ethnicity of the student correctly $67.3 \%$ of the time. However, since $66.9 \%$ of the students included in the sample were White, the model is able to achieve that level of accuracy simply by lumping all but a few students into the White category. The model generated from the data predicts 31,440 students will be White and 330 students will be Hispanic. Although the model predicted the race of the student accurately $67.3 \%$ of the time, it was unable to accurately predict the correct race of any student other than White students. The only other race prediction made was that a student would be Hispanic or Latino which the model predicted correctly 180 times 
out of 3,310 occurences, an accuracy rate of 5.6\%. The other 3,126 Hispanic/Latino students were incorrectly predicted as being White. Students from the remaining race/ethnic categories were incorrectly classified White as well.

The model therefore is valuable in representing the data from the sample included in this study, however the model fails to be useful in making predictions on how the enrollment of students from different races/ethnicities would react if changes were made in the independent variables included in this study. Models built on CHAID analysis can be used to make predictions as outlined in Chapters 2 and 3. Predictions based on the model would be used to determine gains, or how the dependent variable would change based on changes in the independent variables. In the case of this study, gains would normally be used to determine how changes in Pell Grants, Tuition and Fees Paid, and whether or not a student worked during the summer of 2007, would result in gains or losses in the number of students who attend public four-year colleges and universities based on their race/ethnicity. However, based on the independent variables included in the model, the model was only able to predict a student would be White or Hispanic and was unable to make predictions regarding the attendance of students from any of the other race/ethnic categories. Therefore, calculating gains based on the model would not produce meaningful results since the model would predict all gains in enrollment would result in an increase in students who are either White or Hispanic.

In terms of Null and Alternative Hypothesis testing, findings from the CHAID analysis identified statistically significant associations between the Pell Grant Awards, Tuition and Fees Paid, and whether or not the student worked during the summer of 2007, and the dependent variable of attendance at public four-year colleges and universities. Additionally, the independent variables impacted students differently based on their race/ethnicity. Therefore the 
null hypotheses for the study are rejected and the alternative hypotheses are accepted. However, in light of the model's inability to make accurate predictions based on the independent variables, the rejection of Null Hypothesis $2\left(\mathrm{Ho}_{2}\right)$ should be done with caution. While the model found statistically significant associations between the dependent and independent variables, used those associations to segments students who were included in the study, and depicts how changes in the independent variables affected the dependent variable differently based on the race/ethnicity of the student, the model's inability to make accurate predictions on the race/ethnicity of the student indicates the changes in enrollment found in the model are likely attributable to other variables not included in this study. This finding will be discussed in Chapter 5. 


\section{Chapter Five: Summary of the Findings, Recommendations for Policy, Practice, and Future Research, and Conclusion}

\section{Summary of the Study Findings}

This study examined financial factors associated with the attendance of students at public four-year colleges and universities based on race and ethnicity. CHAID analysis was performed on a set of independent financial variables including: tuition charged, student loan indebtedness, Pell Grant award, Work Study award, housing costs for the student, expected family contribution (EFC), balance on credit cards, whether or not a student's parents own their home, whether or not a student worked during the summer of 2007, and whether or not students have reported receiving financial assistance from their parents, to determine which of the independent variables were most closely associated with the attendance of students based on their race/ethnicity. The study not only examined which factors were most closely associated with the attendance at public four-year colleges, but also whether or not the order or degree of association differed between students of different races/ethnicities.

The primary finding of this study was the rejection of Null Hypotheses 1 and $2\left(\mathrm{Ho}_{1}\right.$ and $\left.\mathrm{Ho}_{2}\right)$ lending support to Alternative Hypotheses 1 and $2\left(\mathrm{Ha}_{1}\right.$ and $\left.\mathrm{Ha}_{2}\right)$. CHAID analysis found a statistically significant degree of association between enrollment of students at public four-year colleges and universities and a Pell Grant awards, amount of tuition and fees paid, and whether or not a student worked during the summer of 2007. CHAID analysis also found a difference in the degree of association based on the race/ethnicity of the student. Pell Grant aid received by students was the most statistically significant factor associated with the attendance at public fouryear colleges. This finding is consistent with the findings of prior research by Kim (2004), Santiago and Cunningham (2005), and Swail et al. (2003). Two different financial factors were identified in level 2 of the CHAID analysis as being most closely associated with attendance of 
students at public four-year colleges based on the amount of Pell Grants received by the student. Whether or not a student worked during the summer of 2007 was identified as being most closely associated with the attendance of students who received between $\$ .01-\$ 2,154.00$ in Pell Grant awards, whereas the amount of Tuition and Fees paid was most closely associated with all other levels of Pell Grant awards. While prior research indicates the importance of Pell Grants in students' decisions to attend college and what type of college they will choose to attend (Kim , 2004; Manski \& Wise, 1983; Santiago \& Cunningham, 2005; Swail, Redd, \& Perna, 2003), whether or not a student worked during the summer of 2007 appearing as a significant factor is a unique finding which warrants further investigation and consideration with regard to the financial accessibility of higher education.

A second finding of the study is the identification of cutoff points in the variables found to be most closely associated with the attendance of students at public four-year colleges. Pell Grants are identified in the literature as being an important factor in students' decisions to attend college, however significant cutoff points in the award amounts were not found in a review of the literature and are unique to this study. The same is true of the cutoff points identified in the amount of Tuition and Fees Paid and whether or not a student Worked During Summer of 2007, the two factors most closely associated with attendance at public four-year colleges resulting in the splits for level 1 and 2 of the decision tree. The cutoff points indicate where changes in policy can have the greatest impact. CHAID analysis suggests students identified in nodes on either side of a cutoff point may be significantly impacted by policy changes affecting or targeting those cutoff points. An observation made in Chapter 4 was the identification of a change in the attendance of students based on their race/ethnicity when the breakeven point between Tuition and Fees Paid and Pell Grant Awards was reached. 
A third finding of the study is related to the independent variables not found to be most closely associated with attendance of students at public four-year colleges in the first two levels of the CHAID analysis. Ten independent financial variables were included in the analysis. Each node of the tree represents a chance for a new branch to stem from the tree where each of the independent variables were examined to determine which of the variables were most closely associated with the students contained in that node. CHAID analysis identified one variation in the $2^{\text {nd }}$ level of the tree where the order of the independent variables changed (the branch off of Node 2). The exclusion of the other independent variables does not necessarily indicate a lack of association between them and the dependent variable, rather their exclusion from the analysis may indicate a weaker association than the associations identified in levels 1 and 2 of the decision tree. Since a number of nodes in the tree contain more than 50 students $n>50$, if the tree were allowed to grow an additional level, other independent variables may be found to have an impact on enrollment as well. However it may be relevant to ask, "how many students need to be impacted to necessitate a change in policy?" For the purpose of this study, nodes were allowed to terminate when the number of students in the node drops below $50(\mathrm{n}<50)$. However, a change in policy may not be practical or able to target a population of 50 students. If further studies are built on the work done in this study, a close examination should be conducted to determine usefulness of the information. It may be useful to examine only certain branches of the tree depending on the number of students contained in the branch.

A fourth finding of the study is how the independent variables affected enrollment of students at four-year colleges differently based on the race and ethnicity of the student. CHAID analysis identified statistically significant cutoff points in Pell Grant awards at $\$ 0.00, \$ 2,154.00$, $\$ 4,250.00$, and missing values. While the majority of students included in the study $(67.687 \%)$ 
were merged into Node 1 representing students who received no Pell Grant award, 72.758\% of the node's students are in the White race/ethnic category, which is $5.814 \%$ greater than their representation in the overall study sample. The only other race/ethnic category over-represented in Node 1 is Native Hawaiian/Other Pacific Islander by $0.010 \%$. Students who received some type of Pell Grant Aid included $29.287 \%$ of the study sample with White students being underrepresented in each of those Nodes $(2-4)$. At the same time, Black or African American, Hispanic or Latino, and Other race/ethnic categories are over-represented in those same nodes (2 -4). Asian and Native Hawaiian/Other Pacific Islander, and More than one race race/ethnic categories were over-represented in Nodes 3 and 4, and the American Indian or Alaska Native category was over-represented Nodes 2 and 3.

Tuition and Fees Paid as well as whether or not a student Worked during the summer of 2007 (the two independent variables most closely associated with students in level 1 of the tree resulting in level 2 of the tree) also indicated a difference in how student enrollment was impacted based on the race/ethnicity of the student. White students were over-represented in most of the nodes signifying higher levels of Tuition and Fees Paid (Nodes $9-11,21-22,27$ 29, 32). Students from other race/ethnic categories did not show as consistent of a trend, however as noted in Chapter 4, other race/ethnic categories were found to be heavily weighted in nodes where Pell Grant awards were equal to or exceeded Tuition and Fees Paid (Nodes 7, 18 20, $24-27$ ). White students were found to be over-represented in Node 15 which means White students who received between \$0.01 - \$2,154.00 Pell Grant aid were more likely to have worked during the summer of 2007 than their representation in Node 2 where the branch originated. The only other race/ethnic category over-represented in Node 15 was the More than one race, all other categories were under-represented. Conversely, Node 14 where students Did 
not work during the summer of 2007, Asian, Other, and More than one race were overrepresented.

The final finding of this study was the model's (built from the analysis) inability to correctly predict the race/ethnicity of a student who attends a public four-year college from the inputs identified by the analysis (Pell Grant Award, Tuition and Fees Paid, and Worked during the summer of 2007). Based on the Misclassification Index - Risks Table, when the model used the inputs of Pell Grant Award, Tuition and Fees Paid, and Worked during the summer of 2007 to predict the race/ethnicity of the student, students were predicted to be White $99.0 \%$ of the time. The other $1 \%$ of students were predicted to be Hispanic. Although the model had a prediction rate of $67.7 \%, 66.944 \%$ of the study sample were from the White race/ethnic category. As a result, the model would be correct approximately two-thirds of the time by predicting all students in the study were White. Therefore, while the results of this study certainly help inform factors ultimately impacting enrollment of certain races and ethnicities, the model produced from this study's CHAID analysis should not be used to actually predict enrollment of students from different races and ethnicities.

CHAID analysis of the students included in the study was able segment the study's sample based on the independent variables of Pell Grant Awards, Tuition and Fees Paid, and Worked during the summer of 2007 with a $p$ value of $<0.000$, which means the associations between the independent variables in the model and the dependent variable are statistically significant for the students included in the sample. However, as previously stated, when the model was used to make predictions on what the race/ethnicity of a student would be based on the independent variables of Pell Grant Awards, Tuition and Fees Paid, and whether or not a student Worked during the summer of 2007 , the model was unable to accurately predict what the 
race/ethnicity of the student would be. Since the three independent variables included in the model were the variables most closely associated with the dependent variable, the other independent variables included in the analysis either have weaker associations or no association with the dependent variable. However, since the majority of the students in the sample for the study were from the White race/ethnic category, strong associations between the independent variables and smaller categories of the dependent variable may not appear in the model. Therefore, students representing more diverse backgrounds chose to attend college either based on weaker associations with the independent variables, or students from diverse racial/ethnic backgrounds decided to attend college based on factors beyond those included in this study. Both possibilities warrant further investigation and partially explain why there have been so many approaches used to explore how students make the decision to attend college.

\section{Recommendations for Policy and Practice}

The goal of this study was to determine if the independent variables examined could be manipulated to increase access to public higher education with a focus on students from underrepresented racial/ethnic groups. The study was conducted within the context of a social contract existing between society and public higher education. The social contract is based on providing equal access to higher education for all potential students in exchange for financial support through public funding (Green T. C., 2005). To realize the goal of equal access, the student body should reflect the racial and ethnic diversity that exists in society. However, during a time of increased diversity in society, students at public higher education institutions are still predominately from the White racial/ethnic category. There is an opportunity to focus future policy and practice on fulfilling the terms of the social contract established with society by increasing access for students from under-represented races/ethnicities. Findings of this study 
lend support to the idea that sudents' decisions to attend college are complex. While finances play a role in the decision process, other factors, not examined as a part of this study, are at work as well. As a result, a close and ongoing examination of the cost of college, programs to offset the cost, as well as other non-financial factors should be conducted to determine the best intervention methods for students from traditionally under-represented race/ethnic backgrounds.

The first recommendation for future policy and practice is a call for action. A recent report done by National Public Radio found over 50\% of undergraduate students received federal aid to offset the cost of higher education. The same report also stated that students who came from families with income in excess of $\$ 100,000$ per year received institutional grants at almost the same rate (38\% versus $39 \%)$ as students whose families earned less than $\$ 100,000$ per year (Chappell, 2013). The literature review highlighted the economic challenges associated with attracting students from traditionally under-represented races/ethnicities. To award financial aid to economically challenged students in a similar fashion to those who have substanially more financial resources raises a question of equity regarding access, especially when more financial resources are needed to attract students from traditionally under-represented races/ethnicities. The status quo for current admission policies, financial aid policies, marketing efforts, and precollege counseling, have been inadequate in obtaining a diverse student body within public higher education.

The benefits of diversity in higher education are numerous. Providing access to higher education taps into previously untapped potential for students who would have otherwise decided not to attend college. Many of these students represent the diverse racial and ethnic backgrounds found to be beneficial to the higher education process (See The Value of Diversity in Higher Education in the Literature Reivew of this study). Accessibility for a more diverse student body 
prepares a greater number of students for the demands of a skilled workforce and equips those students to engage in a workplace that is becoming increasingly more diverse.

Therefore a disconnect exists between the value contained in the untapped potential of increasing diversity in higher education and the resources invested in making higher education accessible for students representing diverse backgrounds. Incentives should be put in place to encourage research that is able to inform decisions on the best methods to increase access to Higher Education, especially for students from traditionally underrepresented races/ethnicities.

A second recommendation stems from the first, which is the need for ongoing research to inform policy and practice regarding access to higher education. The composition of the population in the United States continues to change. The higher education process and experience continues to change as well. In some ways, institutions of higher education will automatically orient their change with the changing population in order to continue attracting students to their respective institutions. However, research needs to be ongoing and able to inform decision making with data that accurately reflects current conditions.

NPSAS 2008 data was chosen for this research because of the wealth of variables available in the study, and because the NPSAS has a large study sample size that is difficult to duplicate. However, the NPSAS was originally conducted only once every three years, and more recently is conducted once every four years. Since the bulk of this research study took place in 2012, the most recent data available was already four years old, meaning most of the students surveyed had already graduated. While many changes happen slowly over time, an assumption exists that students who were a part of the higher education process four years ago are still reflective of the students currently attending college. In order to address the needs of students in 
a timely manner, studies like the NPSAS should be conducted more often so the data is reflective of the current student population.

Related to the frequency in which data is collected is a recommendation to make the data more easily accessible. A tension currently exists between the need to have access to data collected in studies like the NPSAS, and the need to protect the individuals included in those studies by restricting access to the data. Although the name Restricted Use Data and the need to obtain a license implies there is a process to obtain access to the data, those two items do not accurately reflect the challenges and restrictions placed on obtaining the data necessary to conduct similar studies. Once a researcher combs through the manual to gain an understanding of the license requirements, the challenge then exists in procuring the resources necessary to fulfill the terms of the license. The first requirement for a Restricted Use License includes identifying individuals to fill three different roles. The three roles are: a Principle Project Officer with credentials of at least a post-doctoral fellow and a strong tie (employment) to an entity where daily practices are closely tied to the research area (e.g. college or university), a Senior Official (at the same institution) with the authority to enter into a legally binding agreement with the Department of Education, and a System Security Officer responsible for implimenting and maintaing security of the data during the project. Identifying those individuals can be a significant challenge and depends greatly on the resources of the institution as well as cooperation across the institution.

The second challenge associated with obtaining a license for restricted use data is identifying a secure project space. In order to gain a license for the data, the project space can only be accessible to project personnel listed on the license and essential security personnel. Identifying a space for the project only fulfills part of this requirement. The other half is 
coordinating the hardware and personnel needed to change locks, distribute keys, and communicate appropriate emergency procedures regarding the secure project space.

The third challenge is securing the resources needed to access the data, perform the analysis, and write up the results. The license requires a stand alone computer to be located in the secure project space. The computer cannot be connected to any network, must be password protected (with certain requirements for the password), must have all but the essential access ports and input/output devices turned off (CD ROM and USB ports), must automatically time out after 5 minutes of inactivity, and must post a warning on the screen that a potential user sees before accessing the machine. In addition, there is an outlined process of how to close out a project using Restricted Use data which includes wiping the hard drive of all data using specialized software. In order to successfully obtain a license, the project team needs to include someone with some expertise with software and hardware configurations.

With some cooperation from an appropriate institution with the right resources, securing a Restricted Use data license is managable. However, the strict requirements of the license can also delay research or prevent the research from happening altogether. In the case of this research project, securing the license was an 18 month project where one Research I institution was unable to produce the necessary resources to secure a license for the data.

Under current procedures, obtaining access to the data used in this project is a one size fits all approach. In order to encourage more research using large data sets like the NPSAS, efforts need to be made to make the data more easily accessible. One recommentation to make NPSAS data more accessible would be to tailor the data set to include only the information necessary to complete the reseach project. Currently, the NPSAS database comes in an all-ornothing package. While having all the data encourages researchers to explore beyond the scope 
of their research, most targeted research will not use a large portion of the data. Limiting the scope of the data to what is necessary to complete the research proposed would allow licensing requirements to be modified to match the risk associated with the data released under the licensing agreement. Research projects posing low risks to the individuals whose data is included in the sample could then be licensed with substanially less resources and security measures in place.

A fourth recommendation stemming from this study is the need to capitalize on the diversity that currently exists at public four-year colleges and universities. While the focus of this study was on the financial factors associated with attendance at public four-year colleges, the portion of the Literature Review that focused on the value of diversity in higher education merits revisiting. The Journal of Diversity in Higher Education focuses on the issue and continues to publish research on the benefits of diversity in higher edcuation, ways to encourage greater diversity in higher education, and how to meet the needs of students from diverse backgrounds.

While the jounal is fairly new, with its first volume published in 2008 , the focus on diversity serves to highlight its importance in higher education. In the first volume, the journal published an article providing evidence of how diversity in the classroom has a positive effect on learning outcomes (Gottfredson, et al., 2008). Another article highlights Roosevelt University's history of being one of the most diverse institutions of higher education in the United States. The article clearly outlines the importance of diversity being engrained in the culture of an institution and highlights programming, intentional support from faculty and administration, and the staying power of tradition as being important in supporting diversity at Roosevelt's campus (Middleton, 2009). 
The results of this study suggest that students from diverse race/ethnic backgrounds base their decision to attend public four-year colleges on non-financial factors, or on financial factors that are more subtle and difficult to uncover than students who are from the White race/ethnic category. However, realizing the financial predictors for White students are different from students of other races/ethnicities is a starting point. Work by Gottfredson and Middleton suggests that in order to support and promote diversity that currently exists, the culture of the instution needs to embrace and appreciate diversity at all levels until diversity becomes a part of the identity of the institution. Policies and programs can be created to be more inclusive, promote better understanding of people from different cultures, and in some cases even dictate a prescribed level of required diversity in the student body (through quota systems). However, until students can align their identities with the identitity of the institution, additional effort will need to be made to attract and retain students from diverse racial/ethnic backgrounds.

The complexity involved in a student's decision to attend college has been mentioned a few times throughout this research project. Research for this project focused on financial factors involved in financing a college educaction. However, a more holistic appoach examining not only the finances involved in funding a higher education, but also other factors impacting a student's decision to attend college and ability to persist through graducation may be a better match for the complex nature of the problem. One area to explore in future research, not included in this study, is college preparedness. Many factors can be explored in relation to a student being prepared to enter college. Some of those factors include: Kindergarten through twelveth grade education, access to college preparation, high school counseling regarding college enrollment and attendance, and a solid support structure i.e. friendships, family, and community, to name a few. College preparedness may also differ depending on the 
race/ethnicity of the student and may have an effect on the enrollment, impacting the diversity found in the student body.

The final recommendation stemming from this study is the need for more targeted outreach to under-represented student populations. The results of this study suggest that in regard to the independent financial variables examined, students from under-represented races/ethnicities make the financial decision to attend public higher education differently than students who are White. This study attempted to uncover the financial variables most closely associated with students based on their race/ethnicity, however the model produced from the data was only able to predict how White students would react to changes in the independent variables. In the Recommendations for Further Research, some suggestions will be made on how to build off of the research method and variables used in this study to more specifically target students from traditionally under-represented races/ethnicities. Additionally, students from different races/ethnicities face different cultural expectations. One challenge for students from diverse racial/ethnic backgrounds is the added pressure they face to start work straight out of high school instead of attending college (College Access and Admission, 2007; Freeman, 1999; Willis, 1977). In the previous recommendation for future policy and practice, a suggestion was made that the culture and identity of public insitutions of higher education need to be aligned with the identities of students from different races and ethnicities. In order to accomplish this task, efforts need to be made to understand the cultures and identities of students from diverse race/ethnic backgrounds. Even if complete alignment of identities is difficult or impossible to achieve, students are likely to recognize the effort and respond positively to even the smallest changes intented to make higher education more inclusive. 


\section{Recommendations for Future Research}

This study set out to build on prior research investigating the impact of finances on access to higher education. At several points throughout the study, acknowledgment was made regarding the complexity involved in students' decisions regarding the choice of whether or not to pursue a higher education as well as what type of institution to attend. The complexity of the problem is explored in the Literature Review and highlighted by the diverse approaches used to investigate the phenomenon. This study attempts to build on prior research, however the complexity of the problem lends itself to being explored through a miriad of approaches. The choice of independent variables included in this study as well as the method chosen to investigate the phenomenon, were well informed decisions based on prior research. However, other research methods and variables are available for further research.

This study confirmed the complexity involved in students' decisions to invest in public higher education. Additionally the study determined students from diverse race/ethnic backgrounds based their decision to attend public four-year colleges and universities on factors beyond the independent financial variables included in the model generated by this study. As policies evolve regarding financing higher education, research should continue to inform policy makers to maximize the impact on making higher education accessible to all students.Having two-thirds of the study sample from one race/ethnic category (White), while reflective of the current population of students attending public colleges and universities, is listed as a limitation of the study. The limitation was acknowledged realizing the associations identified by the CHAID analysis may be overly influenced by factors associated with the two-thirds majority. The strong associations with students from the White ethnic/race category may hide more subtle but telling assocations between other categories of the dependent variable and the independent 
variables. Therefore a suggestion for further research is to perform the same analysis, eliminating students from the White race/ethnic category, to determine if there are any associations found and whether or not the associations are different from the findings in this study.

A similar study limitation exists because state representative samples were collected from California, Georgia, Illinois, Minnesota, New York, and Texas in the NPSAS 2008 study, which resulted in those states being over-represented in the study's sample. Additional research should be conducted to determine if this study's results are unchanged if the effects of oversampling from those six states are removed.

Additionally, CHAID analysis could be performed on each race/ethnic category to focus in on the factors that have the greatest association with students who are identified as being in that race/ethnic category. For example, upon removing White students from the sample, an Hispanic/NonHispanic binary designation could serve as the dependent variable, and each of the independent variables would be examined to determine which are most closely associated with Hispanic or Latino students. CHAID analysis would be useful in this type of study by identifying subsets of students within a race/ethnic category highlighting any differences present within racial/ethnic categories.

CHAID analysis identified skipped answers and $\$ 1,481.00$ as significant and consistent cutoff points in the independent variable of amount of Tuition and Fees Paid. A review of the literature did not reveal any suggestions as to why those particular points would be significant. Additionally, the Hispanic or Latino race/ethnic category was over represented in each of the nodes where Tuition and Fees Paid fell between $\$ 0.00$ - \$1,481.00 (Nodes 7, 18, 24, and 31). Further investigation could be done to determine the reasons why those cutoff points are 
significant, applied to $91.000 \%$ of the students included in the study sample, and why the Hispanic or Latino category was consistently over represented in the nodes where Tuition and Fees paid were in the $\$ 0.00-\$ 1,481.00$ range.

Exploring different segments of the student population attending public four-year colleges is another area of opportunity for future study. Dividing students by race/ethnic categories is only one way of looking at the differential impact of finances on segments of the student population. Future research could employ the same method used in this study to explore the association of the independent variables with the attendance of students at public four-year colleges when the dependent variable is segmented based on different criteria (e.g. gender, state/geographical region, traditional versus non-traditional students, or residential versus commuter students). While the independent financial variables were not found to be good predictors of student attendance based on the race/ethnicity of the student, they may be found to be good predictors of student attendance based on segmenting the student population on one or more of the criteria mentioned above.

Similarly, the same research method used in this study could be used to examine students attending private colleges and universities. The scope of this study was limited to public fouryear colleges and universities, however accessibility to private insititutions of higher education is another direction this research can be taken. One approach would be to mirror this study exactly using private institutions and determine if the impact on different race and ethnic categories differs based on the type of institution the student attends. This approach would not only build off of the findings presented in this study, but would also support prior reseach conducted by Ehrenberg (2001), Hwang (2003), Kim (2004), King (1999), Paulsen and St. John (2002), and Wojciechowska (2010). 
The complexity involved in students' decisions to attend college is supported by the findings in this study. The model developed by the research approach employed in this study was unable to accurately predict attendance of a student based on their race/ethnicity. Therefore more subtle associations between the variables included in this study or factors beyond the independent variables used in this model may be at play The Literature Review identified a number of studies, using different research methods, which explore how students make the choice to invest in higher education.

This study illustrates the need for more research to be conducted. Additional research could focus on eliminating one factor at a time until the factors most important in influencing students' decsions to attend college are left. On the other hand, a more complex and holistic view of students may be warranted. This study focused on financial factors most closely associated with attendance at public four-year colleges, however a more holistic approach could incorporate other factors, i.e. family demographics, pre-colligiate academic preparation, geographic location, and skills and interests inventories. Searching out the factors influencing the decision of students from traditionally under-represented races/ethnicities is particularly important for the benefits diversity brings to the education process, and society's workforce.

\section{Conclusion}

Racial/ethnic diversity in higher education benefits society as well as students. Society benefits by having an educated work force better prepared to fill skilled positions to meet society's needs. Society also benefits because students who experience diversity in higher education are more prepared to interact with a society that is becoming increasingly more diverse. Students benefit by being equipped to meet society's needs and better prepared to 
interact with a more diverse society and workforce. A system of public higher education was established to provide financial access to higher education for any student regardless of their socio-economic status. Within this context, a social contract was established between society and public higher education where society identified a need and provided support for public higher education. In turn, society receives the benefits of access to higher education and graduates who are prepared to meet the needs of a more skilled and more diverse workforce. This study attempted to build off of prior research by investigating which financial factors in a set of 10 independent variables were most closely associated with attendance at public four-year colleges. Within the limitations of this study, results suggest where the greatest impact on access can be made.

Diversity within higher education benefits society as a whole as well as the students attending college. However, the racial/ethnic diversity of the current student population at public four-year colleges and universities does not reflect the diversity present in society. The current situation results in students who are not equipped with the skills necessary to interact with an increasingly diverse society. Additionally, minority students are disproportionately underrepresented and therefore not receiving the benefits associated with a college education. The findings of this study lend support to the idea that the cost of higher education in combination with diminished financial support is having an impact on the accessibility of public higher education. Findings of the study also suggest that traditionally under-represented students (by race and ethnicity) base their decision to attend college on factors that are different than White students and may include factors beyond those included in this study. In order to reach students who otherwise might find higher education financially out of reach, findings of this study suggest a close examination and support for the Pell Grant program, keeping costs (tuition and 
fees) down, and encouraging students to work over the summer break, are good places to start, however the findings of the study also suggest that outreach in this area may not directly affect the enrollment of students from traditionally under-represented races/ethnicities.

It is important that society, government, and public higher education continue working together to provide access to higher education to a racially diverse student body. Information contained in this study as well as in other research is needed to inform policy makers on the best methods to reach out to under-represented populations in an effort to make higher education more accessible to all students. Diversity in the public higher education system benefits society as well as students. The risks associated with the rising cost of higher education are too great to be ignored and will eventually result in a less prepared and more segregated population where the opportunity and benefits of higher education are only accessible to a privileged few. 


\section{References}

Adelman, C. (2010, June 24). The White Noise of Accountability. Retrieved March 3, 2011, from Inside Higher Ed:

http://www.insidehighered.com/layout/set/print/views/2010/06/24/adelman

Advisory Committee on Student Financial Assistance. (2001). Access Denied: Restoring the Nation's Commitment to Equal Educational Opportunity. Washington, DC: Advisory Committee on Student Financial Assistance. Retrieved November 28, 2012, from http://www2.ed.gov/about/bdscomm/list/acsfa/access_denied.pdf

Astin, A. W. (1993). What matters in college? Liberal Education, 79(4). Retrieved 12 10, 2012, from http://www.faculty.umb.edu/john_saltmarsh/Articles/Astin, $\% 20$ what $\% 20$ matters $\% 20 \mathrm{in} \%$ 20college.rtf

Astin, A. W. (1999). How the Liberal Arts College Affects Students. Daedalus, 128(1), 77-100. Retrieved 12 3, 2011, from http://www.jstor.org/stable/20027539

Astin, A. W., \& Oseguera, L. (2004, Spring). The Declining "Equity" of American Higher Education. The Review of Higher Education, 27(3), 321-341. Retrieved 12 10, 2012, from http://muse.jhu.edu.www.libproxy.wvu.edu/journals/review_of_higher_education/v027/2 7.3astin.pdf

Atkinson, R. (2001). Standardized Tests and Access to American Universities. Washington, DC: American Council on Education. Retrieved December 10, 2012, from http://works.bepress.com/cgi/viewcontent.cgi?article=1035\&context=richard_atkinson 
Barinaga, M. E. (1998). Graduate Admissions Down for Minorities. Science, 281, 1778-1781.

Retrieved December 10, 2012, from http://news.sciencemag.org/sciencenow/1998/09/1403.html

Bedsworth, W., Colby, S., \& Doctor, J. (2006). Reclaiming the American Dream. The Bridgespan Group. Retrieved December 2, 2012, from http://www.ezsozcj.givewell.net/files/Cause4/Sponsors\%20for\%20Educational\%20Oppo rtunity\%20(SEO)/132578670\%20Cause\%204\%20ReclaimingtheAmericanDreamWhitePaper.pdf

Birnbaum, R. (1983). Maintaining Diversity in Higher Education. San Francisco: Jossey-Bass.

Borden, V. M. (1995, February). Segmenting Student Markets with a Student Satisfaction and Priorities Survey. Research in Higher Education, 36(1), 73-88. Retrieved November 20, 2012, from http://www.jstor.org/stable/40196179

Bowen, W. G., Bok, D., \& Burkhart, G. (1999, January). A REPORT CARD ON DIVERSITY: LESSONS FOR BUSINESS FROM HIGHER EDUCATION. Harvard Business Review, 77(1), 138-149. Retrieved 12 8, 2012, from http://search.ebscohost.com.www.libproxy.wvu.edu/login.aspx?direct=true $\& d b=b u h \& A$ $\mathrm{N}=1405933 \&$ site $=$ ehost-live

Bowen, W., \& Bok, D. (1998). Get In, Get Ahead: Here's Why. ERIC. Retrieved December 4, 2012, from http://www.eric.ed.gov/ERICWebPortal/detail?accno=EJ575612

Braxon, J. M., Sullivan, A. S., \& Johnson, R. M. (1997). Appraising Tinto's Theory of College Student Departure. (J. Smart, Ed.) Higher Education: A handbook of theory and research, 12, 107-164. Retrieved 12 10, 2012, from http://books.google.com/books?hl=en\&lr=\&id=twYjXLd6pyUC\&oi=fnd\&pg=PA107\&d 
$\mathrm{q}=$ Appraising + Tinto $\% 27 \mathrm{~s}+$ theory + of + college + student + departure\&ots $=$ D6kcM7191\&sig=RMWFaftQMbVlq_jwCuXyktXPskI\#v=onepage\&q=Appraising\%20Tinto's\%20t heory $\% 20$ of $\% 20$ college $\% 20$ student $\% 20$ departu

Cabrera, A. F., \& La Nasa, S. M. (2000). Understanding the College-Choice Process. New Directions for Institutional Research, 2000 (107)(5), 5-22. Retrieved September 14, 2012, from EBSCOhost

Cabrera, A. F., Burkum, K. R., \& La Nasa, S. M. (2005). Pathways to a Four-Year Degree: Determinants of Transfer and Degree Completion. In A. Seidman (Ed.), College Student Reunion: A Formula for Student Success (pp. 155-209). Westport, CT: ACE/Praeger.

Carnevale, A. P., \& Rose, S. J. (2003). Socioeconomic Status, Race/Ethnicity, and Selective College Admissions. New York: Report for the Century Foundation. Retrieved November 8, 2012, from http://tcf.org/publications/2003/3/pb252/get_pdf

Carnevale, A. P., \& Strohl, J. (2013). Separate And Unequal How Higher Education Reinforces the Intergenerational Reproduction of White Racial Privilege. Washington, D.C.: Georgetown Public Policy Institute. Retrieved August 5, 2013, from http://www9.georgetown.edu/grad/gppi/hpi/cew/pdfs/Separate\&Unequal.FR.pdf

Carter, D. F. (2006). Key Issues in the Persistence of Underrepresented Minority Students. New Directions For Institutional Research, 130, 33-46. doi:10.1002/ir.178

Chang, M., Witt, D., Jones, J., \& Hakuta, K. (Eds.). (2003). A Compelling Interest: Examining the Evidence on Racial Dynamics in Higher Education. Panel on Racial Dynamics In Colleges and Universities. Retrieved 12 1, 2012, from http://www.stanford.edu/ hakuta/www/policy/racial_dynamics/Compelling1.pdf 
Chappell, B. (2013). More College Students Rely On Federal Aid, Study Says. Washington D.C.: National Public Radio. Retrieved October 4, 2013, from http://www.npr.org/blogs/thetwo-way/2013/08/20/213901936/more-college-studentsrely-on-federal-aid-study-says $\mathrm{sc}=17 \& \mathrm{f}=1001$

Chow, K. (2013, August 2). Research Says: Actually, Where You Go To College Matters. Retrieved August 5, 2013, from National Public Radio (NPR): http://www.npr.org/blogs/codeswitch/2013/08/02/208273897/research-says-actuallywhere-you-go-to-college-matters

Chromy, J. R. (1979). Sequential Sample Selection Methods. Proceedings of the Section on Survey Research Mehtods, American Statistical Association, pp. 401-406. Retrieved October 31, 2012

College Access and Admission. (2007). ASHE Higher Education Report, 33(3), 29-39. Retrieved May 12, 2012, from http://onlinelibrary.wiley.com.www.libproxy.wvu.edu/doi/10.1002/aehe.3303/pdf

Curs, B. R., \& Singell, L. D. (2010, July/August). Aim High or Go Low? Pricing Strategies and Enrollment Effects When the Net Price Elasticity Varies with Need and Ability. The Journal of Higher Education, 81(4), 515-543. Retrieved November 17, 2011, from http://www.jstor.org/stable/40835664

Deloitte LLP. (2011). Making the grade 2011: A study of the top 10 issues facing higher education institutions. Retrieved October 13, 2012, from http://www.deloitte.com/assets/DcomCanada/Local\%20Assets/Documents/ca_en_ps_making-the-grade-2011_041811.pdf 
Dervarics, C. (2009). Minority-Serving Institutions Seek Long-Term Funding Increases Diverse Issues in Higher Education, 26(15), 8-9. Retrieved March 17, 2011, from EBSCOhost

DesJardins, S. L., \& Bell, A. (2006). Using Economic Concepts To Inform Enrollment Management. New Directions for Institutional Research, 2006(132). doi:10.1002/ir.196

DesJardins, S. L., Ahlburg, D. A., \& McCall, B. P. (2002, Summer). Simulating the Longitudinal Effects of Changes in Financial Aid on Student Departure from College. The Journal of Human Resources, 37(3), 653-679. Retrieved February 17, 2012, from http://www.jstor.org/stable/3069685

Dowd, A. C. (2008, June). Dynamic Interactions and Intersubjectivity: Challenges to Causal Modeling in Studies of College Student Debt. Review of Educational Research, 78(2), 232-259. Retrieved August 18, 2012, from http://www.jstor.org/stable/40071128

Dowd, A. C., \& Coury, T. (2006). The Effect of Loans on the Persistence and Attainment of Community College Students. Research in Higher Education, 47(1), 33-62. doi:DOI: $10.1007 / \mathrm{s} 11162-005-8151-8$

Drucker, P. F. (1994, November). The Age of Social Transformation. The Atlantic Monthly, 274(5), pp. 53-80.

Edward, P., \& St. John, E. (1990). Price Response in Enrollment Decisions: An Analysis of the High School and Beyond Sophomore Cohort. Research in Higher Education, 31(2), 161176. Retrieved 3 15, 2012, from http://www.jstor.org/stable/40195937

Ehrenberg, R. G. (2001). The Supply of American Higher Education Institutions. (McPherson, \& M. O. Schapiro, Eds.) M. S. Ford Policy Forum 2001: Exploring the Economics of Higher Education. Retrieved October 3, 2012, from http://net.educause.edu/ir/library/pdf/ffpfp0102.pdf 
Feeney, M. K., \& Heroff, J. (2010, July 13). The Effects of Need-Based Aid on College

Enrollment and Success Among Low-Income Students. Retrieved October 12, 2012, from http://dx.doi.org/10.2139/ssrn. 1639596

Fisher v. University of Texas at Austin et al., 11-345 (Supreme Court of the United States June 24, 2013). Retrieved October 12, 2013, from http://www.supremecourt.gov/opinions/12.pdf/11-345_15gm.pdf

Freeman, K. (1999). The Race Factor In African Americans' College Choice. Urban Education, 34(1), 4-25. Retrieved January 4, 2012, from http://uex.sagepub.com.www.libproxy.wvu.edu/content/34/1/4.full.pdf + html

Gottfredson, N., Panter, A., Daye, C., Allen, W., Wightman, L., \& Deo, M. (2008, June). Does diversity at undergraduate institutions influence student outcomes? Journal of Diversity in Higher Education, 1(2), 80-94. doi:10.1037/1938-8926.1.2.80

Graham, P. A. (1978, Summer). Expansion and Exclusion: A History of Women in American Higher Education. Signs, 3(4), 759-773. Retrieved May 29, 2013, from http://www.jstor.org/stable/3173112

Green, K. (2012). The Critical iddle Years and the Relationship of Early Access to Algebra on High School Math Course Completion and College Readiness. (Doctoral Dissertation, West Virginia University). Retrieved July 2012, from unpublished doctoral dissertation requested directly from author.

Green, T. C. (2005). Financial Aid, Access, and America's Social Contract with Higher Education. Retrieved March 7, 2011, from Aacrao: http://www.aacrao.org/sem14/Green_WhitePaper.pdf 
Greene, K. (2012, October 27-28). A New Peril for Older Parents: Student Loans They Cosigned. The Wall Street Journal, pp. A3, A12.

Gupta, A. (2006). Affirmative Action in Higher Eduation in India and the US: A Study in Contrasts. Retrieved March 24, 2011, from CSHE: Center for Studies in Higher Education: http://cshe.berkeley.edu/publications/docs/ROP.Gupta.10.06.pdf

Gurin, P., Dey, E. L., Hurtado, S., \& Gurin, G. (2002). Diversity and higher education: Theory and impact on educational outcomes. Harvard Educational Review, 72(3), 330-367. Retrieved May 20, 2012

Gurin, P., Nagda, B. A., \& Lopez, G. E. (2004). The Benefits of Diversity in Education for Democratic Citizenship. Journal of Social Issues, 60(1), 17-34. doi:10.111/j.00224537.2004.00097.x

Hashway, R. M., Brentley, M., \& Carter, J. (2001). Equitable Access. Retrieved February 28, 2012, from EBSCOhost

Haynes, R. M. (2009, August). A Predictive Model of Hispanic Participation in Texas Higher Educaton: Inferences Drawn From Institutional Data in Prevalent Hispanic States. (Doctoral Dissertation, University of North Texas). Retrieved July 21, 2012, from http://digital.library.unt.edu/ark:/67531/metadc11036/m1/1/high_res_d/dissertation.pdf

Hearn, J. C. (1984). The Reative Roles of Academic, Ascribed, and Socioeconomic Characteristics in College Destinations. Sociology of Education, 57(1), 22-30. Retrieved December 18, 2012, from http://www.jstor.org/stable/2112465

Hearn, J. C. (1991). Academic and Nonacademic Influences on the College Destinations of 1980 High School Graduates. Sociology of Education, 64(3), 158-171. Retrieved 10 15, 2012, from 
http://content.ebscohost.com.www.libproxy.wvu.edu/pdf17_20/pdf/1991/SOO/01Jul91/1 4653376.pdf? $\mathrm{T}=\mathrm{P} \& \mathrm{P}=\mathrm{AN} \& \mathrm{~K}=14653376 \& \mathrm{~S}=\mathrm{R} \& \mathrm{D}=\mathrm{ehh} \&$ EbscoContent $=\mathrm{dGJyMNLr40S}$ ep7Y4wtvhOLCmr0qeqK9Ssqi4SrGWxWXS\&ContentCustomer=dGJyMPXs54rz5OeO uePfgeyx44Dt6fIA

Heller, D. E. (1997). Student Price Response in Higher Education. Journal of Higher Education, 68(6), 624-659. Retrieved February 6, 2012

Horn, L. J. (1998). Undergraduates Who Work. Post Secondary Education Descriptive Analysis Reports. Statistical Analysis Report, U.S. Department of Education, National Center for Education Statistics, Washington D.C. Retrieved January 14, 2013, from http://nces.ed.gov/pubs98/98137.pdf

Hossler, D., \& Stage, F. K. (1992, Summer). Family and High School Experience Influences on the Postsecondary Educational Plans of Ninth-Grade Students. American Educational Research Journal, 29(2), 425-451. Retrieved November 26, 2013, from http://www.jstor.org/stable/1163375

Hossler, D., \& Vesper, N. (1993, March - April). An exploratory Study of the Factors Associated with Parental Saving for Postsecondary Education. The Journal of Higher Education, 64(2), 140 - 165. Retrieved November 26, 2013, from http://www.jstor.org/2960027

Hu, S., \& St. John, E. P. (2001). Student Persistence in a Public Higher Education System: Understanding Racial and Ethnic Differences. The Journal of Higher Education, 72(3), 265-286. Retrieved March 18, 2012, from http://www.jstor.org/stable/2649332

Hurtado, S., Milem, J., Clayton-Pedersen, A., \& Allen, W. (1999). Enacting Diverse Learning Environments: Improving the Climate for Racial/Ethnic Diversity in Higher Education. 
ERIC Digest. Retrieved 12 9, 2012, from

http://www.eric.ed.gov/ERICWebPortal/detail?accno=ED430513

Hwang, D. Y. (2003). The Impact of Financial Aid on Persistence: Application of the Financial

Nexus Model. (Doctoral Dissertation, University of Texas). Retrieved July 13, 2012, from http://digital.library.unt.edu/ark:/67531/metadc4317/m1/1/high_res_d/dissertation.pdf

Jackson, G. A. (1978). Financial Aid and Student Enrollment. Journal of Higher Education, 49(6), 548-574. Retrieved November 30, 2012, from http://www.jstor.org/stable/1981139

Jackson, G. A. (1982, Summer). Public Efficiency and Private Choice in Higher Education. Educational Evaluation and Policy Analysis, 4(2), 237-247. Retrieved December 19, 2012, from http://www.jstor.org/stable/1164016

Kane, J., \& Spizman, L. M. (1994). Race, Financial Aid Awards and College Attendance: Parents and Geography Matter. American Journal Of Economics \& Sociology, 53(1), 8597. Retrieved March 13, 2012

Karabel, J., \& Astin, A. W. (1975). Social Class, Academic Ability, and College "Quality". Social Forces (, 53(3), 381-398. Retrieved August 15, 2012, from http://content.ebscohost.com.www.libproxy.wvu.edu/pdf25_26/pdf/1975/SFR/01Mar75/5 283877.pdf? $\mathrm{T}=\mathrm{P} \& \mathrm{P}=\mathrm{AN} \& \mathrm{~K}=5283877 \& \mathrm{~S}=\mathrm{R} \& \mathrm{D}=$ buh $\&$ EbscoContent $=\mathrm{dGJyMNLr}$ 40Sep 7Y4wtvhOLCmr0qeqK9Ss6i4TbaWxWXS\&ContentCustomer=dGJyMPXs54rz5OeOue Pfgeyx44Dt6fIA

Kim, D. (2004, February 1). The Effect of Financial Aid on Students' College Choice: Differences by Racial Groups. Research in Higher Education, 45(1), 43-70. doi:10.1023/B:RIHE.0000010046.57597.43 
Kim, J., DesJardins, S., \& McCall, B. (2009). Exploring the Effects of Student Expectations about Financial Aid on Postsecondary Choice: A Focus on Income and Racial/Ethnic Differences. Research In Higher Education, 50(8), 741-774. doi:10.1007/s11162-0099143-X

King, J. (1999). Money Matters: The impact of Race/Ethnicity and Gender on How Students Pay for College. Retrieved March 17, 2011, from ERIC: http://www.eric.ed.gov/PDFS/ED443364.pdf

Kotkin, J. (2010, July-August). The Changing Demographics of America. Smithsonian Magazine, pp. 1-5. Retrieved October 29, 2012, from http://www.smithsonianmag.com/specialsections/40th-anniversary/The-ChangingDemographics-of-America.html

Kruse-Crocker, M. (2008, June). Financial Aid Type and Student Need as Predictors of Undergraduate Persistence at the University of Denver. (Doctoral dissertation, University of Denver). Retrieved February 16, 2012, from http://search.proquest.com/docview/304634789?accountid=2837

Leslie, L. L., \& Brinkman, P. T. (1987). Student Price Response in Higher Education. Journal of Higher Education, 58, 181-204. Retrieved March 18, 2012, from http://www.jstor.org/stable/1981241

Levin, N., \& Zahavi, J. (2001). Predictive Modeling Using Segmentation. Journal of Interactive Marketing, 15(2), 2-22. Retrieved November 5, 2012, from http://search.proquest.com/docview/229656827? accountid=2837 
Liu, A. (2011). The Admission Industrial Complex: Examining the Entrepreneurial Impact on College Access. Journal of College Admission, 210, 8-19. Retrieved March 22, 2012, from EBSCOhost

Longanecker, D. A., Blanco, C. D., \& Long, B. T. (2004). The Impact of Federal Financial Aid Policies on the Funding, Design, Operation, and Marketing of State and Institutional Financial Aid Policies and Practices: A Review of the Literature. Boston: The Education Resources Institute (TERI). Retrieved March 18, 2012

Lumina Foundation for Education. (2008). The Effectiveness of Student Aid Policies: What the Research Tells Us. (S. Baum, M. McPherson, \& P. Steele, Eds.) New York, New York. Retrieved November 19, 2012, from https://professionals.collegeboard.com/profdownload/rethinking-stu-aid-effectiveness-ofstu-aid-policies.pdf\#page $=123$

Manski, C. F., \& Wise, D. A. (1983). College Choice in America. Cambridge : Harvard University Press.

McCarty, J. A., \& Hastak, M. (2007, June). Segmentation approaches in data-mining: A comparison on RFM, CHAID, and logistic regression . Journal of Business Research, 60(6), 656-662. doi:10.1016/j.jbusres.2006.06.015

McDonough, P. M. (1994). Buying and Selling Higher Education. Journal Of Higher Education, 65(4), 427-446. Retrieved August 3, 2012, from http://ad4tq3gq5x.search.serialssolutions.com/?sid=sersol\%3ARefinerQuery\&rft.aulast= McDonough\&url_ver=Z39.882004\&l=AD4TQ3GQ5X\&SS_ReferentFormat=JournalFormat\&rft.genre=article\&rft_val fmt $=$ info $\% 3$ Aofi $\% 2 \mathrm{Ffmt} \% 3$ Akev $\% 3$ Amtx $\% 3$ Ajournal\&rft.atitle=Buying + and + selli 
McPheson, M. S., \& Schapiro, M. O. (1991, March). Does Student Aid Affect College Enrollment? New Evidence on a Persistent Controversy. The American Economic Review, 81(1), 309-318. Retrieved 11 10, 2011, from http://www.jstor.org/stable/2006804

Middleton, C. R. (2009). Roosevelt university and inclusiveness in American higher education. Journal of Diversity in Higher Education, 2(1), 30-34. doi:10.1037/a0014444

Milem, J. (1998). Enhancing Campus Climates for Racial/Ethnic Diversity: Educational Policy and Practice. Review of Higher Education, 21(3), 279-302. Retrieved 12 10, 2012, from http://muse.jhu.edu.www.libproxy.wvu.edu/journals/review_of_higher_education/v021/2 1.3hurtado.html

Monks, J. (2009, February). The impact of merit-based financial aid on college enrollment: A field experiement. Economics of Education Review, 28(1), 99-106. Retrieved October 13, 2012 , from http://www.sciencedirect.com/science/article/pii/S0272775708000538

National Association for College Admission Counseling. (2008). Report of the Commission on the Use of Standardized Tests in Undergraduate Admission. Arlington: Author. Retrieved September 3, 2012, from http://www.nacacnet.org/research/PublicationsResources/Marketplace/Documents/Testin gComission_FinalReport.pdf

National Center for Education Statistics. (2008). All Variables by Variable (NPSAS:08). Retrieved November 1, 2012, from http://nces.ed.gov/datalab/powerstats/pdf/npsas2008ug_varname.pdf 
National Center for Education Statistics. (2011). Restircted-Use Data Procedures Manual.

Washington, D.C.: National Center for Education Statistics. Retrieved September 21, 2011, from http://www.nces.ed.gov/pub96/96860rev.pdf

Okell, J. (1999, June). Neural Networks versus CHAID. smartFOCUS Ltd. Retrieved December 2,2012, from https://docs.google.com/viewer?a=v\&q=cache:7O8U5EakRxQJ:https://www.ucursos.cl/ingenieria/2004/2/IN47B/1/material_docente/objeto/50198+\&hl=en\&gl=us\&pi d=bl\&srcid=ADGEESikTMEBNLnszHfWeHJMnAp2QCdEcgQe_1_qTKa9KeWXxKfD k4EsgFBtXR6oS_nc6ZBVaPiPT1_sJMcGJvelmlYuE

Organisation for Economic Co-operation and Development. (2010). Highlights from Education at a Glance 2010. Paris, France. Retrieved October 13, 2012, from http://browse.oecdbookshop.org/oecd/pdfs/free/9610061e.pdf

Pascarella, E. T., \& Terenzini, P. T. (2005). How College Affects Students: A Third Decade of Research. San Francisco: Jossey-Bass.

Pascarella, E. T., Edison, M., Hagedorn, L. S., Nora, A., \& Terenzini, P. T. (1996, December). Influences on Students' Internal Locus of Attribution for Academic Success in the First Year of College. Research in Higher Education, 37(6), 731-756. Retrieved 12 10, 2012, from http://www.jstor.org/stable/40196229

Pascarella, E. T., Edison, M., Nora, A., Hagedorn, L. S., \& Terenzini, P. T. (1996, March-April). Influences on Students' Openness to diversity and Challenge in the First Year of College. The Journal of Higher Education, 67(2), 174-195. Retrieved October 27, 2012, from http://www.jstor.org/stable/2943979 
Paulsen, M. B. (1990). College Choice: Understanding Student Enrollment Behavior. ASHEERIC Higher Education Report No.6. Washington, DC: The George Washington University, School of Education and Human Development. Retrieved December 8, 2012, from http://www.eric.ed.gov/ERICWebPortal/detail?accno=ED333855

Paulsen, M. B., \& St. John, E. P. (1997). The Financial Nexus Between College Choice and Persistence. New Directions for Institutional Research, 1997(95), 65-82.

Paulsen, M. B., \& St. John, E. P. (2002). Social Class and College Costs: Examining the Financial Nexus between College Choice and Persistence. The Journal of Higher Education, 73(2), 189-236. Retrieved March 4, 2012, from http://www.jstor.org/stable/1558410

Penske, R. H., Porter, J. D., \& DuBrock, C. P. (1999, May 30). Analyzing Student Aide Packaging to Improve Low-Income and Minority Student Access, Retention and Degree Completion. Retrieved March 17, 2011, from ERIC Database: http://www.eric.ed.gov/PDFS/ED433786.pdf

Perna, L. W. (2000). Racial and Ethnic Group Differences in College Enrollment Decisions. New Directions For Institutional Research, 107, 65-83. Retrieved April 21, 2012

Perna, L. W. (2007). The Sources of Racial-Ethnic Group Differences in College Enrollment: A Critical Examination. New Directions For Institutional Research, 2007(133), 51-66. Retrieved February 19, 2012

Peter, K., \& Horn, L. (2005). Gender Differences in Participation and Completion of Undergraduate Education and How They Have Changed Over Time. NCES 2005-169, U. S. Department of Education, National Center for Education Statistics. Washington, D.C.: U.S. Government Printing Office. 
Sackett, P. R., Hardison, C. M., \& Cullen, M. J. (2004). On Interpreting Stereotype Threat as Accounting for African American-White Differences on Cognitive Tests. Minneapolis: University of Minnesota. Retrieved December 18, 2012, from http://www.asc.upenn.edu/usr/ogandy/C45405\%20resources/Sackett\%20et\%20al\%20ster eotype $\% 20$ threat.pdf

Santiago, D. A., \& Cunningham, A. F. (2005, August). How Latino students pay for college: Patterns of Financial Aid in 2003-2004. Retrieved March 13, 2011, from USAFunds: http://www.usafunds.org/Media/Reports\%20and\%20White\%20Papers/LatinoStudentAid. pdf

Spaulding, S., \& Kargodorian, A. (1982, March 19). Democratization of Higher Education: Issues and Trends. Retrieved March 17, 2011, from ERIC Database: http://www.eric.ed.gov/PDFS/ED216631.pdf

St. John, E. P. (1990). Price Response in Enrollment Decisions: An Analysis of the High School and Beyond Sophomore Cohort. Research in Higher Education, 31(2), 301-334. Retrieved 12 10, 2012, from http://www.jstor.org/stable/40195937

St. John, E. P. (1999). Evaluating State Student Grant Programs: A Case Study of Washington's Grant Program. Research in Higher Education, 40, 149-167. Retrieved December 8, 2012, from http://link.springer.com/content/pdf/10.1023\%2FA\%3A1018730529215

St. John, E. P., \& Noell, J. (1989, December). The Effects of Student financial aid on Access to Higher Education: An Analysis of Progress with Special Consideration of Minority Enrollment. Research in Higher Education, 30, 563-581. Retrieved December 7, 2012, from http://www.jstor.org/stable/40195922 
St. John, E. P., Cabrera, A. E., Nora, A., \& Asker, E. H. (2000). Economic Influences on Persistence Reconsidered. Reworking the student departur puzzle, 29-47. Retrieved July 15,2012 , from http://www.education.umd.edu/EDHI/about/faculty_pages/cabrera/Economic\%20Influen ces\%20in\%20Persistence.pdf

St. John, E. P., Paulsen, M. B., \& Carter, D. F. (2005, September-October). Diversity, College Costs, and Postsecondary Opportunity: An Examination of the Financial Nexus between College Choice and Persistence for African Americans and Whites. The Journal of Higher Education, 76(5), 545-569. Retrieved July 18, 2012, from http://www.jstor.org/stable/3838839

St. John, E. P., Paulsen, M. B., \& Starkey, J. B. (1996, April). The Nexus between College Choice and Persistence. Research in Higher Education, 37(2), 175-220. Retrieved May 22, 2012, from http://www.jstor.org/stable/40196172

Steelman, L. C., \& Powell, B. (1993, October). Doing the Right Thing: Race and Parental Locus of Responsibility for Funding College. Sociology of Education, 66(4), 223-244.

Swail, W. S., Redd, K. E., \& Perna, L. W. (2003). Retaining Minority Students in Higher Education A Framework for Success. (A. J. Kezar, Ed.) ASHE-ERIC Higher Education Report, 30(2). Retrieved November 15, 2011, from http://www.studentretention.org/pdf/Swail_Retention_Book.pdf

Terenzini, P. T., Cabrera, A. F., \& Bernal, E. M. (2001). Swimming Against the Tide: The Poor in American Higher Education. Princeton, NJ: College Board. Retrieved October 19, 2012, from 
http://research.collegeboard.org/sites/default/files/publications/2012/7/researchreport2001-1-swimming-against-tide-the-poor-american-higher-education.pdf

Terenzini, P. T., Cabrera, A. F., Colbeck, C. L., Bjorklund, S. A., \& Parente, J. M. (2001). Racial and Ethnic Diversity in the Classroom: Does It Promote Student Learning? Journal of Higher Education, 509-531. Retrieved October 27, 2012, from EBSCOhost

The National Center for Education Statistics. (2011, August 18). (NPSAS:08) Full-scale Methodology Report - National Centerfor Education Statistics. Retrieved March 3, 2012, from The National Center for Education Statistics: http://nces.ed.gov/pubs2011/2011188b.pdf

The National Center for Education Statistics. (2011). PowerStats Variables. The National Center for Education Statistics. Retrieved November 30, 2011, from http://nces.ed.gov/datalab/powerstats/pdf/npsas2008ug_subject.pdf

Thomas, E. H., \& Galambos, N. (2004, May). What Satisfies Students? Mining Student-Opinion Data with Regression and Decision Tree Analysis. Research in Higher Education, 45(3), 251-269. Retrieved August 4, 2012

Tinto, V. (1987). Leaving College: Rethinking the Causes and Cures of Student Attrition. Chicago: University of Chicago Press.

Tinto, V. (2006). Research and Practice of Student Retention: What's Next. Journal of College Student Retention, 8(1), 1-19. Retrieved 10 5, 2011, from http://edit.uaa.alaska.edu/governance/facultysenate/upload/JCSR_Tinto_200607_Retention.pdf

Trent, W. T., Lee, H. S., \& Owens-Nicholson, D. (2006). Perceptions of Financial Aid Among Students of Color: Examining the Role(s) of Self-Concept, Locus of Control, and 
Expectations. The American Behavioral Scientist, 49(12), 1739-1759. Retrieved February 8, 2012, from http://search.proquest.com/docview/214764630?accountid=2837

Trow, M. (1972, December 1). The expansion and transformation of higher education. International Review of Education, 18(1), 61-84. doi:10.1007/BF01450272

Turner, J., \& Pusser, B. (2004). Place Matters: The Distribution of Access to a State Flagship University. Policy Futures in Education, 2(2), 388-421. Retrieved January 21, 2012, from EBSCOhost

U.S. Department of Education. (2011, January 12). Trends in Student Financing of Undergraduate Education: Selected Years, 1995-1996 to 2007-2008. NCES 2011218. Retrieved March 3, 2012, from National Center for Education Statistics: http://nces.ed.gov/pubs2011/2011218.pdf

U.S. Department of Education: National Center for Education Statistics, RTI International. (2010, December). 2007-2008 National Postsecondary Student Aid Study (NPSAS: 08) Full-scale Methodology Report. Retrieved May 17, 2012, from http://nces.ed.gov/pubs2011/2011188a.pdf

Walpole, M., McDonough, P. M., Bauer, C. J., Gibson, C., Kanyi, K., \& Toliver, R. (2005). This Test Is Unfair Urban African American and Latino High School Students' Perceptions of Standardized College Admission Tests. Urban Education, 40(3), 321-349. doi:10.1177/0042085905274536

Willis, P. (1977). Learning to Labor: How Working Class Kids Get Working Class Jobs. New York: Columbia University Press.

Wojciechowska, I. (2010, August 27). Paying the Price. Retrieved June 19, 2012, from http://www.insidehighered.com/news/2010/08/27/tuition\#ixzz104WtiI9E 
Zwick, R. (2007). College Admissions in Twenty-First-Century America: The Role of Grades, Tests, and Games of Chance. Harvard Educational Review, 77(4), 419-429. Retrieved November 27, 2012, from http://her.hepg.org/content/u67n84589527t80v/fulltext.pdf 


\author{
Appendix A
}

\title{
WestVirginiaUniversity, \\ Orlice of Research Integrity and Compliance \\ To: \\ From: \\ Approval Period: \\ Subject: \\ Protocol Tracking\#: \\ Title:

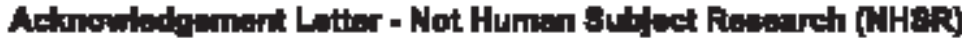 \\ Allison Dagen \\ WVU Office of Research Integrity and Compliance \\ 0409/2013 Expiration Date: 04/08/2018 \\ Not Human Subject Research Acknowledgment \\ 1303026884 \\ Access to Higher Education: Can Enrollment Based on Race or Ethnicity Be Predictod by Student Financial Indicators?
}

Thank you for your submission to the West Virginia University Institutional Review Board (IRB)

It has been determined that your project does not meet the definition of human subject research for the following reason $(s)$ :

- In order to be considered human subject research, individually identifiable private information must be obtained or used in the research. If there is no individually identifiable private information involved, the project is not human subject research and does not require being submitted to the Office of Research Integrity \& Compliance. Private information must be individually identifiable (i.e, the identity of the subject is or may be readily ascertained by the investigator or someone else associated with the information) in order to constitute research involving human subjects.

If you have any questions, please contact the IRB at (304) 293-7073.

Thank you.

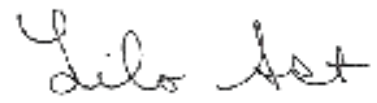

Board Designee: Lilo Ast

Letter Sent By: Lilo Ast on 04/09/2013 at 14:25:30-04:00 
Appendix B

\section{Jeff Terpstra}

From:

Sent:

To:

Subject:
Jeff Terpstra <terpyj@gmail.com>

Monday, September 30, 2013 4:34 PM

'Jeff Terpstra'

Dissertation Assistance with Department of Education - Restricted Use License

From: Andrew C Ellis [mailto:aellis5@luc.edu]

Sent: Wednesday, June 12, 2013 4:29 PM

To: Jeff Terpstra

Cc: Tara C Sullivan

Subject: RE: Dissertation Assistance with Department of Education - Restricted Use License

Dear Jeff,

Only research involving human subjects (as defined by the regulations, 45 CFR 46) requires IRB oversight. Because your work does not involve any data collection through intervention or interaction or use of identifiable private information, there is no need for oversight by the Loyola University IRB.

Please do not hesitate to contact me if you think this assessment is incorrect or you have additional questions or concerns. Thanks, Andrew

Andrew Ellis

Assistant Director for Research Compliance

Loyola University Chicago

Phone: 773-508-2689

Email: aellis5@luc.edu

facebook: researchcompliance 


\section{Appendix C}

Jeff Terpstra

From:

Sent:

To:

Subject:
Jeff Terpstra <terpyj@gmail.com>

Monday, September 30, 2013 5:16 PM

'Jeff Terpstra'

FW: Approved- \#13060008

From: $<$ IESData. Security@ed gov $>$

Date: July 3, 2013, 7:47:12 AM CDT

To: stsullivan6@alucedus

Cc: Marilyn Seastrom marilyn seastrom@ed gov , Jason Browning cibrowning@sanametrix.com?, Jesse

Rine <jesse.rine@ed.gov>, Rafic Jouejati rafic.jouejati@ed.gov>

Subject: Approved- \#13060008

License number: 13060008

Dear Tara Sullivan,

We have completed our review of your application. Your application has been approved. Keep a copy of this License approval email in your License file. Please reference your License number in any future correspondence.

We will be mailing the data and a copy of your License paperwork to you in the next few business days. Please retain the documents in your License file.

Once you receive the data, please contact the IES Data Security Office for the password that you will need to unencrypt the data. You must secure this password from unauthorized access.

You are licensed for the data you requested in your Formal Request. The data you will receive are on loan for the time period specified in your Formal Request commencing with the date of the NCES Commissioner's signature on the signed License document. Once your License expires, please send the data back to IES and close the License or submit an amendment to renew the License.

Please read and have other project staff read the IES Restricted-use Data Procedures Manual at: http://nces ed gov/statprog/rudman/toc.asp . Violations of any of the License or security requirements by any project staff could result in License cancellation.

If during the course of your research you need to add project staff, take staff off of the project, need additional restricted-use data, extend the time period of your License, or need to close your License, please read how to do any of these at: httri//ncesed_gov/statprog/instruct_modasp

Any draft reports or other pre-publication documents that use or contain IES restricted-use data must be reviewed by the IES Data Security office prior to their dissemination outside the licensed project staff. Please send these reports to the email address below.

If you have any questions, please contact us.

IES Data Security Office 


\section{Appendix D}

\section{Terpstra, Jeff}

$\begin{array}{ll}\text { From: } & \text { Rine, Jesse (Contractor) <Jesse.Rine@ed.gov> } \\ \text { Sent: } & \text { Wednesday, October 23, 2013 1:09 PM } \\ \text { To: } & \text { Sullivan, Tara; Terpstra, Jeff } \\ \text { Subject: } & \text { RE: Lic \#13060008: Review of work based on Restricted Use Data }\end{array}$

Hello Dr. Sullivan,

You are cleared to disseminate the dissertation titled "Access to Higher Education: Can Enrollment Based on Race or Ethnicity Be Predicted By Student Financial Indicators?" by Terpstra, to non-licensed persons.

Thanks,

Jesse Rine

IES Data Security Office

From: Terpstra, Jeff [mailto:jterpstra@luc.edu]

Sent: Tuesday, October 22, 2013 7:14 PM

To: IESDataSecurity; Sullivan, Tara

Subject: RE: Lic \#13060008: Review of work based on Restricted Use Data

Hi Jesse,

Thank you for all your help during this process. Attached is a copy of the document with the requested changes made.

Jeff Terpstra

From: IESDataSecurity [mailto:IESData.Security@ed.gov]

Sent: Tuesday, October 22, 2013 2:28 PM

To: Terpstra, Jeff; Sullivan, Tara

Subject: RE: Lic \#13060008: Review of work based on Restricted Use Data

Hello Dr. Sullivan,

The dissertation titled "Access to Higher Education: Can Enrollment Based on Race or Ethnicity Be Predicted By Student Financial Indicators?" by Terpstra, does not conform to IES publication policy. The following items must be revised:

Table

Row

Column

Comment

64 
Appendix E

Descriptive Statistics by Race/Ethnicity - Continuous Variables (Max and Min values rounded to the nearest \$10)

\begin{tabular}{|c|c|c|c|c|c|c|c|c|c|c|c|c|c|c|c|c|c|c|c|c|}
\hline & \multicolumn{5}{|c|}{ White } & \multicolumn{5}{|c|}{ Black or African American } & \multicolumn{5}{|c|}{ Hispanic or Latino } & \multicolumn{5}{|c|}{ Asian } \\
\hline & Min & $\operatorname{Max}$ & Mean & Count & Std. Dev. & Min & $\operatorname{Max}$ & Mean & Count & Std. Dev. & Min & $\operatorname{Max}$ & Mean & Count & Std. Dev. & Min & $\operatorname{Max}$ & Mean & Count & Std. Dev. \\
\hline Tuition and fees & \$o & $\$ 49,070$ & $\$ 5,135$ & $\$ 30,491$ & $\$ 4,439$ & \$o & $\$ 32,800$ & $\$ 4,635$ & $\$ 5,055$ & $\$ 4,018$ & \$o & $\$ 46,160$ & $\$ 3,795$ & $\$ 4,741$ & $\$ 3,689$ & \$0 & $\$ 49,070$ & $\$ 6,872$ & $\$ 3,569$ & $\$ 6,634$ \\
\hline EFC amount & so & $\$ 100,000$ & $\$ 5,703$ & $\$ 30,491$ & $\$ 12,131$ & so & $\$ 100,000$ & $\$ 3,030$ & $\$ 5,055$ & $\$ 7,593$ & \$o & $\$ 100,000$ & $\$ 3,293$ & $\$ 4,741$ & $\$ 8,668$ & $\$ 0$ & $\$ 100,000$ & $\$ 2,598$ & $\$ 3,569$ & $\$ 8,821$ \\
\hline Pell grant & so & $\$ 4,310$ & $\$ 630$ & $\$ 30,491$ & $\$ 1,320$ & \$o & $\$ 4,310$ & $\$ 1,490 \mid$ & $\$ 5,055$ & $\$ 1,799$ & \$o & $\$ 4,310$ & $\$ 1,274$ & $\$ 4,741$ & $\$ 1,708$ & so & $\$ 4,310$ & $\$ 1,041$ & $\$ 3,569$ & $\$ 1,656$ \\
\hline Work-study & so & $\$ 17,080$ & $\$ 62$ & $\$ 30,491$ & $\$ 433$ & so & $\$ 7,500$ & $\$ 121$ & $\$ 5,055$ & $\$ 560$ & \$o & $\$ 10,970$ & $\$ 82$ & $\$ 4,741$ & $\$ 486$ & \$o & $\$ 9,500$ & $\$ 76$ & $\$ 3,569$ & $\$ 498$ \\
\hline $\begin{array}{l}\text { Undergraduate } \\
\text { Loan Balance }\end{array}$ & so & $\$ 150,000$ & $\$ 7,236$ & $\$ 30,491$ & $\$ 13,047$ & \$o & $\$ 140,000$ & $\$ 7,567$ & $\$ 5,055$ & $\$ 12,937$ & so & $\$ 120,000$ & $\$ 5,087$ & $\$ 4,741$ & $\$ 10,355$ & so & $\$ 130,000$ & $\$ 3,846$ & $\$ 3,569$ & $\$ 9,558$ \\
\hline $\begin{array}{l}\text { Balance due on } \\
\text { all credit cards }\end{array}$ & so & $\$ 45,000$ & $\$ 453$ & $\$ 30,491$ & $\$ 2,003$ & so & $\$ 22,000$ & $\$ 359$ & $\$ 5,055$ & $\$ 1,442$ & so & $\$ 35,500$ & $\$ 691$ & $\$ 4,741$ & $\$ 2,306$ & so & $\$ 30,000$ & $\$ 455$ & $\$ 3,569$ & $\$ 2,149$ \\
\hline
\end{tabular}

\begin{tabular}{|c|c|c|c|c|c|c|c|c|c|c|c|c|c|c|c|c|c|c|c|c|}
\hline & \multicolumn{5}{|c|}{ American Indian or Alaska Native } & \multicolumn{5}{|c|}{ Native Hawaiian / Pacific Islander } & \multicolumn{5}{|c|}{ Other } & \multicolumn{5}{|c|}{ More than one race } \\
\hline & Min & $\operatorname{Max}$ & Mean & Count & Std. Dev. & Min & $\operatorname{Max}$ & Mean & Count & Std. Dev. & Min & $\operatorname{Max}$ & Mean & Count & Std. Dev. & Min & $\operatorname{Max}$ & Mean & Count & Std. Dev. \\
\hline Tuition and fees & \$o & $\$ 20,990$ & $\$ 3,789$ & $\$ 319$ & $\$ 3,189$ & so & $\$ 38,930$ & $\$ 4,925$ & $\$ 196$ & $\$ 5,989$ & \$o & $\$ 21,900$ & $\$ 4,717$ & $\$ 125$ & $\$ 4,078$ & \$o & $\$ 49,070$ & $\$ 4,966$ & $\$ 1,023$ & $\$ 4,599$ \\
\hline EFC amount & \$o & $\$ 44,300$ & $\$ 3,957$ & $\$ 319$ & $\$ 7,753$ & \$o & $\$ 98,270$ & $\$ 4,890$ & $\$ 196$ & $\$ 13,106$ & \$o & $\$ 49,530$ & $\$ 2,372$ & $\$ 125$ & $\$ 6,278$ & \$o & $\$ 94,060$ & $\$ 4,394$ & $\$ 1,023$ & $\$ 9,582$ \\
\hline Pell grant & \$o & $\$ 4,310$ & $\$ 1,018$ & $\$ 319$ & $\$ 1,502$ & \$o & $\$ 4,310$ & $\$ 854$ & $\$ 196$ & $\$ 1,551$ & \$o & $\$ 4,310$ & $\$ 1,264$ & $\$ 125$ & $\$ 1,704$ & \$o & $\$ 4,310$ & $\$ 985$ & $\$ 1,023$ & $\$ 1,607$ \\
\hline Work-study & \$o & $\$ 3,350$ & $\$ 47$ & $\$ 319$ & $\$ 295$ & \$o & $\$ 4,000$ & $\$ 86$ & $\$ 196$ & $\$ 479$ & So & $\$ 3,370$ & $\$ 64$ & $\$ 125$ & $\$ 383$ & \$o & $\$ 4,570$ & $\$ 123$ & $\$ 1,023$ & $\$ 563$ \\
\hline \begin{tabular}{|l} 
Undergraduate \\
Loan Balance
\end{tabular} & \$o & $\$ 85,000$ & $\$ 5,154$ & $\$ 319$ & $\$ 11,054$ & so & $\$ 57,000$ & $\$ 5,400$ & $\$ 196$ & $\$ 10,332$ & so & $\$ 55,000$ & $\$ 5,282$ & $\$ 125$ & $\$ 10,918$ & \$o & $\$ 105,000$ & $\$ 9,086$ & $\$ 1,023$ & $\$ 13,598$ \\
\hline $\begin{array}{l}\text { Balance due on } \\
\text { all credit cards }\end{array}$ & so & $\$ 15,000$ & $\$ 315$ & $\$ 319$ & $\$ 1,433$ & so & $\$ 10,000$ & $\$ 585$ & $\$ 196$ & $\$ 1,709$ & \$o & $\$ 7,000$ & $\$ 193$ & $\$ 125$ & $\$ 957$ & \$o & $\$ 35,000$ & $\$ 734$ & $\$ 1,023$ & $\$ 2,413$ \\
\hline
\end{tabular}




\section{Appendix F}

Descriptive Statistics by Race/Ethnicity - Categorical Variables

(Rounded to the nearest 10)

\begin{tabular}{|c|c|c|c|c|c|c|c|c|}
\hline \multicolumn{9}{|c|}{ Worked during Summer 2007} \\
\hline & White & $\begin{array}{l}\text { Black or } \\
\text { African } \\
\text { American }\end{array}$ & $\begin{array}{l}\text { Hispanic } \\
\text { or Latino }\end{array}$ & Asian & $\begin{array}{l}\text { American } \\
\text { Indian or } \\
\text { Alaska } \\
\text { Native }\end{array}$ & $\begin{array}{l}\text { Native } \\
\text { Hawaiian / } \\
\text { Pacific } \\
\text { Is lander }\end{array}$ & Other & $\begin{array}{l}\text { More than } \\
\text { one race }\end{array}$ \\
\hline$\{$ Skipped $\}$ & 6810 & 1240 & 920 & 990 & 90 & 40 & 30 & 260 \\
\hline$\{$ Missing $\}$ & 8050 & 1710 & 1360 & 800 & 130 & 50 & 50 & 70 \\
\hline No & 2720 & 600 & 810 & 840 & 20 & 30 & 10 & 160 \\
\hline Yes & 12920 & 1510 & 1650 & 940 & 80 & 60 & 40 & 530 \\
\hline
\end{tabular}

\begin{tabular}{|c|c|c|c|c|c|c|c|c|}
\hline \multicolumn{9}{|c|}{ Worked to Pay Living Expens es } \\
\hline & White & $\begin{array}{l}\text { Black or } \\
\text { African } \\
\text { American }\end{array}$ & $\begin{array}{l}\text { Hispanic } \\
\text { or Latino }\end{array}$ & Asian & $\begin{array}{l}\text { American } \\
\text { Indian or } \\
\text { Alaska } \\
\text { Native }\end{array}$ & $\begin{array}{l}\text { Native } \\
\text { Hawaiian / } \\
\text { Pacific } \\
\text { Is lander }\end{array}$ & Other & $\begin{array}{l}\text { More than } \\
\text { one race }\end{array}$ \\
\hline$\{$ Skipped $\}$ & 9140 & 1510 & 1400 & 1550 & 90 & 70 & 30 & 370 \\
\hline$\{$ Mis sing & 8510 & 1850 & 1460 & 850 & 140 & 60 & 50 & 80 \\
\hline No & 2530 & 300 & 350 & 330 & 20 & 10 & 10 & 100 \\
\hline Yes & 10310 & 1400 & 1550 & 840 & 80 & 60 & 40 & 480 \\
\hline
\end{tabular}

\begin{tabular}{|c|c|c|c|c|c|c|c|c|}
\hline \multicolumn{9}{|c|}{ Help from parents : tuition and fees } \\
\hline & White & $\begin{array}{l}\text { Black or } \\
\text { African } \\
\text { American }\end{array}$ & $\begin{array}{l}\text { His panic } \\
\text { or Latino }\end{array}$ & Asian & $\begin{array}{l}\text { American } \\
\text { Indian or } \\
\text { Alaska } \\
\text { Native }\end{array}$ & \begin{tabular}{|l|} 
Native \\
Hawaiian / \\
Pacific \\
Is lander
\end{tabular} & Other & $\begin{array}{l}\text { More than } \\
\text { one race }\end{array}$ \\
\hline$\{$ Skipped $\}$ & 3860 & 900 & 550 & 410 & 70 & 20 & 20 & 150 \\
\hline$\{$ Mis sing $\}$ & 8280 & 1760 & 1400 & 860 & 130 & 60 & 50 & 80 \\
\hline No & 9210 & 1620 & 1780 & 1100 & 80 & 70 & 30 & 440 \\
\hline Yes & 9140 & 780 & 1000 & 1200 & 40 & 50 & 30 & 350 \\
\hline
\end{tabular}

\begin{tabular}{|c|c|c|c|c|c|c|c|c|}
\hline \multicolumn{9}{|c|}{ Parents own home or pay mortgage } \\
\hline & White & $\begin{array}{l}\text { Black or } \\
\text { African } \\
\text { American }\end{array}$ & $\begin{array}{l}\text { Hispanic } \\
\text { or Latino }\end{array}$ & Asian & $\begin{array}{l}\text { American } \\
\text { Indian or } \\
\text { Alaska } \\
\text { Native } \\
\end{array}$ & \begin{tabular}{|l|} 
Native \\
Hawaiian / \\
Pacific \\
Is lander \\
\end{tabular} & Other & $\begin{array}{l}\text { More than } \\
\text { one race }\end{array}$ \\
\hline$\{$ Skipped $\}$ & 6150 & 1160 & 780 & 950 & 80 & 40 & 30 & 230 \\
\hline$\{$ Mis sing $\}$ & 8190 & 1750 & 1400 & 830 & 130 & 60 & 50 & 80 \\
\hline No & 1600 & 680 & 660 & 490 & 20 & 20 & 10 & 130 \\
\hline Yes & 14560 & 1470 & 1910 & 1300 & 80 & 80 & 40 & 590 \\
\hline
\end{tabular}




\section{Appendix G}

Number of Students In Each Node by Race/Ethnicity

(Rounded to the nearest 10)

\begin{tabular}{|c|c|c|c|c|c|c|c|c|c|c|}
\hline & Node & & & & & & & & & \\
\hline \multirow[t]{35}{*}{ Race } & & White & $\begin{array}{l}\text { Black or } \\
\text { African } \\
\text { American }\end{array}$ & $\begin{array}{l}\text { Hispanic or } \\
\text { Latino }\end{array}$ & Asian & $\begin{array}{l}\text { American } \\
\text { Indian or } \\
\text { Alaska } \\
\text { Native } \\
\end{array}$ & $\begin{array}{l}\text { Native } \\
\text { Hawaiian / } \\
\text { Pacific } \\
\text { Islander }\end{array}$ & Other & $\begin{array}{l}\text { More than } \\
\text { one race }\end{array}$ & Total \\
\hline & 0 & 21260 & 3520 & 3310 & 2490 & 230 & 120 & 100 & 730 & 31760 \\
\hline & 1 & 15640 & 1740 & 1810 & 1570 & 130 & 90 & 50 & 460 & 21490 \\
\hline & 2 & 1790 & 410 & 360 & 190 & 30 & 10 & 10 & 70 & 2870 \\
\hline & 3 & 1800 & 550 & 540 & 290 & 40 & 20 & 10 & 80 & 3330 \\
\hline & 4 & 1410 & 750 & 500 & 330 & 20 & 10 & 10 & 90 & 3120 \\
\hline & 5 & 620 & 80 & 110 & 110 & 10 & 10 & 10 & 30 & 980 \\
\hline & 6 & 2040 & 250 & 300 & 200 & 20 & 10 & 10 & 70 & 2900 \\
\hline & 7 & 1180 & 220 & 270 & 80 & 20 & 10 & 10 & 30 & 1820 \\
\hline & 8 & 4320 & 600 & 680 & 400 & 40 & 30 & 20 & 160 & 6250 \\
\hline & 9 & 1480 & 130 & 150 & 110 & 20 & 0 & 0 & 40 & 1930 \\
\hline & 10 & 3330 & 250 & 200 & 200 & 20 & 10 & 10 & 70 & 4090 \\
\hline & 11 & 1690 & 130 & 130 & 180 & 10 & 10 & 10 & 50 & 2210 \\
\hline & 12 & 1600 & 160 & 100 & 400 & 0 & 10 & 0 & 40 & 2310 \\
\hline & 13 & 260 & 80 & 40 & 10 & 10 & 0 & 0 & 20 & 420 \\
\hline & 14 & 160 & 50 & 70 & 50 & 0 & 0 & 0 & 10 & 340 \\
\hline & 15 & 920 & 150 & 150 & 90 & 10 & 0 & 0 & 40 & 1360 \\
\hline & 16 & 460 & 130 & 100 & 50 & 10 & 0 & 10 & 0 & 760 \\
\hline & 17 & 210 & 70 & 70 & 40 & 10 & 0 & 0 & 20 & 420 \\
\hline & 18 & 20 & 10 & 50 & 0 & 10 & 0 & 0 & 0 & 90 \\
\hline & 19 & 130 & 60 & 90 & 10 & 10 & 0 & 0 & 0 & 300 \\
\hline & 20 & 430 & 170 & 150 & 60 & 10 & 0 & 0 & 20 & 840 \\
\hline & 21 & 490 & 110 & 70 & 40 & 10 & 0 & 0 & 20 & 740 \\
\hline & 22 & 520 & 120 & 100 & 130 & 0 & 10 & 0 & 20 & 900 \\
\hline & 23 & 110 & 60 & 50 & 40 & 0 & 0 & 0 & 10 & 270 \\
\hline & 24 & 0 & 10 & 70 & 0 & 0 & 0 & 0 & 0 & 80 \\
\hline & 25 & 40 & 40 & 70 & 10 & 0 & 0 & 0 & 0 & 160 \\
\hline & 26 & 280 & 170 & 140 & 90 & 10 & 0 & 0 & 20 & 710 \\
\hline & 27 & 220 & 140 & 40 & 30 & 0 & 0 & 0 & 10 & 440 \\
\hline & 28 & 640 & 270 & 120 & 140 & 0 & 0 & 0 & 30 & 1200 \\
\hline & 29 & 120 & 70 & 10 & 30 & 0 & 0 & 10 & 10 & 250 \\
\hline & 30 & 100 & 10 & 20 & 20 & 0 & 0 & 0 & 10 & 160 \\
\hline & 31 & 30 & 0 & 20 & 10 & 0 & 0 & 0 & 0 & 60 \\
\hline & 32 & 370 & 40 & 40 & 30 & 10 & 0 & 0 & 10 & 500 \\
\hline & 33 & 130 & 30 & 30 & 60 & 0 & 0 & 0 & 10 & 260 \\
\hline
\end{tabular}




\section{Appendix $\mathrm{H}$}

Summary of Output by CHAID Analysis

(Over-represented populations in each node are in bold)

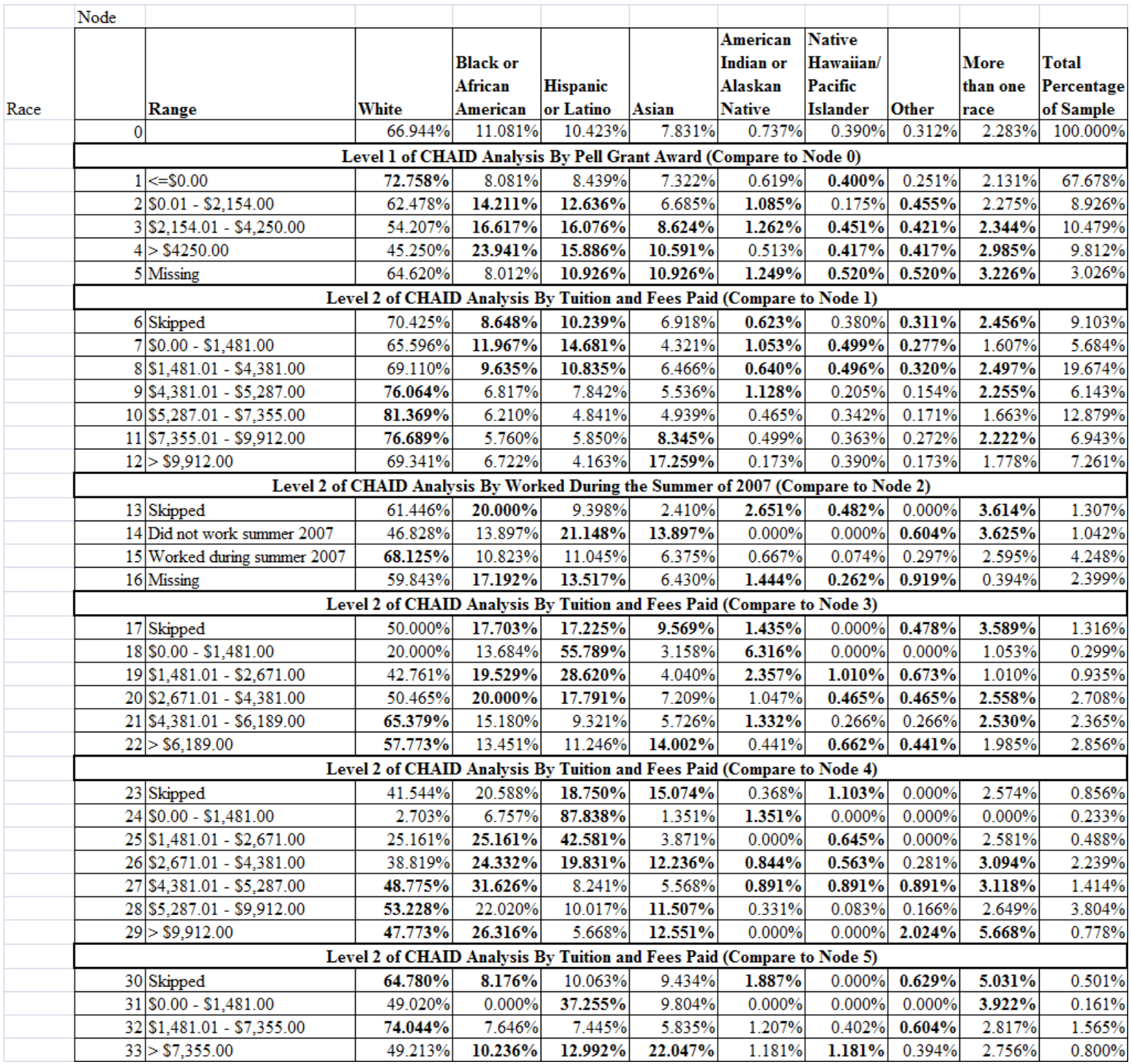

